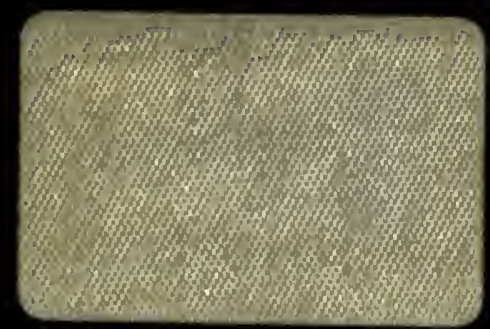

S. I. LIBRARY 

II 

$\checkmark$ 


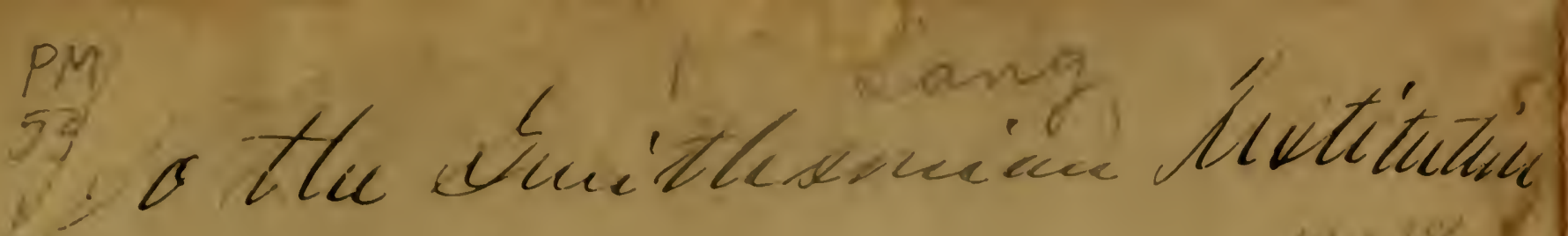

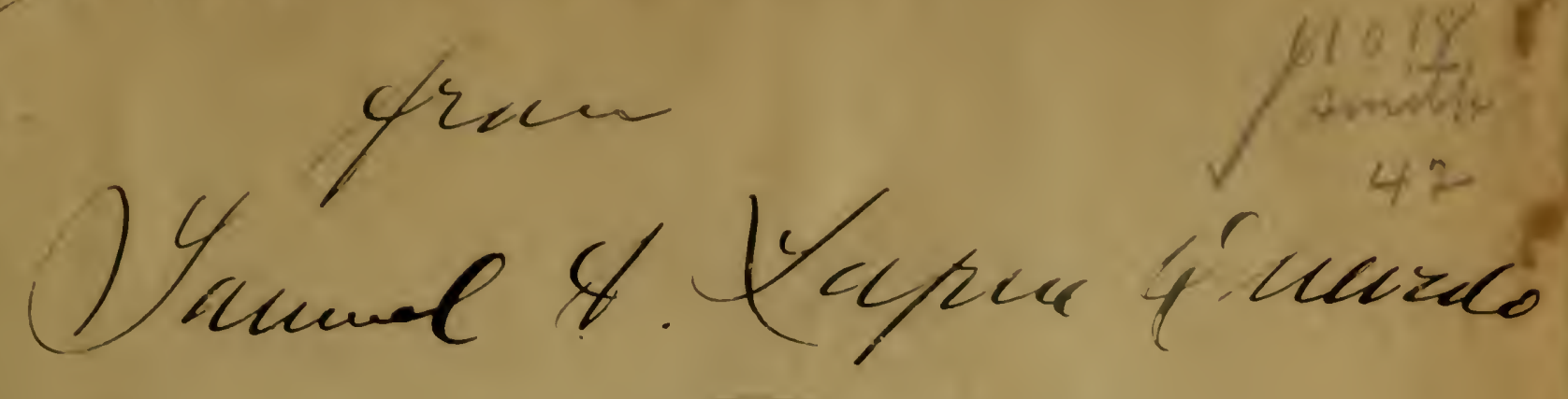

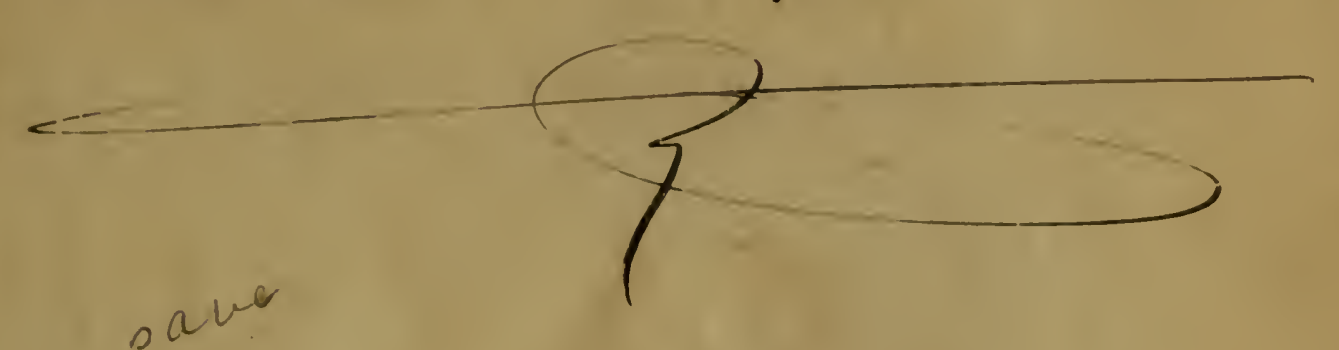

IDIOMA ABIPÓN

11.409 



\section{IDIOMA ABIPÓN}

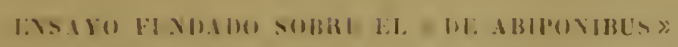

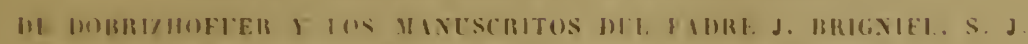

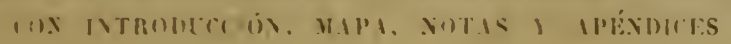

1יil:

SAMUEI. A. LAFONE WUEREDO M. A.

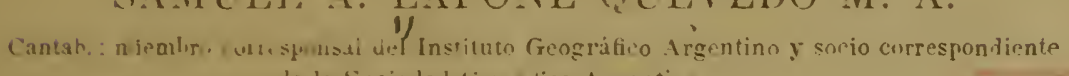
de la Sociedall (jen lica Arsentin i

\section{9}

$-$
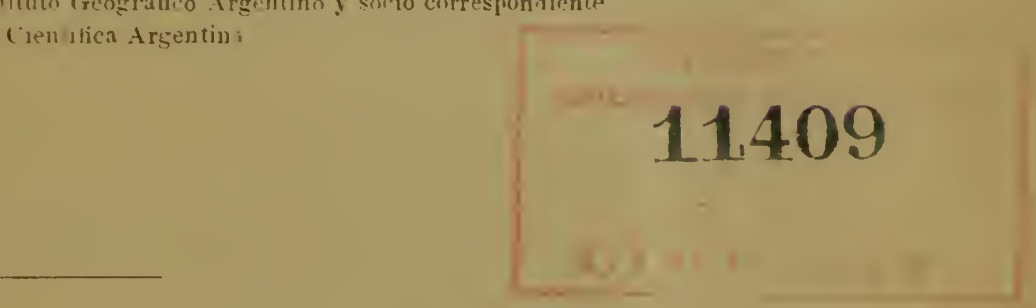

Articulo publicado en ol Bolftin de lat Acadenia Nacional de Ciencias DE Córdobi, tomo $X V^{Y}$, priginas 5 y siguientes

\section{BUENOS AIRES}

IMPRENTA DE PABLO E. CUNL E HIJUS

$$
680 \text { - CALLE PERÚ - } 680
$$

\section{6}


PMS301

. $46 L^{2}$ 


\section{D I $\bigcirc \mathrm{MA} A \mathrm{BIPON}$}

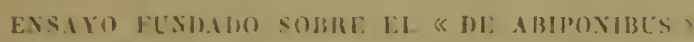



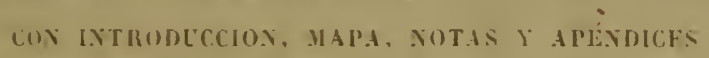

\section{PRÓLOGO}

Cun el Abipon se completa la terna de los tres grandes idiomos que urlados por las lenguas del grupo frataco-Maiaguayo, se disputaban el predominio en el Chaco Argentino. De Santa-fí i CGrdoba, de Córdoba á Santiago del Estero, de este Santiagro a la Concepción del Bermejo, y de Concepcion a Corrientes : la Asunción merodeaban y merodean en zonas rerticales a la corriente de los rios Salado, Bermejo y Pilcomayo, hordas Abiponas. Mocoríes y Tobas. El Abipon casi ha desaparecido ante el empuje del Mocoví; el Mocoví, sin ser menos valiente que el Toba, hoy desaparece ante él, dejandolo sulo para luchar contra las armas exterminadoras de lat civilizacion moderna. 
Durante dos siglos estos indios y sus congéneres tuvieron á raya a las armas españolas, y durante medio siglo más de la era patriótica fueron el terror de la República; pero la Presidencia del General Roca inició la segunda conquista del desierto, y hoy será cuestión de una generación el exterminio de estos indios como elemento étnico-lingüístico.

No es necesario entrar aquí en la cuestiou sociológicopolítica: los indios son un problema, una nuez que no es mi propósito cascar; liré, empero, y de paso, que si el nudo gordiano se cortó con la espada en provecho de un cirujano militar, con el cuchilío tambien se degolló la galliua que ponía los huevos de oro. Sabemos que el indio vive bien en el Chaco, y no nos consta que el Europeo pueda ocupar su lugar en toda la extensión de la frase. La Inglaterra conserva sus indígenas y los protege, sin haberse arrepentido de ello.

Esta monografía fácilmente se divide en cuatro partes: una etnográfica, otra gramatical y las otras dos lexicológicas.

En la primera se trata de lo que eran los $\Lambda$ bipones y de lo que de ellos cuentan autores como Barcena, Techo, Lozano, Dobrizhoffer, Jolis, Azara, d'Orbigny, etc. El primer lugar, por supuesto, en extensión é importancia, corresponal Padre Martin Dobrizhotfer, S.J., quien en su De Abiponibus ha consignado un adınirable panegírico de estos nobles indios.

Desgraciadamente, el buen Padre escribió su De Abiponibus en latin, en un latin bastante rococó y plagado de erudición clásica, muy buena sin duda para fin del siglo xvın, pero intolerable para el nuestro. Con todo, me avergüenzo 
que esta monogratial 110 se hit!a vertido a muestro fonance. mientras que los ingleses puseen lat traduevion de estan obra romo de la del l'. Techo. Sirvame, plles, esto de disculpa si me he valido con lodit extension de los latines del buen Misionero, y he tritido de producir en llamo romance los llosidos y bordindos periodos del famoso De Abipanibus. Años ha se nos anumcici que el Di. Padilla, de la Biblioteca Nacional, preparabir una traducción completa de toda la obra; mas como esta estia an in mubibus. tendran estos extractos el valor de un i cuenta de mayor cantidad.

Cunlieso que Dubrizhoffer me ha dejado enamorado de los Ibipones, ni quiero preguntar si es cier'o todo lo que dice; y como los lbipones son de los primeros indios que van desapareciendo, prefiero suponer que por mejores les sucediera asi.

Como se veri en su lugar, lo que dice Azara es de muy poca importancia; no asi lo que consigna d'Orbigny en su Lhomme Américain, y sus apreciaciones sobre todos estos Indios merecen la más séria atención de nuestros americanistas como que están ellas repletas de datos interesantísimos y le abservaciones muy ajustadas á lo que revelan posterios estudios de lingüística.

Antes de cerrar los cuadernos para la imprenta no desespero de conseguir algunos datos más que agregar á los pocos que se refieren al Abipon en la actualidad.

En la segurda parte se formaba una especie de Arte de la lengua Abipona. Los apuntes que nos ha legado Dobrizhoffer en su De Abiponibus son de mucha importancia, pero incompletos; por el otro lado Brigniel y sus colaborado- 
res se limitaron á darnos elementos para un trabajo como éste, pero se abstuvieron de formular reglas: acaso les sucedió lo que al P. Tarolini, quien empezó su Arte del Mocovi y se plantó al llegar á las posesivaciones.

La verdad es que tratándose de este grupo de lenguas hay que escribir mucho ó nada, hay que extenderse, como lo he hecho yo en esta monografía, ó que limitarse á dar casos concretos para que otros los utilicen. Los Misioneros alcazaron lo que buscaban: apreuder el Abipon como para doctrinar á esos indios y ayudar á los futuros Misioneros que entrasen á ocupar su lugar. Ellos iban á conquistar almas, y no á escribir tratados de filología.

Es verdad que Dobrizhoffer nos ha dejado una obra monumeatal sobre los Abipones y su lengua; pero él la escribió despues de la disolución de la Compañía, cuando tenía ocio para tratar la cosa del punto de vista étnica-lingüístico, como que por aquel entónces se empezaba ya á despertar el interés por esta clase de estudios en Europa.

En esta monografía se verá lo insuficiente que es la explicacion dada por aquel Padre: todo lo que escribe es interesante y exacto, pero muy distante de ser el todo de lo que había que decir. Del más somero exámen de los manuscritos del Padre Brigniel se advierte ésto, y el estudio que tuve que hacer de ellos para preparar mi “Mocovín me dejó persuadido que era indispensable hacer la publicacion de una parte; porque el resto contiene sermones, plácicas y otros textos, que no tuve ciempo de copiar, pero que será hoy tarea fácil interpretar.

Siempre persisto en dar á estas monografías un carácter comparativo; porgue necesitamos formar la cadena de nuestras lenguas con sus aspadas. Dos cosas se pueden hacer de verdadero valor científico: reducir á grupos lo que admita de tal proceder, y asignar á cada lengna su ubicación geográfica. Hecho ésto, y eliminados los arrinconamientos étnico-lingüísticos, se ha de hacer mucha luz en esta clase de estudios. 
De lo dicho en los subsiguientes alpitulus se vera que la Abipona es ma lengua prima-hermama de la Mocovi y la Toba, esta diltima hecha pealazos. Iris larde veremos como este grupo de tres se estabuna por Payarnat, Mbayi-finaycuru, ete. y con el grupo Mataco-Matacruayo por el otro.

Causa admiracion vel euintis formas comunes han conservade estos codialectos a la rez de haber perdido tando. Mdvicrtase que se trata de una articulación complicadísima que al decir de hombre compelente rivaliza en dificultad con los aumentos griegros. Thí veremos como, cámones que logré ilesenterrar de la masa de confusión para formar el "Arte Mocovio, reaparecen en el Mbipon, probandose desde luego que no habia errado al establecer como ley en ese grupo de lenguas lo que se advertía $\mathrm{cn}$ una de ellas.

Con raras excepciones todo lo dicho á proposito del Mocovi queda subsistente en este estudio del Abipon.

Lo yue consigna Idelung en su II ithridates carece de toda importancia. Salros los errores de imprenta, es cierto lo que apunto, pero es ma fraccion mínima de la verdad entera: Yo es imposible que se dé la traducción de aquel trabajo en forma de Ipéndice.

El plan de la segunda parte de esta monografía es el signiente:

Primero se hace un estudio de cierta morbosidad que se advierte en los sonidos. Todo caso va con su ejemplo, y los parangones se instituyen entre el Abijon, Mocuví y Toba; tambien se comparan algunas variantes de sonidos en el Ibipon mismo. En la fonología Mocoví se establecieron ya las principales interequivalencias, de snerte que no se ha hecho necesario reproducir esos argumentos aguí: c! que quiera puede consultailos en a(juella obra que está en venta por el Museo de La Plata.

En seguida se dan los rudimentos gramaticales de la lengua, observando más ó menos el órden de la Gramática Latina, 
para comodidad de referencia, no porque haya mucha analogía entre las respectivas morfologías.

Como en el Mocoví, el Arte del Abipon se reduce á saber usar con propiedad las articulaciones de plural, de posesivacion y de flexión verbal; tarea bien árdua por cierto, pero no tanto para el que tiene buena memoria y oido para oir sonidos de los que Dobrizhoffer ha dicho lo siguiente:

"Jam lingua sibilando, jam naribus rronchissando, jam dentibus stridendo, jam gutture strepitando ".

Isí se habla el Abipon.

Al fin de esta parte se agrega en forma de Apéndices, una Tabla completa de nombres y verbos segun sus posesivaciones y flexiones verbales. Digo completa, porque se incluye todo lo que está francamente posesivado ó conjugado por Dobrizhoffer ó Brigniel; pero la lista podrá alargarse con ejemplos deducidos de los Vocabularios.

Concluye la segunda parte con las Oraciones y Doctrina Cristiana, que nes dan á conocer la sintáxis Abipona. Para mí esto es lo más importante, porque en ellas se ve la lengua en giro, y no parapetada en los escaparates de un Arte del Abipon. El uso suele dar al traste con muchas reglas, y esto no es menos cierto en Abipon que en otras lenguas.

En el manuscrito el texto Abipon lleva la traduccion entre líneas, pero en muchos casos se ve que es romance y no traducción literal. Puede asegurarse que en los más de los casos la version es exacta, y cualquier duda está señalada ó explicada en las notas. Se recomienda al estudiante que al hacer su traduccion consulte los Vocabularios.

\section{III}

Concluida la segunda entran la tercera y cuarta parte que constan de Vocabularios Español-Abipon y Abipon-Español. $\mathrm{Al}$ primero se le agregan la frases y verbos con que concluye 
el rocabulario en el original. Esala partesoblo ha sido arreglada allibitiamente, y reprodure fielmente el mamuscrito yue yo atribuyo a brigniel.

En segruidal estit ol Levicon ó Cinlepino en que se incluyen

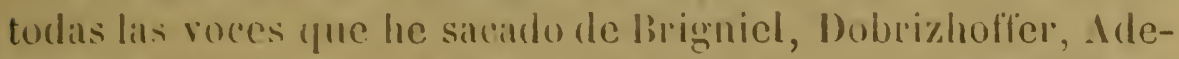
lung ? de los textos. En muchos casos se dan las equiralencias Ifocovies ! Tobas. Con este lexicon sera tarea lácil descifuar los dos volimenes de textus lbipones yue posice la familia limmas, dueña de estos preciosos manuscritos.

Con este trabajo las lenguas del Chaco Argentino, tipo Guaycuru, dejan de ser el misterio yue parecía á filólogos como Latham, ete. Ilgro bastante quedará que hacer aúm en los tres codialectos principales, Toba, Mocoví y Abipon, pues contamos con material para atacar el. Lengua y Mbaya, dicho fuaycurú, ramilicaciones de aquellos, pero ya las sendas estan iniciadas por la selva virgen de estos idiomas y yo quisicra haber tenido lo que aqui ofrezco a mis lectores fruto de mucha labor y paciencia, que si bien concluido en 1895 se empezó en 1888, cuando aúm vivía mi buen amigo el ilustre Dr. D. Andrés Lantas, a quien dedica esta monografia su decidido admirador y amigo,

Pilciac, Setiembre 24 de 1894.

Sayuel A. Lafone Queveno. 


\title{
PARTE PRIMERA
}

\author{
NOTICLAS DE LOS INDIOS ABIPONES
}

SEGLN BARCENA, TECIO, DOBRIZHOFFEI, I.OZANO, ETC. DESDE LA CONQUISTA HASTA NUESTROS DIAS

\section{CAPJTLLO}

\section{OBSERVACIONES GENERALES}

Lus Abipones son ó eran indins del Chaco argentino, de cuya ubicacion geográfica se hablará en utro capítulo y pertenecen á la gran familia á que se da el nombre genérico de Guaycurúes, que equivale á decir: enemigos de los Guarauíes.

Como se ha dicho ya en más de una ocasion, el Chaco Argentino estaba, y si se quiere está, ocupado por indios que se distribuyen en dos grandes familias: la una incluye á los Lules de Machoni y á los Vilelas ó Chulupíes; la otra, á los Mocovies, etc.

Los indios Lules, Vilelas y otros afines, pueden llamarse comparativamente mansos, y hablan idiomas cuyo mecanismo gramatical procede por medio de la subfijacion de partículas pronominales. Ellos y sus lenguas forman el asunto de dos monografías publicadas en el Boletin del Instituto Geográfico.

La familia Guaycurú encierra todas las más belicosas naciones del Chaco, Mocovíes, Tobas, Abipones, Lenguas ó Payaguáes, Mbayas ó Guaycurúes, etc., debiéndose sospe- 
char que los Catcano-Calchaquies, Charruas, Agates I otras hay all pertenecido a este mismo grrupo. De sul lengua y rasgros idnicus, historia. ete., se hat tratado ya en las monografias publicadas por el Museo de Lal Plata en su Revista, bajo el titulo de Arle Mococi? Arle Toba, ésta aun no concluidia.

De lo dado i luz ya, y de lo que se dira mas adelinte en este estudio, so desprende que esta familia de lenguas es de las mils complicadas é interesantes de toda la América. Las publicaciones de Hervas, Adelung, y aun la de Dobrizhoffer, no alcanzaron a hacer conocer los misterios del mecanismo de estos idiomas; y hay que conceder que él no se revela al que pisa y pasa por ese terreno, necesitindose de largos y penusos estudios comparados para llegar á establecer como reghlas lo que á primera vista parecen caprichos de una lengua que no las tiene ni conoce.

No es ćste el lugar de entrar a discutir lo que es la lengua abipona y cómo se eslabona con sus congéneres; ello resultari de las investigaciones posteriores. Antes de eso deberemos imponernos de lo que al respecto de ellos nos cuentan los escritores de las Conquistas Espiritual y Civil.

\section{GAPITULO II}

\section{ALGUNaS NOTIGIAS DEL PAdRe báRGeNa ó báRZANa}

El P. Bárcena en su carta del 8 de setiembre de 1594 al P. Provincial (1) no los nombra á los Abipones, pero sin duda los incluye entre los Frentones ó Frontones, á que hace referencia. La cita es un poco larga, pero vale la pena de

(1) Rel. Geog. de Indias, tomo III, Apéndice III, 
reproducir aquí lo que el apostólico misionero dice, por más de una razón, como lo veremos despues.

"Pero comenzando á entrar por la puerta desta gentilidad los que á ella venimos desde la Provincin de Tucuman, las primeras naciones que se nos pusieron delante, son los que llamamos Frontones, porque traen ellos y ellas las frentes rapadas hasta en medio de la cabeza. Es innumerable muchedumbre de diversas lenguas y naciones. Todos los hombres andan en el traje en que nacieron, aunque ellas andan honestas, cubiertas y vestidas de pieles de animales. No saben de agricultnra, ni edificar, todo su ejercicio es cazar y pescar. El mayor gusto suyo es matarse unos á otros. Sirven muchas destas naciones á los españolus de La Concepcion y algunos á la ciudad de Vera, á quien llaman Las Siete Corrientes, y tambien algunos a esta ciudad (la Asuncion).

"Pero viniendo el tiempo de los baños porque se baña cada año esta tierra por muchas leguas, y en viniendo el tiempo de la algarroba, cuando son las borracheras y juntas, los mas se alzan y vi aun sus propios Señores pueden ir á ellos con seguridad, antes los matan, como hicieron los Mogosnaes habrá dos años á su Señor don Francisco de Vera y á otros vecinos de La Concepcion que fueron con ellos. Son las lenguas que hablan estas naciones seis ó siete diversas y hárbaras. Reducido había la compañia á preceptos dos de ellas, la una que la hablaban mas de veinte y cinco pueblos y la otra mas de diez pueblos grandes; pero con esperar dos años en un pueblo grande de indios domésticos ya cristianos, al cual se acudió con veras con sermones, confesiones, catecismo, manutenencia y en todas las obras que se pudo acudir, nunca hallaron disposicion para poder entregar á la demas frontoneria la predicacion del Evangelio y el santo bautismo, esperando ver primero allanada la tierra.

"La noticia que tenemos de los mismos que se han convertido dellos de su vida y costumbres, es que tratan muy á menudo con los demonios, los cuales no solo acuden secre- 
tamente cuando fos Haman los hechiceros, simo lambien puiblicamente en medio del dia salen dentre los montes mucha muchedumbre dellos en hibito de indios cubiertas las calris y bailan con los indios ? comen y beben. Otras reces los ven en el mismo traje yue pintamos a los denonios y lan fieros y espantosos; y quien trata con tal gente carla dia, ! tienen por maestros perpetuos a los hechiceros, hien podemos congeturar que qué costumbres tienen, por lo cual no hemos osado a bautizar dellos sino algunos niños ? niñas que se han cautivalo en algunos castigos que les han hecho; auncue un Padre de los nuestros que no tenia conocido sus costumbres, bautizó en algunos pueblos que visitó muy do paso muchos centenares de niños y niñs; pero yo atribuí aquel descuicto a providencia particular de $\mathrm{N}^{\circ} \mathrm{Sr}$. porofue de allí á pocos meses vino pestilencia universal por todas esas naciones, en la cual morian casi todos aquellos niños, y grangearian el cielo. Tambien tengo confianza que allanada la tierra, como se va allanando, vernán todas aquestas naciones á la fé jorque son muy agudos, y no solo por señas entienden y no resisten á ser cristianos; y todos sus pecados proceden de ignorancia, aunque son gravísimos y muchos; sed, Supremo Medico nullum insanabile vulnus.

"Dios tiene guardada toda esta frontoneria para Jos briosos obreros que V.R. nos ha de enviar, y ya los va domando otro nuevo capitan, $y$ aunque bien pocos meses ha vinieron á poner fuego á toda la ciudad de La Concepcion y matar á sus moradores, aunque fué Dios servido que fuesen sentidos porque siempre se vela aquella ciudad como tambien esta de La Asuncion. Tienen en dos partes á tres leguas de la ciudad gente de guerra de dia y de noche, por causa de una nacion la más brasa y mas belicosa de esta frontoneria, que llaman Guaycurú; gente tan atrevida; que no solo ha destruido muchos pueblos de la nacion Guarani que servian á los españoles, pero por dos veces despues que yo vine, han venido á dar en las huertas y heredades desta ciu- 
dad, y la primera vez captivaron tres españolas, las dos mataron y la otra dieron por rescate, y mataron cerca de treinta indios, quemaron algunas casas. La segunda vez dieron en otras heredades y mataron mas de veinte, ademas de haber hurtado desta ciudad inas de mill cabezas muerto innumerable ganado vacuno.

"Contra esta gente se apresta agora guerra muy de proposito, y saldrán á ella la flor desta ciudad con muchos centenares de indios guaranies y frontones amigos. Dios les dé la mano, porque allanados estos, no solamente se allanará tuda la frontoneria, pero los muchos millares de guaraníes que ha mas de treinta años que están rebelados en el rio de Parana, ó se reducirán de su voluntad ó se conquistarán de propósito, para que desmontado este gran arcabuco, pueda sembrarse en él la pacífica semilla del Santo Evangelio y sea despojado Satanás. Y aunque estos guaycurús son tan carniceros, Nuestro Señor cumple tambien con ellos las promesas que tienèn (asi) dada á la gentilidad y asi en un asalto que les dieron, prendieron como ciento de ellos y todos quisieron morir cristianos con grandísimo ánimo y viva fé.

"Pero para ceñir en pocas las muchas cosas que se ofrecen de aquestas naciones, sus casas son unas esteras movibles a cualquiera parte que se mudan, de las cuales hacen como pueblo entero donde todos moran juntos con el principal que los manda, al cual en la guerra obedecen, porque de corazon son guerreros y en la paz viven de su trabajo como los otros, que es de pesca y caza. Para lo primero les proveyó Dios de grandísimas lagunas cargadas de pescado, que cada año entra con las crecie ates del rio Bermejo. Sus vestidos son desnudez. Sus bailes gran parte del año y todo con embriaguez, mayormente mientras les dura la algarroba. Sus maestros son los hechiceros. Son tenidas por honestas todos las indias frontonas (asi), y dicen que si alguna no lo es, que la mata su marido á flechazos.

"Aunque esta anchísima provincia del Rio de la Plata 
"Paraguay, desde Buenos Aires, que es la vecina junto al Mar del Norte por donde entra este Rio de la Plata con mas de 30 leguas de boca en la mar, hasta la nueva poblacion de los Niguaras abraza una gran suma de naciones como son Quirandies, Charruas, Calchaquies y Viraguaras, Niguaras, Luses (asi) y todas las naciones de los Frentones, que son muy muchas; pero la mayor suma de rente, mucha ya conquistada y muy mucha mas por conquistar es la nacion que en las fronteras del Piru donde han derramado tanta sangre de españoles, llaman Chiriguanas y aca llamamos Guaranies, los cuales como los españoles tambien tienen brio de conquistar las otras naciones, á las cuales todas llaman esclavos y cuando los rinden se sirven de ellos como tales. Extiéndese esta naciòn, segun he sabi‘o, desde las cordilleras de el Perú á las sierras de Santa Marta y por todo el Brasil y Santa Cruzde la Sierra, que será de largo más de mill leguas y de ancho muchas, aunque por unas partes más y otras menos. Han consumido muchas naciones por las continuas guerras que les hacen y porque muchas dellas comen canne humana, lo cual no se sabe que hagan ninguno de los Frentones. Tenian ell su poder muchos y principalísimos rios con todas las tierras y muchas islas que bañan, entre las cuales es ilustrísimo el que llaman Rio de la Plata, por su grandeza, claridad, suavidad y abundancia de todo géneru de peces grandes, hermosos y muy diversos, que por ser tan grande le llaman Paraná, que quiere decir, "pariente del mar"; el cual, cuando entra, entra sesenta leguas adentro del mismo mar, y antes que lleguen á ver tierra, se coge de él agua dulce. :

Larga es la cita, más larga es la carta, pero llena de interesantes detalles, y tiene que ponerse a contribucion para varias de estas monografías. Entre las muchas cosas dignas de notarse está la acusacion á los Chiriguanos de que son antropófagos, cargo que en nuestros dias se ha reproducido por el P. Cardús. Los Frentones con ser que son aun más indómi- 
tos y más fieros salvan de esta nota que á nosotros nos parece tan fea, porque no nos hacemos cargo que mas bien se debe al culto que á la barbarie. El sacrificio de víctimas humanas trae aparejada la participacion en la carne ó sangre de la víctima.

Otro punto curioso es ese error de Luses por Lules, debido á la confusion de la $s$ gótica ó larga con la $l$.

En un documento de 1595, contemporáneo del P. Bárcena y acaso escrito por alguno de sus compañeros, pues resultó de la fundacion de la Rioja, se encuentra la misma confusion. A ella se atribuye la sustitucion de Hualan por Huasan como sitio de una de las fundaciones de la ciudad del Barco.

Estos Lules y estos Calchaquíes son los de la region Cacana, únicos que conocía el P. Bárcena y de ninguna manera deben tomarse por aquellos otros que (los Calchaquíes) juntamente con los Mogosnas, Natijas y Abipones obligaron á los españoles á desalojar la ciudad de la Concepcion del Bermejo, y que (los Lules) fueron doctrinados por los PP. de la compañía en el siglo pasado.

\section{CAPITULO III}

LO QUE DIGE TEGHO DE LOS ABIPONES

El Padre Techo en su historia de la compañía y libro I cuenta que el P. Bárcena, llamado de su mision entre los Lules de Tucuman, contestó :

a Allá me tendreis o Padre, cuanto antes y á vuestros pies postrado diré :

"Aquí estoy, mandadme, ya que regrese á los Lules, ya que acuda à los Calchaquinos, Caquenses ó Frentones, etc., etcétera." 
Aqui se ve cómo el P. Barcena agrupaba a los "Lules Calchaquinos, Chaquenses y lirentones ") y que son los Lules y Calchaquíes de Tucuman y no los del Chaco á que se refiere en su carta.

En este tiempo se abrió la primera mision a los Frentones del Bermejo, encabezada por los PP. Juan Fonte y Francisco Angulo. Los españoles de la Concepcion del Bermejo llaman i casi toda esta gente Frentones, porque suelen alargarse las frentes, rapándose la parte delantera de la cabeza. Estos indios cargan macana y haces de flechas colgadas del cinto y van armados con palos erizados de quijadas de pescado, que parecen serruchos. Andan desnudos y embijados para aterrar á los demás. Las diferentes parcialidades casi diariamente pelean entre sí, y los cadáreres del enemigo están colgados en largas filas de los árboles para escarmiento de los que pretendan violar los términos intervecinales en sus caceríos. Sus pueblos los trasportan á su talante, como que se forman de esteras. No saben labrar la tierra; viven de la caza y de la pesca. Una cosa buena se les conoce: por lo general se limitan á una sola mujer. Cada tribu tiene distinta lengua, de suerte que en ambas márgenes del Bermejo se cuentan no menos de ocho idiomas: lo que más estorba la conversion de estos infieles es la variedad de sus lenguas.

Fonte y Angulo bautizaron muchos párvulos de los Frentones que despues murieron en una peste que asoló á esas indiadas, como lo refiere Bárcena en su carta.

Retirados los PP. Fonte y Angulo entran los PP. Bárcena y Añasco á evangelizar á los Frentones y se pusieron en la más dificil de todas las tareas, la de aprender los dialectos (idiotismis) que con más generalidad se hablaban entre estos indios. "Así, pues, en el espacio de año y medio Alfonso Bárcena, un anciano de 65 años de edad, ayudado por Pedro Ańasco, aprendió las lenguas Guaranítica, Nática, Quisoquina, Abipónica, Quiranguica, y compuso vocabularios, artes, 
catecismos y platicas, que sirviesen para adquirirlas: y esto que antes de partir los dos del Tucuman, con el mismo fin habían ya reducido á vocabulario y arte las lenguas Tonocotana, Cacana, Paguina, Quirándica, para que los Padres de la Compañía que viniesen despues tuviesen eso adelantado al aprenderlas. Y para que el servicio fuese mayor, Pedro Añasco trascribió varias copias de muchas de ellas, muy especialmente de todo lo que compuso Alfonso Bárcena, en letra clarísima y así reproducidas las dió al público. "

Más que probable es que á estas copias del P. Añasco se deba el precioso manuscrito con arte y vocabulario del Toba generalmente atribuido al P. Bárcena y que hoy para en la Biblioteca del General Mitre.

Los Padres, empero, tuvieron que retirarse cuando los Naticas y Mogosnas mataron á Francisco Vera, hermano del Adelantado.

Años despues, el P. Diego Torres visitó la ciudad de la Concepcion del Bermejo y encontró á los Abipones, Matacos (Mataguas), Naticas, Mogosnas y Tonocotanos constantes en su gentilísimo. A todas éstas llama Techo agnatas nationes de los Frentones. No sería extraño que los Naticas fuesen más ó menos lo que nosotros llamamos Tobas, nombre éste que debe su origen á los Guaraníes y que equivale á Frentones.

El año 1641 el P. Juan Pastor, Rector del Colegio en Santiago del Estero, entró á visitar á los Abipones y aunque no fué grande el lucro espiritual, sirvió la entrada de motivo para que el P. Techo nos diese cuenta de lo que eran estos indios en sus Chacos. Caliquila se llamaba el cacique de la tribu que recibió á los misioneros.

"Los Abipones, por lo general, son de mas que mediana estatura y se distinguen por lo bien proporcionado de su cuerpo, su musculatura es bien desarrollada y sus caras llenas (vultuosi). En el verano andan desnudos, en el invierno se abrigan con pieles. Del cuello les cuelga la macana y 
de los hombros el careaj. En la siniestra llevan siempre el arco y en la diestra una lanza; el cuerpo entero se lo embijan, y ponen overo como tigre para inspirar terror; y para ellos aquellos que ostentan mis partes del cuerpo cruelmente traspasadas y adornadas con plumas de avestruz, que ineten en las narices, labios y orejas, como si estuviesen por volar, éstos son los más dignos de respeto.

"La barba para estos hombres es una afrenta, así que cuando les asoma el vello se lo arrancan. Para ellos la calvicie es un adorno, y nadie tiene derecho á la cabellera no siendo que haya dado muerte al enemigo en la guerra ó en pelea. El homicidio entre ellos es la prueba militar, y mientras eso no se haya logrado conseguir no se conceden honores guerreros. Tienen tambien sus nobles y sus héroes; a ese estado ascienden mediante pasos bien dolorosos; porque quien ambicione el título de héroe tiene que hacer constar su valor á los demás con el sufrimiento de descomunales tormentos: se lastiman las pantorrillas, plernas, brazos, lengua y otras partes del cuerpo, qụe por pudor no se nombran; en seguida, con una piedra afilada, se escarnecen y lonjean la piel de todos los miembros. Por fin cinco de los mayores ponen al candidato á prueba con los mismos tormentos, y si llega á dar señas de dolor con el más pequeño gesto no se le admite al órden de los Patricios. Si empero, en medio del tormento se hubiese portado con valor, entonces nadando en su propia sangre en señal de regocijo y como el que triunfa, recibe las insignias de la dignidad ganada.

" $Y$ para que más seguros estén de obtener ese honor, desde tierna edad, con conchas se punzan y lastiman así. Por lo que en todas partes es de ver á los jóvenes que se traspasan la lengua, labios, narices, orejas y otras partes con espinas y clavos y que ocultan el dolor con risa obligada. Esto por io que toca a los varones.

"Las mujeres del seno abajo se visten con redes bastas; lo demás del cuerpo ora lo embijan, ora lo adornan con piedre- 
zuelas ensartadas, en especial los pechos y la cara. Tambien ellas se rapan, pelandose el colodrillo con cuchillos de piedra o de caña. Cuando mueren sus Caciques todas cambian de nombre, y llorando á gritos dia y noche, que da pena el oirlas, ayunan durante un mes entero. Y así es el ayuno entre los Abipones: pescado no comerás, carne cuanta y cuando quieras tragarás. Solo dos hijos suelen criar, á los demás. ccn una crueldad que sobrepuja á la de Atreo, los matan: el infanticidio lo explican diciendo que los Abipones, acostumbrados á la guerra y al pillaje, carecen de asiento fijo, a donde plantan sus esteras á modo de pueblo allí es su paradero; de ello resulta que no dejan vivir más que un par de hijos de los que con el uno carga la madre, y con el otro el padre, porque no caigan en manos del enemigo; mas si el uno ó los dos de estos ya pueden caminar como para que los sigan á la guerra, cuando sea que la madre dé á luz el tercero ó el cuarto, en ese caso de buen grado crian más de dos.

"Muchas de las viejas son brujas, y tienen mucho que hacer con el demonio."

La relación que precede es larga, pero de interés, y nos da á conocer lo que eran los Abipones en el siglo xvII, así como sacamios de la carta del $P$. Bárcena lo que pudieron ser en el $\mathrm{xr}$, si adınitimos que vayan inclusos entre los demás Frentones. La obra de Techo está en latin y es rarísima, desde luego fuera del alcance de los más que puedan interesarse en estas cosas.

\section{CAPITUIO IV}

\section{LO QUE DICE LOZANO DE LOS ABIPOAES}

No cabe duda que en mucha parte el P. Lozano reprodujo lo que antes de él escribiera el $P$. Techo; pero tambien es cierto que tuvo á la vista los documentos originales, como se 
comprueba con la carta del P. Bárcenal a su Superior, de la que Techo sólo cita un fragmento, y éste con Londres dejado en el tintero. Este Padre traduce por cui Deus Optimus Maximus per te me affixerit: "apuello que Dios por V.R. me diere "; y omite esta gracia del Misionero: "Una sola cosa piclo a Dios Nuestro Señor y i V. R. en su nombre: $n 0$ me vea yo incitil ocupado en comer y parlar y confesar seis espanoles, y en predicar a gente que dice con las obras: Viam scienciarum tuarum nolumus. (Hist. de la Comp., t. 1, pàg. 91).

Por lo diemás en esta historia los Abipones van incluidos en el nombre general de Frentones, y donde se habla de Iogosnas y Naticas, probable es que debamos agregar Abipones tambien. Es en la Descripcion Chorographica del Chaco, por el mismo P. Lozano, que encontramos la descripcion más completa de estos indios. El libro es rarísimo, por lo cual conviene que aquí se reproduzca íntegra.

"Por fin del rio Bermejo, y caminando á orillas del Parana el rumbo al Sur, está la nación de los Abipones. Fué antiguamente muy numerosa, pues en un solo pueblo de ellos cercano á la ciudad de la Concepción, halló el Padre Juan Fonte, uno de los primeros obreros de esta Provincia, más deocho mil almas, y en la nacion de los Matarás, ó Amulalas, (que estaba ocho leguas de la misma ciudad, encontró Pueblo le más de siete mil, y es constante había más de cien mil Indios en el contorno de aquella ciudad del Rio Bermejo. El dia de hoy se mantiene un Pueblo Christiano de la nacion de los Matarás en la jurisdiccion de Santiago del Estero: los demás, y los Abipones no son tantos, como antiguamente; pero es nacion numerosa, y la que tienen casi arruinada a la ciudad de Santa-Fè de la Vera-Cruz. Llámanse el dia de hoy Callagaes, que antiguamente se llamaban Abipones.

"Dichos Abipones, andan totalmente desnudos, aunque las mujeres se cubren con mantas de pellejos bien aderezados, á que llaman queyapi. Usan las armas que todos los del Cha- 
co, y pelan la cabeza, al modo que los Guaycurús, aunque el cabello que les queda algo largo, lo atan atrás, con una trenza, porque no les impida, cuando anden en el agua, que es muy de ordinario, por ser grandes nadadores. Son de grande y formidable estatura, y bien agestados pero se labran la cara, y cuerpo, y se embijan, con que encubren la blancura natural. Taládranse el labio inferior de que pende un barbote, ó como acá llaman Mbeta. Sou muy dados á la milicia, exercitándose de continuo en la guerra sobre leves causas que las más ordinarias sobre si vino á pescar, ó cazar. dentro de sus límites. Estos los amojonan con unos horcones largos, y en ellos cuelgan las cabezas de los muertos, por haber violado los términos de ajena jurisdiccion. Desde niños se van curtiendo y fajando el cuerpo, para hacerse robustos en su desnudez, y así tienen viejos diputados que les sajan á ciertos tiempos piés, piernas, brazos y cuerpo con puntas del pez Raya muy agudas, y lo que es más, la lengua que da compasión verlos, y ellos pasan riendo. Los mozos al modo que los Guaycurús no entran con los demás á beber ni i otras acciones, hasta que pasan por el martirio, de que cuatro viejos les traspasen como, y cuantas veces gustaren con espinas la parte que mas recata la honestidad, lo que han de tolerar sin dar la menor muestra de flaqueza, ni un quejido, y desde entonces se pueden ya juntar con los valientes. Cuando salen á la guerra se punzan muy bien la lengua, y con aquella sangre se untan todo el cuerpo, y sobre este matiz hacen mil labores con carbon, y de esta suerte, dicen ellos con dolor, que llevan, que quanto topan, lo destruyen sin distincion de edad, ó sexo, y su mayor alabanza es matar á cuantos más pudieren, y segun el número de los que huvieren muerto, se les permite poner otras tantas plumas en el dardo. Con ser en muchas cosas semejantes á los Guaycurús, tienen con ellos ordinariamente guterra, solo divide á ambas naciones el Rio Bermejo.

"Cuando se anega su tierra, que es en los cincos meses 
del año, se retiran a vivir en Islas, y aun sobre los arboles y en enjugindose la campaña, se acercan á las lagunas donde hay dehesas de lindisimos pastos para ganado. Suelen sembrar algo, pero uny poco, y cuando caulivan algumos españoles, los primeros meses los ocupan en guardar las sementeras. Su ordinario sustento es la pesca, y caza, en que no perdunin it los tigres, cuyas hediondas carnes aprecian mucho, y las reparten en pedizos, como por reliquia entre los parientes y amigos, porque dicen, que con las carnes de esta fieria se les infunden brios y valentía.

"No tienen conocimento algumo de Dios, viviendo como bestias sin policía, ni govierno, y solo hay algunos Caciques, á quienes los de su familia, y emparentados únicamente siguen, y solo quando van á guerra tienen cabeza superior, que los gobierne. Hechiceros sí, que hay muchos entre ellos, que hablan con el Denonio, quien se les aparece en sus fiestas, $y$ borracheras feo y abominable y á su semejanza se embijan los Indios por darle gusto, sin tributarle ninguna adoracion ó culto. Y aunque á las veces el Demonio que quicra aparecer a los Hechiceros, ellos fingen, que se les ha aparecido, para que así los demás les temau, y honren, y llamen en sus enfermedades, que son palillos, piedras o cabellos, que llevan encubiertos en la boca; mas guádese el Hechicero de no acertar la cura, y de que muera el doliente; porque luego se conjuran los parientes, y le matan porque dicen, ha sido él la causa de la muerte.

* No obstante la falta de conocimiento de alguna deidad creen la iumortalidad del alnıa, y dicen, que va á una tierra de sunos deleites, donde danzan, y beben á su gusto, en que está la felicidad de esta gente ciega. Cuando muere el marido, la mujer guarda celibato, y ayuna un año que es abstenerse de comer pescado, y al tiempo salen estas viudas al campo diciendo que su marido viene ya á darles licencia, para que se casen con otro. No tienen de ordinario más que una mujer, y estas son curiosas y diestras en hilar el hilo del 
chaguar, y labrar algunas cosas para gala suya, y en particular en coser las pieles de las nutrias, ó venados para sus mantas, que las cosen tan curiosa y prolixamente que admira. En esto se ocupan las mujeres, que los varones fuera tiempo de guerra son haraganes, y solo se entretienen por las tardes en hacer alardes, y los muchachos desde el amanecer en correr para excitar las fuerzas. Aunque ellos son muy entregados á la embriaguez, las mujeres son muy abstemias, y sirven de esconderles en aquel tiempo las armas porque no se maten.

"Cuando la mujer pare, ó el hijo enferma, el marido se echa en la cama hasta que pasan algunos dias, y se abstiene de comer pescado, porque con eso dicen sanará el hijo y la madre y sinó morirá. Las mujeres no crian más que dos hijos ó hijas; los demás que paren los matan por evitar el trabajo de la crianza, que es cosa bien particular, y agena del amor natural de las madres, aun entre bestias fieras, y es sin duda permission divina, para que no se aumente demasiado tan bárbara gente, y tan enemiga de Christianos. "

No cabe duda que en los dos primeros siglos de la conquista eran los Abipones de los Indios más numerosos y de más valer en el Chaco. El P. Bárcena hizo arte y vocabulario de esa lengua ([ esc.Chor., pág. 116) y tuvieron gran parte en la destruccion de la ciudad de la Concepcion del Bermejo, segun nos lo cuenta el mismo Lozano en su Historia de la Conquista, tomo 3, páginas 274-80. Mogosnas, Abipones, Naticas, y otras tribus Frentonas contribuyeron todas á este triste fin de una de las ciudades fundadas en tiempo del adelantado Vera y Aragon. Más tarde fueron el azote de Corrientes y la Asunción. 


\section{C.IPITULO I}

\section{LOS AIIPONES SLGUN JOLIS}

E) P. Jolis fuc doctrinero de las reducciones del Chaco entre los Vilelas, el año 1767, y publicó su obra el año 1789 , cinco años despues de la de Dobrizhoffer.

I.os apuntes que se reproducen en seguida se hallarán en el Libro VI, artículo 8 ; por si alguno tiene la suerte de poseer esta preciosa y rarísima obra.

En primer lugar, confirma Jolis la noticia que frentones son todos aquellos que producen calvicie artilicial en la parte anterior de la cabeza, é incluye entre ellos á las naciones Mogosnas, Chisoquinas, Naticas, Tobas, Mocovíes, Yapitalagas y Abiponas, de las que ya en su tiempo parece que lıabian desaparecido las tres primeras.

Los Abipones se dividian en tres tribus Naquetaget (del bosque), Rigagé (del campo), Yaschaniga (del agua). Tan numerosos eran, que uno de sus pueblos quese hallaba en las inmediaciones de la destruida ciudad de la Concepcion contaba con más de 8000 almas. Jolis cree que en su tiempo la nacion entera, inclusive las reducciones de San Jerónimo, del Rosario, del Timbó y de San Fernando y San Regis, no alcanzaba à esa cifra.

Segun este autor la extincion de estos indios se debía no tanto al mal tratamiento de los encomenderos, como que no los tenían, sinó más bien à las pestes y á sus guerras contínuas y exterminadoras. De las primeras se cuentan cuatro terribles $1590,1591,1616$ y 1718 .

En cuanto á su estatura, excede aun á la de los europeos. Son fieros y esforzados y muchas veces tuvieron apuradas á las ciudades de Santiago del Estero, Corrientes y Santa-Fé. 
El año 1747-48 fueron sometidos estos indios y colocados en las reducciones antedichas y desde entonces dejaron de ser una amenaza para los pueblos de esprañoles.

La costumbre demartirizarse con huesos agudos y espinas y usar el barbote ó tembetà parece que se estaba dejando ya en tiempo de Jolis, y critica este autor la noticia de que criaban sólo dos hijos y daban muerte á los demás; mas como él mismo dice, muchas otras costumbres que les atribuyen Lozano, Charlevoix y Techo, si es que las tuvieron en la antigüedad, ya las habían dejado en tiempo del más moderno autor, quien uo se contenta con la negacion general sino que entra á especificar; pues asegura que ni se perforan con plumas de avestruz, ni se hace obligatorio cometer un homicidio para poder dejarse criar la cabellera. No todos los de la tribu mudan de nombre cuando se les nuere el Cacique, sino los parientes, etc., etc.

Se ve que estos eran Abipones degenerados, que con su gentilismo habían dejado tambien mucho de to que antes los distinguiera, al decir de los dos escritores de los anteriores siglos.

\section{CAPITULO VI}

\section{LOS ABIPONES SEGUN EL PADRE DOBRIZHOFFER}

El P. Dobrizhoffer, S. J., doctrinero de los Abipones y compañero del P. José Brigniel, que aún permanecía entre ellos el año 1667 en que fueron expulsados los Jesuitas, nos ha dejajdo la más completa monografía sobre estos indios, y por cierto que los pinta en colores tan brillantes que no podemos menos que acordarnos de la Germania de Tácito, que muchos sospechan deba algo á la imaginacion del famoso historiador. 
El buen Padre escribio su relacion de los Abipones en latin y la claveteó con tal abundancia de citas clásicas que se vuelve tarea bien pesada el lener que entresacar lo que atañe á nuestros indios de la masa informe de erudicion que no sirve sino para perturbar al que lee. Por lo tanto, aquí sólo se hari un resúmen de lo que cuenta el Padre con referencias al capítulo del origrinal, de suerte que el que quiera y tenga cómo acudir à la fuente original pueda hacerlo; porque, sea dicho de paso, esta obra es tan escasa como las demás que aquí se citan.

\section{CAPITLISO VII}

UBICACION GEOGRAFICA Y NOMBRES QUE LES MABAN LAS OTRAS NACIONES ( 1 )

Los Abipones como indios nomades que eran y de á caba110 merodeaban en todo el Chaco, sin más límite que el estorbo que podían ponerles las naciones circunvecinas. Su asiento de orígen parece haber sido la márgen del rio Grande ó Bermejo, que ellos llamaban Iñaté. Más tarde emigraron hácia el Sud y ocuparon el valle que antes fuera de los llamados Calchaquíes de Santa-Fé. Allí los conoció el P. Dobrizhoffer, su doctrinero. El cacique Ichamenr'aikin contó al Padre que no había tradicion conocida que indicase el país de su procedencia; pero por ciertas expresiones de ellos, cuando algo les desagradaba, parece que más bien se inchnaban á tener al Norte por su patria de orígen; bien que ello podía reducirse á que en el Norte había menos españoles y más probabilidad de poder conservar allí su libertad.

11 Tomo II, capitulo I. 
En términos generales puede decirse que el campo de sus correrías se extendía desde el Bermejo hasta Santa-Fé, y desde Santiago del Estero hasta el rio Paraná.

Al norte del Bermejo y en país de lo sTobas (Nataguebit) se establecieron algunas tribus Abiponas que allí existían hacia fines del siglo xviI.

Despues de averiguado el territorio que puede llamarse país de los Abipones nos interesa saber cómo se designaban esas tribus entre las convecinas.

Los Tobas, Mocovíes y Yapitalagas daban á los Abipones el nombre de Callagaik, mientras que los Guaycurúes los llamaban Comidi. Al decir Guaycurú debe más bien comprenderse alguna nacion Mbaya; porque todos los autores coufunden á varias naciones en la designacion general Guaycurúes, de las que algunas son reconocidamente Tobas, como se deja ver en los vocabularios. No está de más esta nota al texto del Padre.

Los españoles dieron este mismo nombre de Callagaes á los Abipones, pero tambien los incluían entre Frentones; porque éstos como tantos otros de estos indios se aumentaban el alto de la frente mediante una rapadura de toda la parte anterior de la cabeza.

Los Vilelas trataban á los Abipones de Luc-uanit, voz que significa: "Los que viven al Sud"; en el mapa del Padre hay Abipones Callagaes al sud de Vilelas.

Un vocabulario manuscrito en la coleccion d'Orbigny dice que los Tobas Ilamaban á los Abipones Caliazee. Brigniel da esto en su Vocabulario Abipon, Gigante Carigo.

Los Abipones son indios ginetes y tienen muchos cabaIJos. 


\section{CAPITULO VIII}

COLOR DE LOS INDIOS Y RASGOS ÉTNICOS DE LOS ABIPONES (')

En cuanto á su tez los Americanos no son ni negros como los Africanos, ni blancos como los Eurnpeos; sin perjuicio de que haya muchos de aquellos que superen á muchos de éstos en blancura. Los Abipones, Mocovíes y Tobas, con ser que habitan una zona mucho más tórrida que los Aucas, Puelches y Patagones, no obstante son más blancos que éstos. Puede asegurarse, pues, que los indios del Chaco tipo AbiponGuaycurú son de los menos morenos de nuestro continente. Hoy ya se sabe que no basta el calor para producir la negrura del africano, pero en tiempo de Dobrizhoffer era proposicion que contaba con más novedad, y las observaciones del Padre son muy pertinentes al caso.

"El Padre Thomas Falconer, inglés, filósofo, médico, mi compañero en el Paraguay, por muchos años apóstol de las tierras Magallánicas se rie de lo que creen los Europeos porque cuentan á los Patagones por gigantes, y declara que Aangapol, lejos el primero de los Caciques de esa tierra, y que descollaba entre todas por su altura le pareció tener 7 piés más ó menos.

"Y si por acaso pudo engañarse la vista de éste, recíbase el testimonio mío, que tambien lo ví con mis ojos. Recien llegado de Europa ví en la ciudad de Buenos Aires un gran número de estos bárbaros. Verdad es que á ninguno de ellos medí, pero con muchos mediante un intérprete pude hablar. Debo confesar que los más eran de un alto extraordinario, pero no al grado de merecer el título de gigantes; porque si

(') Tomo II, capítulo II. 
calificamos á los Patagones de gigantes fuerza será que hagamos otro tanto con todas las tribus ecuestres del Paraguay: Abipones, Mocovíes, Lenguas (ó sean Oaecacalot), Mbayas, etc. Los más de éstos en nada ceden á los Patagones en cuanto á la altura de su talle; si bien tenga que admitir que éstos sean más corpulentos, más morenos de cara, y de cuerpos no tan esbeltos. 》)

Lector si no te bastan los testimonios de Falconer y Dobrizhoffer, aquí va otro. El que esto escribe vió indias Patagonas en Buenos Aires cuando estuvo allí Horqueque. Eran unas mujerazas, desarrolladas en todas direcciones, de unos 6 pies de alto y toscas como unos elefantes. Concluye el P. Dobrizhoffer con estas sensatas palabras: “De los huesos de gigantes podrás creer lo que te plazca, pero si te parece bien estar á lo que yo pienso dejjate de tener á los Patagones en reputacion de Gigantes. "

\section{CAPITULO IX}

RASGOS ÉTNICOS DE LOS ABIPONES ( ${ }^{1}$ )

Los Abipones, por lo general, son de una hermosura noble, sus caras agradables, y sus facciones más ó menos como las de los europeos, si exceptuamos la tez que no es del todo blanca, pero ni con mucho puede compararse con la de los africanos. El sul y el humo algo los achicharra, por eso los adultos son algo más morenos. Entre las mujeres se cuidan algo más, y cuando viajan se resguardan del sol con sombrillas de plumas de avestruz; así que la tez de ellas es mucho más blanca.

") Tomo II, capítulo III. 
Entre los hombres es un mérito ser feo, porque así creen infundir el espanto en sas enemigos.

Los ojos son negros y mas bien pequeños; pero ello no quita que con ellos vean mejor que nosotros con los nuestros. Por pequeño que sea el objeto lo distinguen sin dificultall, y saben lo que es cuando nosotros apenas si adivinamos que algo hay. Ellos ven mejor con la simple vista que nosotrus con las ayudas que acostumbramos. La nariz, por lo general, es aguileña, mas bien larga y puntiaguda. Las mil y una deformidades del cuerpo que nosotros conocemos entre ellos no se ven.

Los enamos son rarísimos. En 7 años que estuvo el Padre entre los Ibipones sólo tres de éstos conoció. El primero fué Debayalaykin, cacique principal, llamado por los españoles el Petizo, otro era Kevachichi, y el lercero, Hamihegemkin.

La dentadura la conservan sana y blanca hasta que mueren.

Carecen estos indios de barba y si alguna vez se presenta debe atribuirse á mezcla de raza. El vello, cuando les asoma, lo tuestau con rescoldo y lo arrancan con tenacillas. Tambien se hacen arrancar las cejas y pestañas; y motejan á los espanoles de hermanos del avestruz al verlos tan poblados ile una y otra cosa. Cuenta el Padre que con trabajo se escapó de las garras de una de las viejas barberas, que estaba empeñada en hacerle pasar por ese martirio.

El cabello es negro retinto, albinos y de cabellera roja no los hay. Los Abipones de la selva que no están aún reducidos, al raparse se dejan un cerquillo como el de los frailes. Esta operacion la efectúan con conchas y quijadas de palometa, cuando les falta la navaja ó cuchillo. Los indios reducidos initan el coleto de los soldados españoles. Sus peines los hacen de las cerdas del jabalí ó del oso hormiguero.

Por la mañana, al despertar, las mujeres arreglan las cabelleras de los maridos. Crespos hay pocos de nacimiento, por artificio ni uno. Tarde y nunca encanecen y rara vez se ve calvicie natural. 
Todo Abipon, Mocoví, Toba, etc., sin distincion de edad ni sexo, se rapa ó arranca el cabello de la parte anterior de la cabeza, hasta la altura de unos tres dedos. Esto que llaman Nalemra es para ellos lo que la circuncision para el Judío y el bautismo para el cristiano.

Si muere el marido, la viuda se hace rapar la cabeza y la cubre con un bonete negro de Caraguatá, que usa hasta llegado el tiempo de poderse volver á casar. El viudo tambien guarda su duelo, y entre otras cosas se hace cortar el cabello, y se cubre la cabeza con un bonete ó redecilla, que no se quita mientras no se le vuelve á criar la cabellera.

\section{CAPITULO X}

DE Cómo SE AFEa EL ABIPON AL QUerer ENGaLANARSE ( ${ }^{(1)}$

El Abipon ni bien adolece ya empieza á deformarse convirtiéndose en verdadero espanto.

En primer lugar está el tatuage con sus dibujos, unos de éstos propios del hombre, otros de la mujer. Con una espina aguda se punzan las carnes y con unas friegas de negro de carbón se hace indeleble el dibujo. Son especiales de los Abipones y por ellas se distinguen de las demas naciones las siguientes marcas ó señales. En media frente una $(+)$ cruz y más abajo, en la raíz de la nariz, y entrecejo, un jaquelado de cuatro rayas. De cada ojo hacia las orejas parten otras dos rayas paralelas $=$.

$\mathrm{Ni}$ los Abipones mismos saben lo que significan estos signos, ni menos el Padre Dobrizhoffer, al decir del mismo; pero se deduce que sean como amuletos que sirvan para preser-

(1) Tomo II, capítulo IV. 
var al que los carga. La cruz, las dos rayas y los jaqueles se repiten ad nauseam en la alfarería, etc., de la region Catamarcana, y en el Museo de La Plata, estí una tinaja mortuoria con la + colocada como en la cara de los Abipones. Estos llaman à la cruz Likinr'ánala, lo que prueba que no es necesariamente de origen cristiano entre ellos.

Y no es sólo en los rostros que los Abipones cargan la cruz. Cruces negras sobre fondo bermejo son frecuentes en el tejido de sus trajes. I acaba el misionero: " $\Lambda$ qué fin empero los. bipones imprimian la figura de la cruz en sus caras y en sus vestidos coufieso que no sé rotundamenten.

Andando el tiempo alla lo veremos, y tal vez algo nos cuente al respecto el conde Goblet d'Alviella cuando suplemente su La migration des Symboles con ejemplos americanos como estos de los Abipones.

En fin las mujeres sou tan ávidas de este pintar de sus cuerpos á punta de aguijon que rostros, pechos y brazos parecen más bien un entapizado de esos abigarrados que llaman de Turquía. Ni bien llegan á la edad de poderse casar tienen todas que someterse á este sangriento rito. Lna vieja le coge la cabeza á la mozuela en sus faldas y empieza el tormento, un aguijon por pincel, carbon mezclado con sangre, la tinta. La que pinta hinca, y con ganas como vieja en moza. Y si la víctima se queja llueven los denuestos y las burlas para acabar con la amenaza que sin este afeite solterona tiene de quedar. Y el tormento no es de un dia sino de muchos: mientras dura vive encerrada, y se abstiene de ciertas comidas como ser carne, pescado, etc., y sólo se alimenta con ciertas frutas que llamau Kakié, Reayanu y Nanapr'ahete. Con la irritacion de las punzadas ó el veneno de las espinas se les pone la cara como monstruo. Pero era la costumbre y pasaban por todo. Cuanto más la nobleza de la moza, mayor el número de figuras. Por fin los misioneros consiguieron abolir esta abominable costumbre entre las tribus reducidas. 


\section{GAPITULO XI}

DEL BARBOTE Y DELTAPON QUE USAN LOS INDIOS “OREJONES》 $\left.{ }^{1}\right)$

Los Abipones parece que antes tambien usaban barbote; pero los que conoció Dobrizhoffer hacía tiempo que lo habían dejado y sólo lo conocía entre los Guaraníes alzados, Mbayas, Guanas, Payaguáes, etc., á quienes por sus deformes labios los Abipones liamaban Petegmek. Estos se metían un canutillo del tamaño de una pluma de escribir, que desde el labio inferior lesalcanzaba al pecho. Otros usaban un hueso ó algun boton de vidrio, goma ó metal amarillo (introducido éste por los europeos). Este adorno era exclusivo de los hombres; las mujeres jamás lo usaban. A la verdad, con su fiereza y noble talle, todos emtijjados con distintos colores el cabello tiznado de un tinte purpúreo como el de la sangre, las orejas traspasadas con las plumas de algun enorme cuervo, y relucientes sartas de abalorios que Jes colgaban de cuello, brazos, rodillas, pantorrillas, eso que se paseaban con su largo pito á todo largar humo, era cosa que causaba terror y espanto.

A propósito de otros indios Caribes, es decir antropófagos, que en lugar de tembetà ó barbote acostumbran abrirse una segunda boca abajo de la natural, dice el Padre, que los Mocovíes y Tobas sólo apurados del hambre comen alguna vez carne humana. Cuenta que el cacique Abipon Alaikin y seis compañeros que perecieron en una pelea con aquellos ndios fueron asados y comidos por ellos. Tambien degollaron y se comieron un muchacho de 12 años que le servía á la mano al Padre: pero á una vieja la dejaron; porque como le

(1) T omo II, capítulo V. 
conto al mismo un Nororí que participó del festin: Cacher gaie Lpahe chigal e!g!a. tan la yhó!.

Pasemos ahora a la perforacion de lats orejas que les abren a todus los chicos desde la mis tierna edady sin distincion de sevo. Los hombres, por lo general, no cargan aros, sólo alguno: viejos se colocan cualquier objeto de cuerno, palo, hilo de colores ú otra cualquiera cosit. De las mujeres, empero, pocas ó ninguna hay que carezcan de este adorno. Con unos róllus de hoja de paluna se agrandan la abertura á tal grrado que cabe por ellas una hostia de las mayores que se usan para la misa. Lo que entre los Abipones se reserva para las mujeres vió que era causa de orgullo entre los varones también de los Tobas y Oaekakalot (Lenguas).

Curiosa cosa sería si esta diferencia á que llama la atencion el Padre nos diese algua dato étnico por el cual se pudiese retrotraer la historia de los indios del Chaco á una época en que ellos y los Peruanos, tambien Urejones, derivaron la costumbre de algun orígen comun.

\section{CAPITLLO XII}

DE LA ENTEREZA Y AGILIDAD DE LOS ABIPONES ( ${ }^{1}$ )

Los que tienen en menos á los indios Americanos y los acusan de ser una raza inferior se equivocan si tratan de estas naciones en general. El Abipon es bien desarrollado, fuerte, ágil, soporta la intemperie de un modo admirable. La obesidad no se conoce entre ellos. El mucho ejercicio á pié y á caballo no les permite engrosar, porque nunca están quietos:

(1) Tomo II, capítulo VI. 
las correrías, la caza, los juegos y sérias lides los tienen en movimiento continuo.

Las enfermedades crónicas de Europa les son desconocidas. Dias enteros andan ellos en el rayo del sol, sin resguardo alguno y jamás se ha oido que de ello les resulte mal alguno. Muertos de sed recorren los campos ardientes, y cuando llegan á los esteros ó lagunas beben el agua abombada, salobre, amarga, turbia sin reparo ni mal resultado. No parecen hechos de carne y hueso. Comen carne de todo animal, y frutas las que hallan: todo lo digieren, todo les aprovecha. A fuerza de baños en el rio y de exponerse á las intemperies sanan de cualquier molestia. No usan calzado. Se acuestan en medio del agua, pero ni por esas sufren de cólico ni de reumatismo.

Espind que no la pueden sacar la extraen con carne y todo. Cabalgan cuando quieren parados sobre la montura. Se trepan á los árboles más elevados, y se roban la miel sin el menor reparo.

Cuando los ponían en el trabajo de labrar la tierra y se sentían cansados exclamaban: Ya se me cansó la sangre. En seguida se abrían una vena con el cuchillo y dejaban correr la sangre, que despues restañaban aplicando un bolo de barro à la herida, con lo que decían se sentían bien.

De las pestes parec a que la viruela haga menos risa entre los Abipones que entre los demas indios.

De heridas sólo que les peguen en la cabeza ó en el corazon mueren. Muchos de ellos han vivido largos años con balas en el cuerpo.

Llegan á una avanzada edad y con todo el vigor de jóvenes. No sucede otro tanto con lus Guaraníes, Lules, Isistines, Vilelas y otros indios pedestres, que más ó menos son como los europeos. 


\section{C.APITU1.0 XIII}

Los Abipones se deben á sí y á sus padres esa vigorosa existencia que les es tan especial. Durante la adolescencia se abstieneı! en absoluto de todo acto lujurioso, y aun cuando sean fogosos por naturaleza, el amor en tierna edad es para ellos desconocido. Oid esto, padres de esas niños que desde la más tierna edad frecuentan casas de tolerancia: hijos de padres escrofulosos, padres de hijos escrofulosos, orígen de tantos males que forman los cinco actos de la tragedia humana.

Oid esto tambien, que no ha mucho se dijo por un filósofo: "Empero sabemos que razas, que en chicos son ya padres, llegan à la senilidad, cuando otras en que es menos precoz la virilidad ostentan la plenitud de su vigor. ) El Padre jesuita del siglo xvir, está de acuerdo con el naturalista del siglo xix. Los Abipones saltan, brincan, se divierten, pero siempre salvan la honestidad. Por instinto rehuyen todo lo deshonesto, varones y mujeres. El Padre habla con la experiencia de siete años entre aquellos indígenas; y á fé que la palabra de un confesor es un testimonio irrefutable.

Las madres crían á sus propios hijos, no los despechan anles del tercer año, y "segun cuentan » se abstienen de juntarse con el marido durante ese intervalo. El Padre no lo asegura. En seguida, despues de algo de erudicion (que nunca falta) continúa: Los abiponcillos no saben lo que son cunas, plumazos, polvos de arroz, fajas, besos, juguetes; cuando viajan por ahí los meten las madres entre las denas 
cosis del aduar. Aprenden á nadar, á equitar, á tirar con flecha, á luchar casi desde que pueden andar.

La ropa que usan es poca y suelta. Un manto de pieles les sirve de abrigo en tiempo de invierno, ó cuando hace frio.

El juego favorito de ellos es el de arrojar la macana, en que se ejercitan todos, y el que logra hacerla llegar más lejos se lleva el premio y el aplauso de todos.

Las mujeres no tienen participacion en los juegos de los varones ni los presencian. Su ocupacion es la de atender á las necesidades del toldo.

Carne, pescado, aves, raices, todo comen. No desprecian ni la del tigre. La sal les gusta mucho, pero es escasa, porque esa tierra no la produce. Suplen la falta con lo que los espanoles llaman vidriera, que es la ceniza de una planta salitrosa. Las"más de las veces los Abipoues comen sin sal.

Son voraces para comer carne los Abipones, cuando la tienen, y, cuando no, sufren el hambre alegres y sin detrimento. Para ellos el que no come debe estar enfermo ; porque no cabe en su cacumen que un hombre se abstenga en habiendo carne que comer.

Los Abipones se bañan mucho, y sin médicos que merezcan el nombre de tales llegan á una edad avanzada.

\section{CAPITULO XIV}

DE LA RELIGION DE LOS ABIPONES (1)

Los Abipones, con ser que su lengua es abundante en otros términos, carece por completo de un que diga Dios. Por

(1) Tomo II, capítulo VIII. 
eso los minioneros adoptaron el término Dios, ecrnam vao garic: Dios, el Hacedor, como que ncaré es el verbo que dice: hacer. Confiesa Dobrizhoffir haber asegurado que era de aplaudir a los Abipones por su ingenio y la viveza de su imaginacion; pero se desdice en atencion à que ni nombre tienen para Dios, mientras que al Diablo, que ellos conocen bajo el nombre de Aharaigichi ó Queevet, con todo ariño le dan el trato de su abuclito, Groilperikie, y esta representado en el cielo por las Cabrillas. Cuando ellas desaparecen, dicen que su abuelo esti malo y entran á recelar que se les quiera morir y celebran su reaparicion en Mayo con el ruido de sus instrumentos y gran clamoreo, felicitindolo por su convalecencia. Llenan el aire con sus gritos de alegría, buscan la miel, preparan la chicha y al ponerse el sol empieza la liesta. Los casados chupan sentados sobre pieles de tigre, sus mujeres cantan paradas á la vuelta, y los demas solteros se pasan la noche en grande algazara y aplaudiendo en medio de una gran iluminacion de antorchas. Ún porongo con semillas sirve de castañuelas. El baile se limita á un saltillo en el mismo local, primero se planta un pić, despues el otro adelante. Este ridículo danzar de una mujer que delira se festeja de cuando en cuando con golpes de música ó sea el ronquido de cornetas y trompas, y los circunstantes la aplauden con gran vociferacion llevándose las manos á la boca para ello. Pero esto hay que observar, que todo se hace con la mayor honestidad, y nada hay que ofenda al pudor ni huela á lujuria. Los hombres y las mujeres están separados y lo mismo las mozas y los mozos.

Dice el Padre que le costó extirpar esta supersticion entre los Abipones catecúmenos. 


\section{GAPITULO XV}

\section{DE LOS BRUJOS Y HECHICEROS}

Los Abipones respetan y veneran á sus hechiceros á quien llaman Kebet, porque creen que han conseguido el poder sobrenatural de su abuelo el Demonio. Éstos pueden cambiarse de forma y no hay cosa que no sepan ni puedan hacer segun lo creen estos bárbaros. En manos de los hechiceros dicen que está el producir enfermedades y causar la muerte. Éstos pueden curar enfermos, predecir lo que está remoto en el porvenir. Ellos pueden hacer disparar las nubes, la piedra, la tempestad, aparecer las almas de los difuntos y avisar de lo que está oculto. Ellos plueden volverse tigres y manosear serpientes impunemente.

Los Abipones creen en la inmortalidad del alma, como se ve en la ceremonia esa para hacer aparecer !os muertos, y en la costumbre de enterrar con éstos la olla, vestidos, armas y caballos empalados, porque los tengan si les hace falta en la otra vida. Unos patos pequeños que ellos llaman Ruilili creen ellos que son las almas de los que mueren.

A los hechiceros los respetan en vida y los adoran despues de muertos, conservando sus reliquias con la mayor veneracion. Cuando los Abipones ven un meteoro, ú oyen tronar como descargas de artillería, lo atribuyen á la muerte de algun hechicero. A ellos los consultan cuando piensan emprender una guerra ó expedicion cualquiera. Para ellos es una parte del botin, y para ellos cuanto se les antoja, que todo lo que piden les dan.

Si el brujo tiene algun agravio con cualquiera, lo llamáa éste á su casa y lo martiriza á su antojo: nadie se atreveá contradecir ni á desobedecer al hechicero. Aunque los haga 
carbonada con la quijada de una paloneta ni jay! no chistan.

Los españoles y los hechiceros son la sola causa de la muerte; si no fuese por esto serian immortales. Así lo creen los Abipones.

\section{CAPITLLO XVI}

DEL ABLELO DE LOS ABIPONES. - LAS CABRLLAS (1)

Así como los Abipones, tambien Jos Mocovíes, Tobas, Yapitalagas, Guaycurúes y otras tribus ecuestres del Chaco se jactan de ser nietos del Diablo. Su símbolo son las Cabrillas ó Pleiades. El por qué, lo ignora el Padre, ni halló Abipon alguno que se to pudiese explicar.

\section{CAPITLLO XVII}

DE LAS TRIBLS DE LOS ABIPONES Y DE LAS CAUSAS DE SU CORTO NúMERO (?)

Los $A$ bipones, dice Dobrizhoffer, se dividen en tres clases: los Rükané (hé?), que viven en los campos abiertos; los Nakaigetergehé, que prefieren los escondites de las selvas; y por último los Yaaukanigâs, una sola tribu con lengua suya propia, que habiendo sido destruida en un malon contra los españoles, sus hijos y mujeres fueron absorbidos en las vecinas tribus Abiponas, $y$ mas tarde perdieron su len-

(3) Tomo II, capítulo X.

(') Tomo II, capítulo XI. 
gua particular. I.os usos, costumbres, inteligencia y la lengua de todas las tribus son los mismos, si se exceptúa en la lengua alguna diferencia en contadas voces. Cuando están por dar en contra del español es admirable la paz y armonía que reina entre todos ellos; pero no tratándose de esto viven en un continuo pelear entre sí, y ni los vínculos del parentesco más estrecho son causa para que dejen de matarse unos á otros sin misericordia.

Algunos de los Abipones acostumbran la poligamia, pero más bien mediante la repudiacion de la mujer anterior; mas esto no es muy frecuente. Toda la nacion estímase en 5000 alm:s; á este número se ven reducidos, gracias á sus guerras intestinas y con los de afuera, al contagio de la viruela y otras pestes, y al infanticidio. Esta crueldad de las madres se explica de este modo. La lactancia de tres años, durante los cuales no deben juntarse con los maridos, da lugar á que éstos se busquen mujer por otro lado; de suerte que las mujeres, de miedo de perder los maridos, dan muerte á los recien nacidos, eso curndo no se anticipan al parto natural produciendo el aborto. Rehuyen el ser viudas de marido que no ha muerto, y por ello nada les parece el ser peores que tigres.

Las madres se inclinan más bien á perdonar la vida á las hijas mujeres, porque éstas les pueden traer el valor del dote. Otra cosa nos cuenta Gumilla de las pobres chinas caribes. Por esta causa, y la de quie no entran en las matanzas de sus peleas intestinas, son muchas más las mujeres que los hombres; y cada real de estos indios, para un hombre, tiene una turba multa de mujeres, muchas de ellas viejas eternas.

No hay que culpar á los españoles de la decadencia de estas tribus: ello se debe á las causales enunciadas.

Los indios conversos dejaron estas horribles costumbres y en seguida viose aumentar el número de ellos. 


\section{C.APITLLO XVIII}

DE LOS JUECLS, CACIUUES Y ORGANIZACION SOCLAL DE LOS

$$
\text { ABIPONES (1) }
$$

Los Abipones uo desconocen que tengan un jefe supremo de su nacion o tribu. á quien ellos dan el título de Nelar'e!frat: cabeza. El hijo mayor le sucede siendo idóneo; pero no siéndolo la tribu no está obligada ni á elegir sucesor de la misma familia del extinto. Poco ganan con ser Caciques y upenas si los obedecen. En sus borracheras hasta los suelen matar.

Abandonan cuando quieren su cacique y su tribu, y del mismo modo vuelven.

Para convidarse à la guerra celebran un gran festin, y lo que en borrachos prometen eso mismo cumplen cuando se les pasa.

Al cacique piden cuanto se les artoja, y si éste les niega cualcuier friolera se abispan y reniegan de su autoridad.

\section{CAPITL LO XIX}

LOS ALIMENTOS, MigRaGloNes y otros asuntos DE LA VIDA DIARIA DE LOS ABIPONES (

Los fieros Abipones viven como las fieras, ni siembran ni cosechan. Saben por instinto dónde y en qué tiempo han de

(1) Tomo II, capítulo XII.

1z) Tomo II, capitulo XIII. 
buscar su alimento de frutas y de aves del campo. Todo lo poseen en comun. Ellos no conocían ni el azadon, arado, ni segur: la flecha, el venablo, la macana, el caballo, esto era con lo que se proporcionaban el alimento, el vestido, el hogar. Por esta misua razon no podían permanecer largo tiempo en un misme lugar. Los avestruces, los huevos de éstos, que los hay abundantísimos, corzuelas, tigres, leones, conejos y perdices, ciervos, javalíes, venados, osos hormigueros, monos, papagayos, pescado de todas clases, lobos, perros, carpinchos, nutrias, gansos, cisnes, cuervos del agua, todo les sirve para satisfacer su hambre; pero las tortugas parece que les repugnan.

Las palmas les proporcionan comida, bebida, remedio, casa, vestido, armas: no hay cosa para qué no sirva. Si todo esto falta, allí están las raíces que sacan del agua y de la tierra. La algarroba les sirve de comida y bebida á la vez, y la conservan casi todo el año.

Cuando se mueven todos van á caballo, y las mujeres como hombres, y éstas cargan con todo el ajuar de sus tolderías, hijos y cacharros incluidos. Los varones cargan guardamontes con que animan á los caballos golpeándolos con las azoteras.

A veces dos y aun tres mujeres montan en el mismo animal, por el interés de la chacota.

Perros tienen muchos y á ellos les arrojan los menudos de las aves que cazan.

El Padre pasa á dar muchos detalles sobre los caballos y perros y modo de servirse de ellos, que están muy en su lugar en esa interesante monografía, peroque no corresponden á este estudio; porque ambos son animales derivados de los españoles y que desde luego introducen elementos de la vida de ellos que no corresponden á su historia como habitantes pre-colombianos del Chaco.

Cuando no lo logran de otra manera incendian el campo para procurarse la casa. Fuego sacan en cualquier parte con 
dos palitos, uno de madera más blanda que el otro. El blando, que es el de abajo, tiene su cierti taladradura, y el duro afilado en punta se hace girar ripidamente como al molinillo para chocolate. El aparato éste llámase Neénatá. El palo blando suele ser de $A$ mbay, de Caraguatá, de cedro ú otro árbol y el duro de Tatayî.

Por donde van estin en su casa, como el caracol en la suya, porque con parar las esteras ya tienen su aduar.

Nadan como peces, pero hacen uso tambien de la Pelota, que ellos llaman Nataé, y que sin duda recibieron de afuera como los caballos.

\section{CAPÍTULO XX}

DE LA FORMa Y Material de SUS VESTIDOS, Y DE Cómo SE PROPORCiONaN LO QUE necesitan (1)

A su modo, las mujeres Abiponas son modestas en su traje. Lu manto cuadrado se echan por las espaldas, se lo ciñen con un cinturon, y tienen especial cuidado de sugetarlo al montar á caballo para no quedar desnudas. Al cuello se atan una especie de pañuelo, y á la cabeza una bincha.

Las mujeres trasquilan las ovejas, hilan y tiñen la lana, y la tejen admirablemente. Conocen el uso del alumbre. Sus telares son unos cuantos palos y cañas.

Saben hacer ollas y cántaros, que ámoldan con las manos, y los queman á campo raso con montones de leña. No saben vidriar las ollas, pero las pintan de colorado y les dan lustre con una especie de cola.

(1) Tomo II, capítulo XIV. 
Cuando las apura el frio se tapan con mantos de pieles de nutria. No las curten pero las soban y cosen con sumo arte y maestría.

\section{CAPÍTLLO XXI}

DE LAS COSTUMBRES Y MOdo DE SER DE LOS ABIPONES $\left(^{1}\right)$

No todo entre los Bárbaros bárbaro es, dice el buen Padre.

Los Abipones dejan ver en su rostro y en su apostura cierta alegre modestia y seriedad viril, al que está con ellos. En todo son moderados. Cuando se reunen de ordinario, todo procede en paz y tranquilidad. Toda expresion descompuesta y mordaz la evitan. Les agradan las galas en el decir, pero no se advertirá una palabra deshonesta. Amenizan sus viajes con relaciones festivas, pero no se oye una expresion que raye en lo material. Si se suscita alguna cuestion ella se resuelve con sangre fria. Todo esto empero se dice dęl Abipon sano y sin licor; porque cuando ebrios sueltan la rienda á sus iras y arde Troya.

Cuando todo va bien oyen al que habla con atencion y cultura, sólo se permiten alguna exclamación de asentimiento ó aplauso.

Là, es la voz de salutacion entre ellos, como entre los Tobas y Mocovíes.

Es costumbre de ellos saludar á todo transeunte y preguntarle á dónde va, y es tan inveterada la costumbre que no la omiten ni cuando están en el campo haciendo aguas, y eso que son tan circunspectos en lo demás.

Ya se dijo que más bien se inclinaban al cambio que á la

(1) Tomo II, capítulo XV. 
multiplicacion de mujeres; muchos se atienen it una sola. la incontinencia habitual con cualquiera ni nombre tiene entre estas grentes. Mozos y mozas son alegres, pero jamis se entreveran los sexos.

Barbaros se han mostrado los Abipones, inhumanos, feroces, lo confiesa el Padre, pero contra aquellos que tenían por sus enemiggos.

El hurto no se conoce entre ellos. Lina vez resultó que hubo un robo, y' se descubrió que había sido la autora una cautiva: en seguida le dieron muerte, y ni los ruegos y amenazas del Misionero bastaron para salvarla del suplicio.

Admirable es cómo soportan las fatigas de larguísimas jornadas, aigunas de ellas de más de 300 leguas. Para ellos, rios caudalosos. vastos bañados, más peligriosos que los rios, nada solı. los salvan á nado. Cruzan à través de campos extensos sin agua y sin leña. Cabalgan dias enteros en aperos más duros que una tabla y sin estribos para los pies. La mano carga con el peso de una larguísima lanza. Los caballos, por logeneral, son trotones y tienen que dejarles los cuerpos molidos. En cabeza sufren el rayo de sol, la lluvia de dias enteros, la tierra y el huracan. Si calienta el tiempo se bajan el ropaje y lo dejan colgar de la cintura; acuden eatonces mil sabandijas y les quedan los cuerpos chorreando sangre. Comen las aves que cazan.

El agua la levantan donde la encuentran y se la disputan á los tigres, serpientes, mosquitos y otras alimañas. El suelo duro, caliente ó mojado es su lecho, y cuando llueve pasan la noche en vela en medio del agua. Pasan dias y noches sin dormir y sin comer, para bombear y salvarse de una sorpresa. Esto hacen, esto sufren los Abipones, dice Dobrizhoffer, sin prorrumpir en esas quejas y exclamaciones en que abundan los europeos, cuando algo los contraría.

Ello se explica: lo que para nosotros es sufrir con paciencia, para ellos es la misma naturaleza. A esto conduce ese crucificarse y martirizarse desde chicos. El prurito de 
la gloria que les toca en suerte al adquirir fama de valientes, les hace invencibles, los obliga á callar.

La mujer Abipona se lo pasa todo el día en sus quehaceres. La ropa para el marido, para los hijos es su cuidado. Ella cocina, ella se procura la algarroba, ella la muele, ella la convierte en chicha ó aloja, ella se busca la leña y acarrea el agua.

Como catecúmenos, los más dóciles son Jos viejos y las mozas. A las viejas les cuesta dejar sus costumbres, Vlos mozos dejavi de hacer sus proezas, entre las cuales deben enumerarse el cortar las cabezas á los españoles, y pillarles las haciendas.

La mujer Abipona no sólo es casta sino tambien sobria. Ella, es cierto, le prepara la chicha para el marido, pero no la prueba; agua y agua sola es la que bebe. Esto no quita que entre sí libren batallas por cualquier friolera, por un velloncico de lana, ó el alma de algun pariente. Si esto hacen sin vino ¿qué no harían con él?

Los varones, por el contrario, á no ser en sus borracheras, observan una paz inalterable en sus tratos y son enemigos de toda gritería, discordia y descompostura. iOjalá los cristianos imitasen su anabilidad, su honestidad, su tolerancia, su perseverancia! ¡Ojalá tantas virtudes de los Abipones no se viesen overeadas con manchas negras como sucede con la piei del tigre!

Así acaba el buen Padre para pasar á darnos una idea de la lengua de estos Indios. Da tristeza pensar que Indios con tanta nobleza de carácter y tantas prendas admirables se vean destinados á la extincion, porque se resisten á recibir esa civilizacion europea que les es postiza y porque con sus matanzas intestinas é infanticidios ayudan á las pestes á hacer desaparecer tan interesante nacion; pero da tambien grima el saber que mucha parte de su exterminio se debe á la codicia del europeo por las tierras de estos pobres indígenas. 


\section{CAPITULO XXII}

DF LOS CASAMLNTOS DE LOS ABIPONES ( $\left.{ }^{1}\right)$

Entre Ins $\Lambda$ bipones los varones rara vez se casan antes de los 2j, las mujeres antes de los 20 años. Son castos en todo, y entre ellos el adulterio, la fornicacion promiscua, el incesto, etc., son del todo desconocidos.

Cuando algumo pretende alguna muchacha para mujer tiene que tratar por ella con los padres. Unos cuatro ó más caballos, unas sartas de cuentas ó conchas, vestidos de lana teñida, una lanza con punta de hierro, etc., es el precio que se paga por la novia.

Muchas veces sucedió que hecho el pacto entre el novio y los padres la pretendicla se negaba á dar el si, y huía al monte ó se asilaba lıasta en las gradas del altar.

Si todo marcha de acuerdo, la novia es conducida por ocho doncellas que cargan una manta á modo de palio, abajo de la cual camina ella con los ojos fijos en el suelo. El novio la recibe en su casa, pero sin mucha demora vuelve ella á casa de sus padres y allí permanece visitada por su marido hasta que empieza á tener familia, pues que recien entonces la madre se resuelve separarse de la hija. El dia de la boda se conduce tambien á casa del marido todo aquello que forma parte del ajuar de la esposa, como ser, porongos, ollas, cántaros, telares, etc.

Los varones celebran la boda con sus copas.

Es costumbre que los Abipones se atengan á una sola mujer, pero á veces los caciques se casan con dos y más; por lo general, la segunda mujer está en otra parte $\left({ }^{2}\right)$.

(') Tomo II, capítnlo XIX.

(s) Tomo II, capítulo $\mathbf{X X}$. 
Cuando se cansan de una mujer la despachan con lo que le pertenece, y uno y otro vuelve á casarse sin más trámite. Allá en sus borracheras no deja de ser motivo de querella entre los que se consideran agraviados.

La costumbre de criar los hijos dándoles el pecho durante tres años, y de no juntarse con los maridos en todo ese tiempo, es causa de muchos de estos áivorcios, y en muchos casos puede atribuirse á ésto tambien la funesta costumbre del infanticidio, tan general entre ellos.

Los Misioneros introdujeron otro modo de vivir, pero de lo que se trata es de los usos y costumbres de estos bárbaros antes que ellos entrasen por el cristianismo.

Los Abipones no se casan con parientes. Un cacique casó con dos hermanas, cosa que no era de costumbre; nadie se lo echó en cara, pero tampoco nadie se lo imitó.

La mujer le es fiel al marido. Los padres educan á los hijos, las madres á sus hijas.

La imujer, cuando pare, se va con la criatura al rio, y allí se lava ella y hace oiro tanto con la cría, hecho lo cual vuelve á sus tareas diurnas; de lo único que se abstiene es de ciertas carnes y frutas. El marido, empero, se mete en cama, se abriga bien y se abstiene de varias clases de comidas, porque teme que de no hacerlo así puede perjudicarse la criatura. Un cacique rehusó una narigada de rapé porque dijo que su mujer había parido el día anterior $\left({ }^{1}\right)$.

Si al cacique le nace un varon, entonces se celebra la fiesta de la Araña, Haualí. Las mujeres bailan al rededor de la casa con hojas de pálma, y la más fuerte de todas vacon un vestido de plumas de avestruz y esta es la que debe hacer lo de la araña. En seguida se tejen unas macanas de tiento, y con ellas azotan á los hombres que encuentran en las casas. Al otro dia luchan mozos con mozos, mozas con mozas, cada sexo en su lugar apartado. Así tambien son los bailes del ter-

j) Tomo II, capítulo XXI. 
cero dia y la que hace de directora es ma vieja con sonaja en la mano. El cuarto dia la que hace de araña, da vuelta a los toldos y desafía a la que cree que puede igualarla en fuerzas, $y$, vencedora o vencida, lo mismo es para que todos lo celebren $\left({ }^{1}\right)$.

La fiesta dura ocho dias, y estos se emplean ó en repetir to descrito is en borracheras de las mayores.

\section{CAPITLLO XXIII}

DE LAS ENFERMEUADES Y SUS CURACIONES

Los Abipones son sanos y casi ni un dolor de muelas sufren. Enfermedades crónicas no las conocen. Para ellos el que está enfermo "no come» y el que sana "ya come» $\left({ }^{2}\right)$.

En concepto de ellos, si no fuese por las armas de los. Españoles ó el maleficio de sus hechiceros, ninguno de ellos moriría.

Creen que si le arrancan la lengua $y$ corazon al muerto, si las asan al fuego y se las dan á comer á los perros, que el brujo criminal pagará con su propia vida la de su víctima; y aunque nunca hau visto que se muera nadie se contentan con cumplir con la costumbre de sus mayores.

Cuando se acusa a un individuo de ser causa de la muerte de algun finado, dificilmente escapará con vida, y las viejas hechiceras logran la ocasion de desquitarse de cualquier agravio.

Los Abipones suelen enfermar de un mal de rabia o locu-

1) Tomo II, capítulo XXIl.

(2) Tomo II, capítulo XXIII. 
ra (parecido al amuk de la Oceanía). Furiosos recorren las calles y todos huyen ó se esconden. Los enfermos de algunos dias sanan $\left({ }^{1}\right)$.

La viruela, sarampión y otras pestes han hecho risa en los pobres indios $\left({ }^{2}\right)$.

Los médicos que tienen llámanse Keebét, el mismo nombre que dan al demonio; porque dicen que esos curanderos ó hechiceros lo representan; y á él se le debe que anden sanos ó enfermos, y los hechiceros son sus vicarios sobre la tierra, y tienen potestad hasta sobre la lluvia, las tempestades, y las almas de los muertos, para que reaparezcan y dejen saber lo que está por suceder $\left.{ }^{3}\right)$.

El principal modo de curar que acostumbran estos curanderos es el de chupar el maleficio.

\section{GAPITULO XXIV}

\section{DE LA MUERTE Y ENTIERRO DE COS ABIPONES}

Cuando se enferman de muerte, las mujeres rodean al doliente y meteo un ruidoinfernal con bombos, sonajas, etc., tapándolo al enfermo con un cuero, para que no se vea su agonía. Muerto el individuo se le arranca lengua y corazon, se hacen hervir en agua y se dan á comer á los perros, para que muera quien fué causa de la defuncion, como se dijo ya. El cadáver se envuelve vestido en un cuero y se

(1) Tomo II, capítulo XXIV.

(2) Tomo II, capítulo XXV.

(3) Tomo II, capítulo XXVI. 
precinta bien con tientos. I la cabeza la ensuelven con enidado.

Temen al moribundo y huyen de él. Lgunas veces se apuran tanto por librarse del cadaiver que entierran aún vivo al moribundo $\left({ }^{1}\right)$.

Creen que el alma ó sombra sobrevive, a que ellos llaman Loakal ó Lkigihi. Con el muerto entierran la olla, traje, armas, caballos, ete.

Lus Abipones conducen sus muertos por largas distancias despues de una pelea. Despojan de carne a los huesos; á esa la entierran y citus los conducen por 200 y mis leguas en un cueru.

Tienen sepulero de familia y en él quieren ser enterrados.

Muchas de las cosas del finado se queman ó quiebran. L.os caballos y ganado menor se sacrilican sohre su túmulo. El toldo se derriba. La viuda, sucesión y resto de familia se mudan a otra parte. Nombrar al finado es una ofensa que sólo se expía con bofetadas, heridas y mucha sangre; y entre borrachos es causa de serias y muy sanguinarias contiendas. De él se hablará así: Yoalé eknam chitcaeca: el hombre que no existe. Esta ha sido causa de que muchos nombres le cosas se cambien.

Los allegadis ! anigos del muerto tambien se mudan el nombre.

Los síbditus de un cacique se cortan la cabellera. Las mujeres hacen otro tanto y se cubren la cabeza con una red de caraguatá, y la conserran así mientras no contraen segundas nupcias.

Las ceremonias con lloronas y todo duran nueve dias, y en el nono se hacen pedazos las ollas del finado.

El cabo de año se celebra con el mismo ruido, baile, borrachera y demás ceremonias.

1. Tomo II, capítulo XXVII. 


\section{CAPITULO XXV}

Hemos concluido con el simpático cuadro que nos pinta Dobrizhoffer de los fieros y nobles Abipones. Pasemos ahora á conocerles segun los describe el faınoso Azara en su Historia del Paraguay. Como la relacion es corta, conviene que se reproduzca en su integridad. Se extracta de la edicion de Madrid, 1847, tomo I:

"Los españoles les dan este nombre, los Lenguas el de Ecusgina y los Enimagas el de Quiabanabaité. Corrían el Chaco al Occidente del rio Paraná hácia los 28 grados de latitud, sin tener las canoas ni el número de guerreros que les da Schimidels, capítulo 18 , y Lozano, libro 2, capítulo 5 . Hácia la mitad del siglo diez y ocho, se empeñaron en una guerrá sangrienta contra los alocobis ( $\left.{ }^{1}\right)$, á quienes no cerien en orgullo, fuerzas ni estatura; mas como eran inferiores en número, se vieron precisados á solicitar la proteccion y una guardia que les acordaron los españoles, formándoles el pueblode San Gerónimo, que encargaron á los padres Jesuitas (1748). En él estuvo 20 años el jesuita aleman, que vuelto á su patria escribió en latin, en un tomo en cuarto, la historia ó descripcion De Abiponibus; pero no pudo entender su idioma lo bastante para traducir en él el catecismo; porque es muy gutural, difícil y. diferente de todos. Continuando el fundado temor de los abipones de dicho pueblo, como la mitad de él pasó el rio Paraná en 1770, y fundó el pueblo de las Garzas. En ambos pueblos visten mucho las camisas y ponchos que les dan los españoles, sin que haya un cristiano ni civil, y conservan casi todos sus antiguas costumbres, iguales á las

11) Mocovíes (?) 
de los Mocories. I sa nel barbote del número 13, y las mujeres adultas llevan indeleble uni cruz en la frente y cuatro lineas horizontales entre las cejas, con otrats dos en cada angrulo exterior del ojo."

Lo que dice este autor acerca del número de los Abipones debe ser tan digno de crédito como aquello otro acerca de Dobrizhoffer. Sun noticias de esas yte se din para llenar un parrafo. Podemos estar muy segurus que si el Padre Misionero no hubiese podido reducir sus enseñanzas a las fórmulas de un catecismo no hubiese permanecido un solu dia en esa misión. La presente monografía reproduce el catecismo, oraciones, etc. del P. Brigniel, que el Dr. Lamas atribuía al mismo Dobrizhoffer, $\mathbf{y}$ allí están las pruebas que tan fảcil es catequizar en Abipon como en toda otra lengua que Dios ha permitido que se evolucione en la tierra. Azara no pudo haber visto la obra en que el buen Padre hace el panegírico de los nobles Abipones, ni menos quien le dió las noticias inexactas que reproduce en su coita y poco satisfactoria noticia de estos indios.

La fundacion del pueblo de las Garzas, en la margen izquierda del Paraná, nos explica la razon por qué d'Orbiguy encontró Abipones en la provincia de Corrientes.

El "tal.uaje» es el mismo que tan grríficamente ha descrito el Padre.

\section{CAPITULO XXVi}

LO QUE DICE D'ORBIGNY DE LOS ABIPONES

(L'homme americain)

D'Orbigny clasifica á los Abipones como de su raza Pampeana, y esta es la descripción de sus rasgos fisiológicos:

"Tez moreno-verdosa de un cobrizo subido. Estatura 
mediana: 1 metro 688 milímetros. Talla hercúlea. Frente arqueada. Cara ancha y aplastada. Nariz muy corta y muy ñata ó roma $\left({ }^{1}\right)$, con ventanas anchas y mu abiertas. Boca muy grande. Labios gruesos y sobresalientes. Ojos horizontales, á veces levantados en ángulo exterior. Pómulos muy pronunciados. Facciones varoniles y muy marcadas. Fisonomía fría, á veces feroz.» (T. II, pág. 5).

Despues de algunos párafos de observaciones generales pasa á enumerarar las naciones que él incluye en este grupo:

"Los Patagones ó Tehuelches, de las regiones más australes, Jos Puelches de las Pampas, los Charruas de la Banda Oriental y de la provicia de Entre-Rios, los Mocovíes ó Tobas, los Abipones, los Lenguas y los Mataguayos del Gran Chaco. Creemos poder agregar, sin haberlos visto, á los Payaguáes, á Mbayas y Guaycurúes. descritos por Azara, etc., ctc. ») (Ibid. pág. 8 y 9 ).

Antes de haber leído lo que escribía este autûr, fundándome en las lenguas de estas naciones, había caído yo en la misma clasificacion; creo con d'Orbigny que al Abipon debemos incluirlo en el mismo grupo general con las demás nacicnes citadas, mutatis mutandis se entiende; porque un Guajcurú con un Quichua no se ha de mestizar como un Guaycurú con un Guaraní.

D’Orbigny asigna á estos indios la regiou inmediata a I Paraná entre los $28^{\circ}$ y $30^{\circ}$ de latitud sud, direccion al Gran Chaco. El visitó la reducción de las Garzas en la provincia de Corrientes. No hay para qué reproducir lo demás que dice este autor acerca. de estos indios, porque ello está de acuerdo con lo que cuenta Dobrizhoffer. Insiste d'Orbigny en el. interparentesco del Abipon con el Toba, que él hasta cierto punto confunde con el Mocoví. El estudio comparado de estos tres idiomas nos enseña lo mucho que se parecen y al mismo tiempo las diferencias que se notan. En conclusión, 
cree d'Orbigny que los Abrpones, Tobats y Charruas, son los eslabones que unen las naciones de las Pampas con los Chiquitos. Este autor se funda mas bien en comunidad de rasgros tisiológicos, sin dejar de tener en cuenta para algo la prueba lingüistica. Hoy gue conocemos algo mis de todas estas lenguas parece que se contirma el parecer del famoso viajero francés.

\section{C.APITLLO TITII}

LOS ABLPONES EN LA ACTUALI DAU

Esta es una de las naciones del Chaco que marcha rápidamente i su extincion: poco ó nada se oye de ellos. El año 1858 pasé yo con una escolta de Santa-Fé á Córdoba por la frontera del Quebracho Herrado, Tio, etc., y en el lugar del Sauce dimos con una reduccion de indios Abipones. De ellos sólo me acuerdo que los racionaban con yeguas y que eran indios grandes. Ln amigo, el señor Telésforo Ruiz, mi convecino en Andalgala, que militó en las fronteras de Sanciago del Estero con el general Antonino Taboada, me dice que en ese tiempo les hacían sus corridas á los Abipones, bajo el nombre general de Guaycurúes. Hoy más bien deben buscarse entre los indios Montaraces, que merodean entre Santa-Fé y Santiago del Estero. 


\title{
SEGUNDA PARTE
}

\author{
ARTE DEL ABIPÓN, SEGÚN LOS PADRES DOBRIZHOFFER \\ Y BRIGNIEL, S. J.
}

\section{FONOLOGIA}

Ante todo conviene que se lea lo que se ha escrito acerca de la Fonología Mocoví en mi trabajo sobre esta lengua, publicado por el Museo de La Plata: allí se ha tratado minuciosamente de cada letra, razon por la que en este estudio me he limitadoá llamar la atencion á las equivalencias entre éste y los otros dos codialectos Mocoví y Toba.

A lo que se re, el alfabeto es más ó menos el que sigue : $\mathrm{A}, \mathrm{C}$ ó $\mathrm{K}$, $\mathrm{Ch}, \mathrm{E}, \mathrm{G}$ ó $\mathrm{R}$ etc., $\mathrm{H}$ ó $\mathrm{J}, \mathrm{I}$ ó $\mathrm{Y}, \mathrm{K}$ ó $\mathrm{C}, \mathrm{C}, \mathrm{LL}$, $\mathbf{M}, \mathbf{N}, \tilde{\mathrm{N}}, \mathrm{O}, \mathrm{P}, \mathrm{Q}, \mathrm{C}$ ó $\mathrm{K}, \mathrm{R}$ ó $\mathrm{G}, \mathrm{T}, \mathrm{U}$ ó $\mathrm{V}, \mathrm{X}$ ó $\mathrm{S}$ gruesa, Y ó $\mathrm{I}$.

El objeto principal de esta parte dél estudio es facilitar la comparacion de los temas entre los tres codialectos citados: no se puede llamar completo, pero otros podrán con más facilidad continuarlo. Los ejemplos dados bastan para hacer ver lo complicado del asunto.

\section{$\mathbf{A}$}

A. l,etra que puede ser inicial, medial ó final.

Aa. Corresponde al Aa Mocoví, ex. gr.: Aaca, pariente. Aák. 
$\mathbf{A}=$ Aga. Toba, ex. gr: Naacachinat, medida. Lacotetenagat.

$\mathbf{A}=\mathrm{E}$. Toba, ex. gr.: Acaloctenanat, huso. Necalep-netagaté.

$\mathbf{A}=\mathrm{E}$. Mlocovi, ex. gr.: Achangué, rio. Actiengué.

$\mathrm{A}=\mathrm{E}$. Abipon, ex. gr.: Napaquenalaoel, palma de ia mano. Apequena, mano.

$\Lambda=\mathrm{E}, \mathrm{L}, \mathrm{U}$. Toba, ex. gr. : Napagaic, viudo. Pessoy'c, Pussoic.

$\Lambda=1$. Toba, ex. gr.: Rkìhagelk, relampaguea. Casilgahì.

$\mathrm{A}=0$. Mocoví, ex. gr.: n-Acarig, bautizado. Occoriguí. Ri-akayà, abomino. Li-oqquià. Apa, manta. Apó.

$\mathbf{A}=0$. Mocoví, ex. gr.: Ajape, culo. Ossap.

$\Lambda=\mathbf{L}$. Toba, ex. gr.: Agira, pozo. Ushidé. Caitaic, calvo. Cuitaic.

Aa $=$ A. Mocoví, ex. gr.: Aacatai, palabras. Accatari. Aa $=A$ ca. Toba, ex. gr.: Aatek, lechiguana. Acaték.

$A a=$ Aga. Mocoví, ex. gr.: Aaccà, freno. Agaccá.

$\Lambda \mathrm{a}=$ Aha. Toba, ex. grr.: Aalà, mistol. Ahalà.

$\Lambda a=A v a$. Mocoví, ex. gr.: Aal, nieto, nieta. Aval.

$\Lambda a=$ Gua. Toba, ex. gr.: Riaàl, soy perezoso. Digual.

Aa y $\mathrm{A}=0$. Toba, ex. gr.: Aacachinat, medida. Acotetenegath; Aachiga, sueño. Otiagà.

$\mathrm{Ae}=0$ Toba, Oe Mocoví, ex. gr.: Aenatan, trabajo. Sonatagan, trabajar. Nonnactarnah.

$\mathbf{A e}=$ Oe. Miscoví, ex. gr.: Yaet, hace. Yoet.

$\Lambda \ddot{e}=0 y$. Toba, ex. gr.: Kaëpah, madera. C'oypàk.

$\mathbf{A} \mathbf{i}=\mathbf{E y}$. Toba, ex.gr.: Ar'air'aik, mauso. Oreyraik.

$\mathbf{A o}=\mathbf{A}$ vo. Mocoví, ex. gr.: Naoglinaol, carretilla. Navoglinalé.

Ao $=$ Le, Au, Tobà, y Oê, Mocoví, ex. gr.: Aoe, yo hago. Sueto, Auot, Soet.

Aoe $=$ Ave. Mlocoví, ex. gr.: Aoenà, olla. Avennà.

Aoe $=$ Oa. Mocurí, ex. gr.: Aoel, corazón. Oal-là. 


\section{C ó $\mathbf{K}$}

Letra que puede ser inicial, medial ó final. Debe observarse que en Abipon parece que este sonido era más firme que en Mocoví, es decir menos expnesto á desaparecer. Este punto sin embargo no está muy bien coinprobado.

K ó $\mathrm{C}=\mathrm{G}$. Abipon. Ver G'Dios, a Dios.

$\mathrm{C}=\mathrm{H}$. Toba, ex. gr.: Acàm, vientre. Tahám.

\section{Ch}

Como inicial es difícil hallar este sonido en Mocoví ó Toba. En el primero debería convertirse en $C t i$ ó $T i$, en $T i$ para el segundo; pero en los más de los temas Abipones que empiezan así parece que el Chi es prefijo negativo y corresponde al Sca ó Sa de los otros idiomas. En Abipon puede ser inicial ó medial, y tal vez final. Ver Ich.

$\mathrm{Ch}=\mathrm{Ch}$ ó Ti, Toba, ó Ct, Mocoví, ex. gr.: Nachilac, banarse. Nachil ó Natil, bañarse. Mocoví, Nactil-l, me baño.

$\mathrm{Ch}=$ Ct. Mocoví, ex. gr.: Acalach, cebolla. Accalactí. Achangué, rio. Actiengué.

$\mathrm{Ch}=\mathrm{Ss}$. Toba, ex. gr.: Lichiga, resina. Lissi.

$\mathrm{Ch}=\mathrm{Ti}$ o Ch. Toba, ex.gr.: Lachigat, lengua. Latiagat ó Uachagat.

D

Sonido que falta en Abipon. Búsquese bajo la $\mathbf{K}$. 


\section{$\mathbf{E}$}

Inicial, medial y final.

$\mathrm{E}=$ A. Mocovi, ex. gr.: Hanek, viene. Annák.

$\mathrm{E}=1$. T'oba, ex. gr.: Eé, sí. Ahá.

$\mathrm{E}=$ A. Mocoví, ex. err.: Epép, abuelo materno. Appî.

$\mathrm{E}=\mathrm{\Lambda}$, alijo de $2^{\mathrm{a}}$, ex. gl'.: 1 Ri-omkatá; 2 Groemketá.

$\mathrm{E}=\mathrm{Y}$. Toba, ex. gr.: Aegec, delante. Tatayget, delante de tí.

$\mathrm{E}=0$. Toba, ex. gr.: Etatá, vena. Otà. Mocoví, Ooctà.

$\mathrm{E}=0$. Mocoví, ex. gr.: Apequena, mano. Appoquennà.

Eë =I. Hocoví, ex. gr.: Këëpe, hacha. Nquippé.

$\mathrm{Ee}=$ Oe. Yocovi, ex. gr. : Greenan, bueno. Noen.

$\mathrm{Eë}=$ Oi. Mocoví, ex. gr.: Apëëgi, cierre. Appoigui.

$\mathrm{Ee}=\mathrm{Li}$. Toba, ex. gr.: Geetagui, vaso. Uicchiguí.

$\mathrm{Ei}=0$. Mocoví, ex. gr.: Elqueiniaic, bayo. Coñoyek.

$\mathrm{Ei}=$ Oi. Mocoví, ex. grr.: Eichi, haces. Oicti.

$\mathrm{E} 0=\mathrm{A}$. Tuba y Mocoví, ex, "gr.: Neoga, dia. Naàg y Naàgaà.

Eu $=1$ ó Ii. Toba, ex. gr.: Ejeura, flauta. Yaside ó Lashiidé.

G

Sonido que puede ser inicial, medial y aun final. Ver: Groacalig, me duele.

$\mathrm{G}=\mathrm{C}$. Supuesta ecuacion en prefijo pronominal, $G r$. Ver Mocoví Cod, C'ad.

$\mathrm{G}=\mathrm{C}$ ó K. Ver G'Dios, á Dios.

G desaparece en IIocoví, ex. gr.: Quî̀, alma. Ver Ilquigi y Quiyi, sombra.

$\mathrm{G}=\mathrm{H}$. Toba, Y Mocoví, ex. gr.: Napagai, viuda. Pahoy, Pai, Pâyé. 
$\mathrm{G}=\mathrm{H}$. Toba, ex. gr.: Ilquiyi, alma. Hiquihi.

$\mathrm{G}=\mathrm{S}$. Toba, ex. gr.: Nageurà, flauta. Yaside. Agic, cara. Assik.

$\mathrm{G}=\mathrm{C}, \mathrm{S}$ ó X (=sh ó $x$ Cat.). Toba, Agipi, labio. Naciph ó Naxip.

$\mathbf{G}=\mathbf{S}$ Toba, $\mathbf{Y}$ Mocoví, ex. gr.: Napagaic, viudo. Pessoyc, Pussoic; Pâyéke.

$\mathrm{G}=\mathrm{Sc}$. Mocoví, ex. gr.: Agipec, caballo. Ascipigà.

$\mathrm{G}=$ Sch. Mocoví, ex. gr.: Nigité, zarcillos. Ischite.

$\mathrm{G}=$ Rg. Toba, ex. gr.: Noałogañigo, escúchame. Naiaargani.

$\mathrm{G}=\mathrm{V}$. Toba, ex. gr.: Grelougà, nuestra muerte. Leuva. $\mathbf{G G}=$ dudoso. Toba, ex. gr.: Lapaugganga, arena. Lovagana, ó sea Lauangra.

$\mathrm{Gl}=$ Arl. Mocoví, Ver: articulaciones, en el Arte Mocovi.

$\mathrm{Gl}=\mathrm{Cal}$. Toba, ex. gr. : Glachigachi, tu lengua. Calatiagath.

$\mathrm{Gr}=$ Ard ó Rd. Prefijo pronominal.

$\mathrm{Gr}=\mathrm{D}$. Mocoví, prefijo pronominal de flexion, ex. gr.: Grihi, tú deseas. Dissii.

Gui $=\mathrm{H}$ (J). Toba, ex. gr.: A paguiñi, abrigo. Napohina. Gui $=$ Qui. Mocoví, ex. gr.: Apaguiñi, abrigo. Nappoguina.

Gui =S. Mocoví, ex. gr.: Ajañiguigam, me levanto. Laassinsigon.

Gui $=\mathrm{X}$ ó Si ( $x$ gallega) Toba, ex.: gr. Grauiguigam, subirnos. Kixiguem. Mocoví, Assisigom.

\section{H ó $\mathbf{J}$}

Sonido que puede ser inicial y medial.

H. Desaparece en Mocoví. Hanek, vengan. Annak, Hañiha, ella sentada. Annissó. 
$H=$ C. Toba, ex. gr.: Ahategkaté, tijeras. Dalgalcalih.

$\mathbf{1 1}=$ J. Toba, ex. gr'.: Rìhahagalgé, apuro. Adijalì, ì prisia.

$\mathrm{H}=\mathrm{S}$. Toba, ex. gr.: Hakaleént, yo me acuerdo. Sasihuelamaté. Movoví Ri-ihé, deseo: Dissiì.

$\mathbf{H}=\mathrm{S}$. Mataco, Ahahaichi, demonio. Asot.

$\mathrm{H}=\mathrm{s}$. Toba, ex. gr.: Ahat, saltar. Huasot.

$\mathbf{H}=\mathbf{X}$ (=sh inglesa). Toba, ex. gr.: Lahic, ya me voy. Larik. Mocovi, Asih.

Ha = A. Mocovi, ex. gr.: Hanek, viene. Annàk.

\section{$\mathbf{J}$ ó $\mathbf{H}$}

Sonido que puede ser inicial ó medial.

$\mathrm{J}=\mathrm{C}$. Toba, ex. gr.: Yajà, harto está. Yocó.

$\mathbf{J}=$ Ce. Mocorí, Lajac, quijada. Laccà.

$\mathrm{J}=\mathrm{H}$. Toba, ex. gr.: Ajanat caec, almohada. Sahancaté.

$\mathbf{J}=\mathbf{S}$. Toba, ex. gr.: Ajam, puerta. Lasóm. Mocoví Assom.

\section{I ó $\mathbf{Y}$}

Sonido que puede ser inicial, medial ó final y que se confunde con la e como en Mocoví. Nu se abunda en ejemplos porque en Mocoví la confusion resulta de asimilacion y otro tanto puede suceder $\in \mathrm{n} A$ bipon, si bien en menor escala.

Aparte de que I es rocal y Y consonante, se confunden los dos sonidos.

$\mathrm{I}=$ Hi. Toba, ex. gr.: Alaic, mano derecha. Lahi, Icait, limpio. Cohitetà. 
Véase $\mathrm{H}$.

$\mathbf{J}=\mathbf{S}$. Toba y Mocoví, ex. gr. : Enajá, este. Ennasó ó Innissó.

$\mathbf{K}$

Este sonido puede ocupar cualquiera de los tres lugares. (Véase $C$ ).

Letra que suple á la $Q$ ó $\mathrm{C}$ ante $e$ ó $i$, ex. gr.: Këëpe, hacha. Queipe, hacha.

$\mathbf{L}$

Sonido que puede ocupar un lugar inicial, medial ó final.

$\mathrm{L}=\mathrm{G}$ ó R. Toba, ex. gr.: Aralaic, nuevo. Dalagaic ó Dalraic.

\section{LL}

Sonido dudoso. Dobrizhoffer lo emplea v. gr.: Ellar'anr'an, él caza. Pero muy bien puede suceder que la $l l$ ésta deba sonar así el-la. Los indios, por lo general, confunden LL y Y.

$\mathbf{M}$

Sonido que puede usarse como inicial, medial ó final. En Abipon no sucede lo que en Mocoví, que como final desaparece, como por ejemplo en la terminacion am de futuro que se reduce á $o$.

$\mathbf{M}=\mathbf{N}$ ver $\mathbf{N}$.

$\mathbf{M}=\mathrm{V}$. Mocoví, Ame, ras. Vó. 
Letra que puede ocupar los tres lugares inicial, medial y tinal.

N confundida con $\boldsymbol{K}$, ex. gr.: Yoamcachiñi, lo de adentro es bueno Yoancachiguinegue, provechoso.

N que desaparece, ex. gr.: Atounâm, ayudado. Mocoví Soctoan.

$\mathbf{N}-\mathrm{g}=\mathbf{G}$. Toba, ex. gr.: Anoegqui, bolsa. Yogoquí.

$\mathbf{N}=$ Rn. Mocovi, ex, gr.: Nitanata, corazon. Litarnacta.

\section{$\tilde{\mathbf{N}}$}

Este sonido puede ser inicial ó medial y responde á la combinacion NI.

$\overline{\mathbf{N}} \mathrm{i}=$ ni. Toba, ex. gr.: Aj-añi, me siento. Sooni. Mocoví, Iñitarà, el. Inni.

\section{$\mathbf{O}$}

Sonido que puede ocupar los tres lugares.

$0=$ M. Toba, ex. gr. : Naoàla, cama. Yumà, Lomà. Mocoví Ommà. Aquí parece como si en el tema Abipon hubiese desaparecido la M.

$0=$ II. Toba, ex. gr.: Navachiqui, corcovado. Namach (?)

$\mathrm{O}=\mathrm{V}$. Toba, ex. gr.: Lavá, ala. Lavá.

Oa = Aa. Mocoví, ex. gr.: Noaá, esclava cautiva. Nâa.

$\mathrm{Oa}=\mathrm{Aha}$. Toba, ex. gr.: Naac, cautivo. Nahach.

Oa $=$ A. Mocoví, ex. gr.: Yoalé, marido. Toba, Yahalé.

Incoví. Yal-lé.

$\mathrm{Oa}=0$. ex. gr.: Noagilete, asta de lanza. Loheleté. 
Oa= Uva. Toba, Ovà. Mocoví Yoalé, marido. Yuvà; Yovà.

$0 \mathrm{a}=\mathrm{Va}$. Toba, ex. gr.: Oaranaga, casada. Vadónr.

$\mathrm{Oa}=$ Vo. Toba, ex. gr.: Iñoaka, dos. Nivoca.

$\mathrm{Oe}=\mathrm{A}$. Toba, ex.gr.: Noetaren, estoy sanando. Natadén.

Oe = Aa Mocoví, ex. gr.: Noetà, pueblo. Aa, plural: Aaté.

$\mathrm{Oe}=\mathrm{I}$. Toba ${ }_{\text {s }}$. gr.: Groegéc, comezon. Disique.

Oi = Aí. Mocoví, ex. gr.: Oénék, muchacho. Naînéke.

Ou = Ao. Mocoví, ex. gr.: Lelougà, muerte. Lel-laogà.

\section{$\mathbf{P}$}

Sonido que se usa como inicial ó medial. Se sospecha que pueda degenerar en $\mathbf{U}$ ó $\mathbf{M}$, etc., en los otros codialectos. Ex. gr.: Gricapat, tengo hambre. Toba, Eccowott.

$\mathbf{P}=\mathbf{U}$. Toba, ex. gr.: Gricapat, tengo hambre. Eccouót. (?) $\mathbf{P}=\mathrm{V}$. Mocoví, ex. gr.: Uitapilite, crees. Ovilék.

P. que desaparece en Mocoví, ex . gr.: Raiz, Kapit=Coict, amar. Tal vez se puede incluir esta otra: Abipon, Elpagé, carne. Lâácte. Mocoví, Epep, abuelo, es Apé en Toba y Appî en Mocoví. Etapegé, sombrero, es Adoó en Mocoví. Yapiloctà, ayudo, es Sôctoan en Mocoví. Npaàc, aborrecido, es Oqqui en Mocoví.

El primero es el único ejemplo satisfactorio: voces con $\mathrm{P}$ en ambos dialec๋os abundan.

\section{$\mathbf{Q}$}

Recurso del español para escribir los sonidos $K e, K i$. Véanse Këëpe y Queipe, hacha.

Quin $=$ Gn. Toba, ex. gr.: Queiñiquiñi, nació. Nigni. véase la $\mathrm{C}$ ó $\mathrm{K}$. 
$\mathbf{R}$

Sonido que se usa como inicial y media!. Lis signo que en general representa la D del Mocoví, y otras está por esa letra que ni es $\mathbf{G}$ ni es R, como lo dice Dobrizhoffer.

$\mathbf{R}=\mathbf{C h}$. Quíchua, si. Yàraige, sabe; procede de Yacha. $\mathbf{R}=$ Ch. I Ri-igarañi: 2 Gregachañi.

$\mathbf{R}=\mathbf{D}$. Mocoví, ex. gr.: Graré, pestañas. Diadé.

$\mathbf{R}=\mathbf{D}$. Mocoví, ex. gr.: Rahachi, tú saltas. Dassocti.

$\mathbf{R}=\mathbf{D}$. Tobal, ex. gr'.: Aariaingat, adorno yo. Adioetó, adornar'se.

$\mathbf{R}=\mathbf{G}$. Leyera, la vida. Leleiga.

$\mathbf{R}=\mathbf{G}$. Toba, ex. gr.: Noaarar'anrelé, pelea á lanza. Noaganath.

$\mathbf{R}=\mathrm{Gr}$. Toba, ex.gr.: Hapaer'at, yo caliento. Paygrat. $\mathbf{R}=\mathbf{L}$. Toba, ex. gr.: Aguirec, muchacho. Socolech.

$\mathbf{R}=\mathrm{L}$. Toba, ex. gr.: Aralaic, nuevo. Dalagaic.

$\mathbf{R}==\mathbf{L}$. Mocoví, ex. gr.: Rahat, él salta. Lassot.

$\mathbf{R}=\mathbf{L}$. Mocoví, ex. gr.: Rat, y. Lot.

$\mathbf{R}^{\prime}=\mathbf{R}$. Toba, ex. gr.: Ar'air'aik, manso. Oreyraic (L.). $\mathbf{R}=\mathbf{T}$. Toba, ex. gr.: Rategham, cuervo. Tatogesam ó Tegesan.

\section{$\mathbf{S}$}

Sonido que se buscará en la Gr, J ó H.

\section{$\mathbf{T}$}

Sonido qque se usa como inicial, medial y final.

$\mathrm{T}=$ Ct. Mocoví, ex. gr.: Aatar'kié, cinturon. Ossoactarqui. Latè, madre. Laccteé.

$\mathrm{T}=\mathrm{T}$. Toba, ex. gr. : Laté, madre. Até. 
= T. Toba y Mocoví, ex. gr.: Yuiac, gordo. Yutiach, Yôchàcâ.

\section{$\mathbf{U} \dot{o} \mathbf{V}$}

Sonidos iniciales ó mediales.

C = P. Mocoví, ex. gr.: Hauali, araña. Appal-lactrêgà.

$\mathrm{I}=\mathrm{V}$. Mocoví, ex. gr.: Naué, negro. Navé.

Ver 1 .

\section{CAPITULO I}

\section{ARTículo}

No cabe duda que el Abipon, como el Mocoví, tiene algo parecido á lo que nosotros llamamos artículo. El prefijo de relacion concreta es L, así que "los ojos de Pedro", serían $L$-atoete; mientras que "los ojos" serían $N$-atoete. Esta $\mathrm{N}$ entónces equivale al artículo ó prefijo de relacion abstracta, y viene á ser una simple sincopacion del demostrativo Ene que forma la raíz del tema Eneha : él, presente.

Dobrizhoffer nos suministra la mejor prueba de que el prefijo $\mathbf{N}$ es abstracto y $\mathbf{L}$ coucreto.

Naetar'at: filius, quin cujus sit, exprimatur.

Yaetr'at: meus filius.

Graetr'achi: tuus filius.

Laeet'at : illius filius.

En seis de los siete ejemplos distingue del mismo modo; y en el séptimo no hay excepcion, porque en todas tres personas 
se pour la $\dot{\mathrm{X}}$, por ser de los temas que exigen este refuerzo. Dobrizhoffer mada dice acerca del articulo. Ver: Arte Mocovi.

\section{CAPITLLO II}

DEL, GÉNERO

Dobrizhoffer concede que el Abipon cuenta con grénero masculino y femenino, pero que éste sólo se puede distingruir cou el ejercicio. Sus ejemplos soll :

$$
\begin{aligned}
& \text { Grahaulái: sol (femenino). } \\
& \text { Grauék : luna (masculino). } \\
& \text { Ariaik : bueno. } \\
& \text { Ariayé : buena. } \\
& \text { Cachergaik : viejo. } \\
& \text { Cachergayé : vieja. }
\end{aligned}
$$

La verdad es que $i$ ó yé son terminaciones de femenino, como ek ó ik lo son de masculino; de suerte que vista y oída la palabra no cabe duda del género.

Si la voz termina en ac para femenino se cambia el subfijo en aga, r. gr.:

Aalancatac: perezoso.

Aalancataga: perezosa.

El Mocorí hace las mismas distinciones, r. gr.:

Masculino

- Eddocoleék

Pactiornáca

Eogodach
Femenino

Eddocolassé criollo

Pactiornagá médico

Eogotayé pobre 
Véase : Arte Mocoví, Títulos etc., página 45.

Á primera vista se desprende la íntima conexion entre éstos y aquellos subfijos.

Adjetivos como Naá, malo, y Neen, bueno, sirven para los dos géneros; pero es de advertir que ni uno ni otro acaba en la partícula participial $k$, circunstancia á que tal vez deba atribuirse la anomalía.

En el capítulo de los pronombres se hará nctar otro modo de expresar el género de ellos.

Conviene advertir que la forma femenina es la que se usa tambien para los plurales. Ex. gr. : Eergr'aik, estrella; plural: Eergr'ayé.

\title{
CAPITULO III
}

\author{
DEL NÚMERO
}

Es tan complicado el modo de terminar los plurales en Abipon como en Mocoví. "Es tal la variedad, dice el Padre, que casi no cabe regla ".

He aquí algunos ejemplos:

A' en Era: Singular Oalod́; plural Oáloera, condenado.

$\mathrm{A}^{\prime}$ en A': singular Letatá; plural Letatá, vena.

A' en El : singular Aoená; plural Aoenel, olla.

A' en Arí: singular Pana; plural Panarí, raíz (D.). Singular Olpana; plural Elpaneri, raíz (B.)

Al en Ela: singular Quetal; plural Quetela, oreja.

A' en Al: singular Oachigranigá; plural Oachigranigal, ciervo (D.). 
Co k en Ca ó Cí : singular Ilialc; plural Ilialcal, cachorron. Singular Namilgic; plural Namilgica, castigo.

C ó K en A: singular Ahëpegak; plural Ahépéga, cabaIIo (I).).

C. en Ga: singu'ar Cilpáic; plural Capieliga, grato.

C. en Ya: singular Iquilc; plural Iquilyz, cotorra.

C en Cqui: singular Yic: plural Yicqui. casa.

$\mathrm{K}$ en E: singular Eergr'aik; plural Eérgraié, estrella.

K en R'a: singular Ketélk; plural Ketelr'a, mulo (I).).

K en Gke: singular Leték; plural Letegké, hoja de arbo: (D.).

Ca en Ga: singular Oegeca; plural Oegega, hormiga.

E' en El: singular Gaté; plural Loatel, llaga.

E en Ete: singular Noalouge; plural Noạlougete, culpa.

E' en E': singular Letegué; plural Letegué, hoja.

E en E': singular Neogue; plural Veogué, palma.

E en Te: singular Noalouge; plural Noalougete, perado, Ec en Ca : singular Ligilaléc; plural Ligilalcá, vestido. Ec en E': singular Aguirec; plural Aguiré, muchacho. Ec en Ca: singular Lapaanatec; plural Lapaanatca, discípulo.

Eca en A: singular Caipeca; plural Caipca, palı.

G en Gal: singular Lémág; plural Lemága. bautizado.

Gr en Gui : singular Nacarig; plural Nacarigui, bautizado. Gi en Cachi: singular Lemág; plural Lemacachi, bautizado. G en Gla: singular Nacarig; plural Nacavigla, bautizado. Gil en Tá: singular Nengá; plural Neotá, día. Singular Neoga; plural Neogotá, dia (D.).

Gaic en Arca: singular Natannogaic; plural Natannoarca, desgraciado.

Gé en Ké: singular Lachaogé; plural Lachaoké, arroyo (D.).

Gec en Jáca: singular Nachagec; plural Nachajaca, pié.

Ga en Gri:singular Iñiga; plural Iñigri, año.

I en Ye: singular Acatleguei; plural Acatlegueye, caña. 
I en Ite: singular Naquequi; plural Naquequite. estribo.

L en Lá: singular Elparil; plural Elparilá, tallo.

L en Lí: singular Loatal; plural Loatalí, chispa.

M en Mi : singular Lajam; plural Lajami, puerta.

$\mathrm{N}$ en Naca ó Nca: singular Lajatan; plural Lajannaca, pregunta. singular Neyen; plural Neyenca, regalo.

N en Ne: singular Queregan; plural Queregane, jerga.

T en Ta: singular Grepalit; plural Grepralita, golondrina.

T en Cate: singular Caalat; plural Caalcate, brazo.

T en Te: singular Liilet; plural Liilete, hijo.

T' en Te: singular Ncaocate; plural Ncaocaté, amadu.

$\mathrm{T}$ en Tr: singular Najataoa; plural Najatraoa, presente.

Ye en Yaole: singular Laoregye; plural Laoregyaole, higo.

ALGUNOS PLURALES ANóMALOS

Npaagnagô: enemigos.

Náaná, plural: Naánâ̂lli, espina.

Plural por reduplicacion : Lerc, plural Lelerc, letra. Plural con subfijo Aite: Quiñigatanat aile, ofrendas muchas.

Dobrizhoffer agrega estos ejemplos:

Yoalé: un hombre.

Yoaleé ó Yoaleéra: algunos hombres.

Yoaliripi: muchos bombres.

Ahëpega: caballo.

Ahëpegiripi: muchos caballos. 


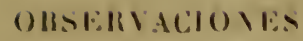

I" No todas las particulas son muy generales, pues muchas de ellas se convecu por un solo ejemplo. Las mas usadas parrece que son: Ca, Cale, Te, Y, A, L.

La $L$ no es tan comun como debería esperarse, pero ello tal vez resulte de que nos faltan voces en que entra.

-2 Nicil, Na y Ca son partículas que conviene se compare con el subfijo naca de pluralidad en Aymará.

$3^{\text {a }}$ Todas las partículas del numero 1, y otras que no se han incluido, pueden reducirse á pronombres demostrativos. Este modo de furmar temas de plural to comprendemos perfectamente: así en inglés de child, niño, se forma children, niños: siendo $r$ y $n$ ambos subfijos de pluralidad por separado, y de orígen pronominal. Nada de extraño, pues, tiene este recurso del Chaco, de acumular partículas de igual valor gramatical unas sobre otras.

$4^{a}$ La imposibilidad de expresar con nuestros signos alfabéticos los sonidos chaquenses hace que muchas cosas suenen á irregularidad, que más bien resultan de la extension natural de los sonidos en temas en que se aumenta sílaba. Aparte de esto, una apócope restaurada para recibir el aumento de númpro en temas de plural, puede dar salida a muchas de las aparentes anomalías. Nosotros decimos ciudá, pero en ciudades restanraremos la $d$ perdida. Se recomienda la lectura de las páginas xir y cru del Arte Mocori. Allí se trata in extenso de este punto.

$5^{*}$ El plural que acaba en $l$ es comun al Toba, Mocoví, Abipon, Mataco y otras lenguas del Chaco, y con la $i$ merece ser estudiado en todas sus ramificaciones.

$6^{\text {a }}$ El subfijo ipi ó ipi de nuchedumbre es comun al Toba Mocoví y Abipon. 
$7^{2}$ La correlacion que existe entre el Abipon y el Mocoví está a la evidencia en estas partículas finales de pluralidad. Para mayor claridad se darán en seguida algunos ejemplos concretos:

\section{Pestañas}

Singular: Mocoví Dadé (3).

Plural: Abipon Graré. Mocoví Dadé.

Nótense las ecuaciones: $G r$ inicial $=D ; R$ medicil $=D$.

\section{Enernigo}

Singular: Mocoví Npaguennavá.

Plural: Abipon Npaagnagô. Mocoví Npaguennavâ.

Nótese la $g$ de un lado y la $v$ del otro; pero adviértase que en Mocoví hay otra voz que dice enemigo tambien: Ncoaguá.

\section{Olla}

Singular: Abipon Aoená. Mocoví Avenná.

Plural: " Aoenel. " Avennal.

\section{Hueso}

Singular: Abipon Ipiinc. Mocoví Ipinnèh.

Plural: " Ipiinca. " Ipinnacî.

Nótese la sincopacion nc. 
Año

Singular: Mbipon lñiga. Mocovi Iñiagú.

Plural: " Iñigri. "Iñardi.

Nótese la ecuacion $q$ ri $i=r d i$.

\section{Camino}

Singular: Abipon Cataic. Mocoví Naaddik.

Plural: " Calaica. " Naaddico.

En Mlocoví $o=a$ abipona.

\section{Puerta}

Singular: Abipon Lajam. Mocoví Lassôm.

Plural: \Lajami. " Lassommi.

Nótese la ecuacion $j=s s$.

Pero basta de ejemplos.

\section{CAPITULO IV}

DEL CASO

Dice Dobrizhoffer que los nombres no cambian de forma para expresar lo que se entiende por caso ó declinacion, pero que prefijan una partícula que corresponde á nuestra prepo- 
sición. El ejemplo que él da es de una M, v. gr.: de Aym, yo; M'ayim, á ó para mí. En otros casos puede ser $k$ etc. como se verá al tratar de estos afijos.

Caso empero tienen los pronombres, como se verá cuando se trate de ellos, y en la forma posesivo-genitiva estas partículas se aplican como afijos á los nombres sustantivos etc. para indicar relacion: estas partículas, segun la persona y número; pueden ser prefijos ó subfijos ó ambas cosas á la vez.

\section{GAPITULO $\mathrm{V}$}

DE LA POSESIVACION

Este es uno de los recursos más curiosos del Arte Abipon como lo es en los demás idiomas del mismo tipo en el Chaco.

Dobrizhoffer se limita á dar ejemplos sólo de dos modos de posesivar, que por pocos y de importancia se reproducen aquí:

1. Hijo: Naetar'at D.j

Dobrizhoffer

Sing. : 1 a Y-aetr'at (Meus). 2a Gr-aetr'achi (Tuus). $3^{\text {a }}$ L-aetrat (Illius).

Notas. - $1^{\text {a }}$ La $t$ hace chicheo al herir el subfijo de 2 a persona $i$.

9a En el Toba se nota que
Brigniel

Sing. : fa $\mathrm{Y}$-aitat.

2a Gr-aitach-i.

3a L-aitat.

Plur. : /a $\mathrm{Gr}$-aicat.

$2^{a} \mathrm{Gr}$-aicach-ii.

$3^{\text {a }}$ L-aitat-e.

Notas. $-1^{2}$ Voz que usan de 
Bíreena escribia como Brigniel sonidos que López daba como Dobrizhoffer. Por ejemplo: Agua (1590) Bárcena : Nelaht: (1888) López : Nelagrgrdt.

Yo mismo lo he apuntido de lo que oi, y con Bárcena en la mano. hijo vivo, cuando no se les ha muerto ninguno.

ga Obsérvense las ecuaciores :

$$
\begin{aligned}
a e & =a i \\
t r^{\prime} a t & =t a t .
\end{aligned}
$$

$3^{x}$ Los temas de $1^{\text {a }}$ y $2^{a}$ en plural deben resultar de fuerts: sincopación.

2. Abuelo materno: Nepép.

Dotrizhoffer

Sing. : la Y-epép. 2a (rr-epepé. 3" L-epép.

Nota. - La é por $i$ subfijo de $2 a$ persona sin duda resulta de asimilacion.

$$
\begin{gathered}
\text { Mocovi (Tavoiini) } \\
\text { Nappi pl. Nappiri. }
\end{gathered}
$$

Sing. : 1a Y-appí.

2a D-appí.

3a L-appí .

Plur. : 1a Ard-appí.

2a D-appí.
Brigniel

Esta voz falta en el vocabulario de este Padre.

NoтA. - Obsérvese que se trata de abuelo materno, y véase abajo.

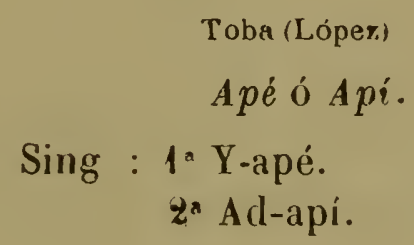

En Lule de Machoni 'abuelon es Pepé ó Pé, y el hecho de que Nepép sea "abuelo materno" parece que indica la procedencia étnica de uno de los abolengos mujeriles de los Abipones; y como la palabra es comun á todos los tres 
dialectos, parece que todas las tres naciones se hayan emparentado con los dichos Lules.

3. Nieto: Naál

Dobrızlıoffer

Sing. : 1 a Y-aál.

$2^{\text {a }}$ Gr-aalí.

$3^{a} \mathrm{~L}$-aál.

Mocovi (Tavolini)

Sing. : fa $\mathrm{Y}$-val.

2a C-val-lí.

$3^{\text {a }} \mathrm{L}$-val.

Etc.
Brigniel

Sing. : 1a Y-aal.

2a Gr-aal-í.

Toba (Bárcena)

Sing. : Faltan las tres personas.

$3^{\text {a }}$ Lava.

Notas. - la La $v$ orgánica en el Mocoví y Toba parece que se pierde en el Abipon, y esta morbosidad se advertirá en muchos otros casos. A no dudarlo se trata de un sonido oa que puede trocarse en aa, en mérito de la ya establecida ecuacion :

$$
\text { Abipon } \mathrm{A}=0 \text { Mocoví. }
$$

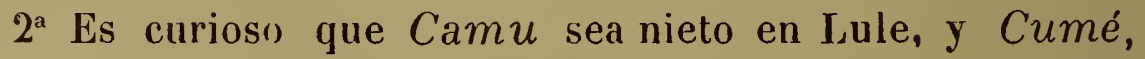
abuela, en Toba; Comená en Mocoví.

$3^{\text {a }}$ La supresion de la $l$ final en el ejemplo Toba $\sin$ duda resulta de que en este dialecto este subfijo hace tema de plural.

1. El hermano menor : Nenák

Dobrizhoffer

Sing. : 1a Y-enák.

2a Gr-enaré.

$3^{\text {a }}$ L-enák.
Brigniel

Se deduce que es Aoenec con Añalejoa prefijado. 
Notas. - 1" Nam Aoenec es : medor.

$2^{a}$ Ln el Abipon faltan muchas de las roces que se relacionan con los gradus de parentrsio; por el contrario, en los cuadernos de Barena esta una tabla compleb, pero que no dice bien con lo de arriba. Lo mis parecido es Lanoladasán, hermana menor de el ó de ella. Lin Mocovísólo tenemos Cayí, hermani en general; pero es indudable que debe existir una serre tan completa como la del Toba.

$3^{a}$ En el Lule tenemos: En $/ / p$, mi hermano menor. Dadas las omofuniats anteriores, ésta arlquiere importancia; porque al fin la $p$ linal en Lule es mas ó menos lo que la $k$ en los otros idiomas.

5. Asta de lanza: Nohelelé.

Dobrizhoffer

Sing. : la Y-obelete. $2^{2}$ Gir-obelichi. $3^{\text {a }} \mathrm{L}$-ohelete.

Mocovi (Tavolini)

$\mathrm{N}$-ictaquiaràih, vel

N-aquui, pl. Nayquil-li.
Brigniel

Sing. : Faltan las otras tres persomas. $3^{\text {a }} \mathrm{N}$-vagileté.

Toba (Bảrcena y López)

Taquiagay (B.)

Tayuiláy ;L.)

Notas. - I L Lin Dobrizholfer la voz dice, el asta de la lan$z a$, mentaras que en los otros tres ejemplos se refiere á la lanza á secals.

$2^{a}$ En Lule una ianza de palo $(E)$ llamase $E$ A yé : cosa larga de palo. El tiempo dira si has correlacicn enue estos temats.

6. La vida: Nalatr'a

Dobrizholter

Sing. : I' Y-atatr'a.
Brigniel

Sing. : fa Y leigá. 
2 a Gr-atatr'e. $3^{a}$ L-atatr'a .

Mocovi (Tavolini)

Sing. : 1a Ye leâgá.

2a De-leâgaí.

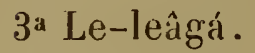

Plur. : ła Arde-leâgá.

2a Arde-leagai. $2^{a}$ Gre-leigué.

亏a Le-leigá.

Plur. : 1 are-leigá.

2a Gre-leigueyi.

$3^{a}$ Le-leigá .

Toba (Bárcena)

Calcolagatech.

El manuscrito no da la posesivacion.

Notas. - $1^{a}$ Dobrizhoffer sin duda se refiere á una vida que no es la de los otros ejemplos; aunque la terminacion $r^{\prime} a$ puede encerrar una sincopacion de la raíz Laga etc., que segun parece es la de los otros temas.

$2^{a}$ La terminacion e de segunda persona es el equivalente del diptongo ai.

$3^{a}$ En Lule Uató es vida. Esta raíz cabe en el tema (D.).

Estos son los ejemplos que en Dobrizhoffer representan la posesivacion normal, como que son seis entre siete. Del último se hablará á su tiempo. Lo extraño es que no haja dado el plural; por suerte éste lo podemos suplir del vocabulario de Brigniel, quien nos conserva unos cuarenta y tantos ejemplos de esta declinacion posesivada.

- De ambos autores se desprende que, como en Mocoví, lo más general es el uso de esta serie de afijos :

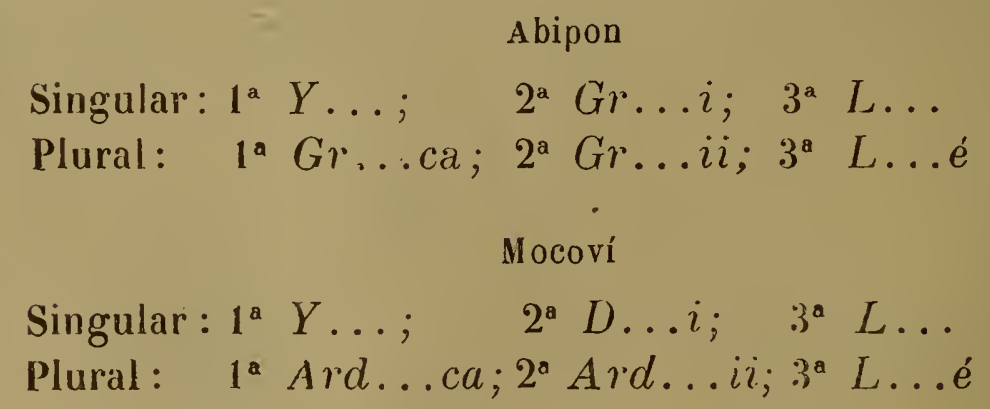


No se crea que en el plural haya la regularidad del subfijo de $1^{a}$ y $3^{a}$ persona que figura en la fórmula; pues cualquicra de las partículas de pluralidad parece que puede servir. En el Apéndice se da la série completa de nombres posesivados con explicaciones, y allí podra estudiarse el punto á fondo.

Del siguiente ejemplo podrá asegurarse ex uno disce omnes.

Antes de proceder adelante, es necesario advertir que el Ibipon, como el Mocoví y otros idiomas del tipo Guaycurú, posesiva de dos modos, del uno sin prefijo auxiliar, del otro con él.

GRUPO SIN PARTÍCULA AUXILIAR

\section{1' Declinacion}

$$
\begin{aligned}
& \text { Singular: } 1^{\mathrm{a}} Y \ldots \text {. } \quad 2^{\mathrm{a}} G r \ldots i ; \quad 3^{\mathrm{a}} L \ldots \\
& \text { Plural: } \quad 1^{\text {a } G r \ldots p l: ~} 2^{\text {a } G r . . . i i ; ~} 3^{\text {a }} L \ldots p l \text {. }
\end{aligned}
$$

Abipon

Naacatéc: L.a palabra.

Sing. : $1^{\text {a }}$ Y-aacatéc.

2 a $\mathrm{Or}$-aacatigui.

3a L-aacatéc.

Plur. : fa Gri-acatéc.

$2^{\text {a }}$ (ip-aacatiguí.

3' L-aacategue.
Mocovi

Naccatéh, plural Naccatcd.

$$
\begin{aligned}
& \text { Sing. : } 1^{\text {a }} \mathrm{Y} \text {-accatéh. } \\
& \text { 2a D-accactiguii. } \\
& 3^{a} \text { L-accatéh. }
\end{aligned}
$$

Notas. - $1^{\text {a }}$ Aquí todo es 10 mismo; sin embargo el IIocoví distingue entre mi palabra, nuestra palabra, mis palabras, nuestras palabras. 
$2^{a}$ En este ejemplo la $t i$ no ha sufrido chicheo. Toba Yacatac (B.); Akatká (L.) ( $\left.{ }^{1}\right)$.

Se ha elegido este ejemplo porque la misma raíz sirve para formar lus tres temas, y porque los afijos son tambien idénticos. En el Mocoví se han probado ya las ecuaciones :

$$
\begin{gathered}
R=D \\
G r=D
\end{gathered}
$$

Pasemos ahora á la segunda declinacion de los temas sin refuerzo.

$$
\text { 2. Declinacion }
$$

$$
\begin{aligned}
& \text { Singular: } 1^{\mathrm{a}} Y \ldots ; \quad 2^{\mathrm{a}} A r \ldots i(?) ; 3^{\mathrm{a}} I l \text { ó } E l \\
& \text { Plural: } \quad \text { 1 }^{\mathrm{a}} A r \ldots \text { (?); } 2^{\mathrm{a}} A r \ldots \text { ii. (?) } 3^{\mathrm{a}} \text { Il ó El... (?) } \\
& \text { Abipon (1767) } \\
& \text { Mocoví(1860) } \\
& \text { Ylquigí: El ánima. } \\
& \text { Nquii, pl. Nquiil: El alma. } \\
& \text { Sing. : la } \mathbf{Y} \text {-quigi. } \\
& \text { 2a Al'-quigí. } \\
& 3^{\text {a }} \text { Yl-quigí. } \\
& \text { Sing. : fa } \text { Y-qquii. } \\
& \text { 2a Ar-quiii. } \\
& \text { 3a L-quii. }
\end{aligned}
$$

Causa admiracion que se haya conservado hasta la serie mediu anómala de los afijos. En el Apéndice se encontrarán dos rjemplares mas de esta posesivacion. Toba Hiquihi (B. y L..).

Sólo ell un estudio comparado cono éste se puede apreciar en su verdadero valor la impurlancia de los trabajos que nos han dojat., los misioneros S. J.

('i) B. es Toba de Bárcena, L. de Lopez. 
Nos queda que dar cuenta de un curioso ejemplo cuya réplica tambien se halla en el Mocoví. Abipon: Iligat, penis. Mocovi: Anneglet, miembro.

\section{Abipon}

Yligat: Peni.



Sing. : $1^{\text {a }}$ Il-igat.

2 Cach-igach-i. 3a Yl-igat elajá.

Plur. : (ralta).
Wocovi

Anneglet: Miembro.

Sing. : 1a Aiglét.

2a Castil-lictí.

3a Al-ìoglet.

Plur. : 1a Cocteglét.

2 Arcactilictí.

Como la ct suena ch en Abipon y st ó ct en Mocoví, y las rocales se intercambian en uno y otro dialecto, queda establecida la identidad de los dos ejemplos. La raíz. à lo que se ve es ig ó iga; y si en el ejemplo Mucoví la $g$ desaparece en la segunda persona, debe advertirse que la $l$ se vuelve $l-l$ lo que encierra una mudanza fonética.

GRUPO CUARTO

\section{Con refuerzo inicial}

A lo que se ve todos los idiomas de la familia Guaycurú tienen dos modos de posesivar, uno sin refuerzo inicial, otro con él.

El mas general de estos refuerzos es el prefijo $\mathbf{N}, \mathbf{y}$ lo ha- 
llamos en Mocoví, Toba, Guaycurú ó Mbaya y Abipon, etc., por esta razon se le asigna el primer lugar.

En los casos en que el prefijo aumenta una G, Ga ó Gue, la $\mathbf{G}$ corresponde á la $\mathbf{G}$ en $\mathbf{G r}$. Lo que falta que averiguar es la razon de las variantes en los prefijos. Sin duda en parte ello resulta de exigencias eufónicas cuyos cánones aún están por determinarse.

$$
\begin{aligned}
& \text { Sing.: } 1^{\text {a }} \hat{N i} \ldots: \quad 2^{\text {a }} N, G n, G u e n \ldots i ; 3^{\text {a }} N \ldots \\
& \text { Plur.: }{ }^{a} N, \text { Gan, Guen...ca; } 2^{\mathrm{a}} N, \text { Gan, Guen ...ii; } 3^{\mathrm{a}} N \ldots e \\
& \text { Abipun } \\
& \text { Mocovi } \\
& \text { Mano } \\
& \text { Muñeca } \\
& \text { Sing. : fa Ñ-appoquená. } \\
& \text { 2a } \mathrm{N} \text {-appoquennai. } \\
& 3^{\text {a }} \mathrm{N} \text {-appoquenná. } \\
& \text { Plur. : la Arn-appoquenná. } \\
& \text { 2a Arn-appoquenná. }
\end{aligned}
$$

Estos ejemplos están llenos de instruccion. En primer lugar nos hace conocer que la voz que dice mano en Abipon sirve para nombrar la muñeca en Mocoví. Está de manifiesto que estos temas son complejos, y que entra en ellos la raíz Guaraní $P o$, mano, así como en appia (Mocoví) hallamos el $P \hat{\imath}$, pié Guaraní, en Achagec, el Chaqui, pié, Quíchua. Son omofonías éstas que abren un vasto campo á las filologías respectivas.

El tema Apequena se forma de las raíces Apa é iquena, de las que la segunda puede referirse á la idea de dedos. Ver Iquiannanachi.

Suprimido el refuerzo $n$ se liquida una $i$ de primera persona que es tan característica de estas lenguas.

Se recomiendan los capítulos que tratan de este punto en el Arte Mocovi. 
A estat posesivacion correspoude el septimo ejemplo de Dobrizhufler: Nakirék, sobrino.

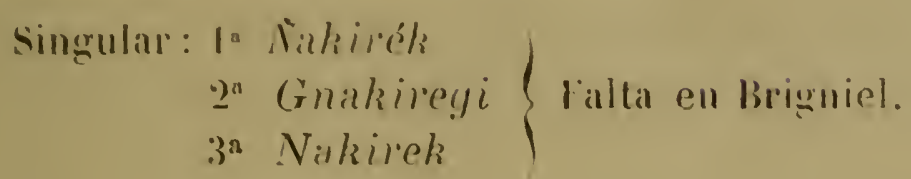

En Toha sería: LLagnec maligi yaléc; en Mocovi : Lectece.

Este nrupo tiene dos subclases, como se verí en el Apéndice. En l Ibipon se prefija una $A$ eufónica fuera de la $1^{a}$ persona de singular; en 'Toba (B.) se sustituye el prefijo $\mathrm{N}$ con la partícula $E l$ en los mismos casos. Se deja ver que en este caso la razon es eufónica, y para evitar anfibalogía con otros temas parecidos de diferente valor léxico.

GRUPO QUINTO

\section{Con refuerzo inicial Gr}
Singular: In Gri...:
$2^{\mathrm{a}} G r \ldots i$ :
$3^{\mathrm{a}}\left(\begin{array}{l}\mathrm{x} \\ \mathrm{r}\end{array}\right.$
Plural: $1^{\text {a }}$ Gro...:
$2^{\mathrm{a}} \mathrm{Gr} \ldots \mathrm{ii}$;
$3^{2} G r \ldots r$.

\section{Pestañas}

Abipon

Sing. : $1^{a}$ Gri-aré.

2. Gr-arí.

3a Graré.

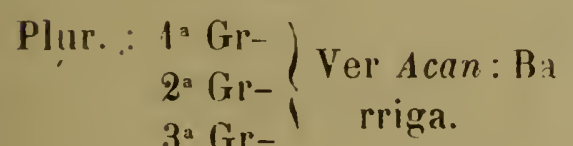

Mocovi

Sing. : fa Di-adé.

2a Rd-adii.

:ja D-adé.

Plur. : la Rd-adé.

Q̨a Rd-adíi. 
Es este uno de los ejemplos más útiles para comprobar una série de equivalencias fonéticas, y sobre todas esta : $\mathrm{Gr}=$ RD y D.

Que este prefijo $\mathrm{Gr}$ corresponde al Cad Toba, se deduce de este ejemplo, Gracami, tu vientre (Abipon); Cadahán (Toba).

Esta y las siguientes posesivaciones faltan en Dobrizhoffer.

GRUPO SEXTO

Con refuerzo inicial $L$ ó $G l$

Singular: 1a $L i \ldots$; $\quad 2^{2} L$ ó $G l \ldots i ; \quad$ 3a $L \ldots$

Plural: $\quad$ 1a $L \ldots$ (?); $\quad 2^{\text {a }} L \ldots i i ; \quad 3^{2}(?)$

\section{Lengua}

Abipon

Sing. : $1^{2}$ Li-achigat.

$2^{2}$ Gl-achigachi. $3^{\text {a Falta. }}$
Toba

Sing. : fa Falta. $2^{a}$ Calatiagdth. $3^{\text {a }}$ Latiagat.

Por esta vez nos falta el tema análogo en el Mocoví, pero se suple bien con el Toba, gracias á que el Vocabulario de Bárcena da la $3^{a}$ persona, y la tabla de Partes del hombre la $2^{a}$. De aquí se deduce con toda seguridad la ecuacion. $G l=C a l$.

Otro ejemplo:

$$
\text { Lajaganac: Risa }
$$

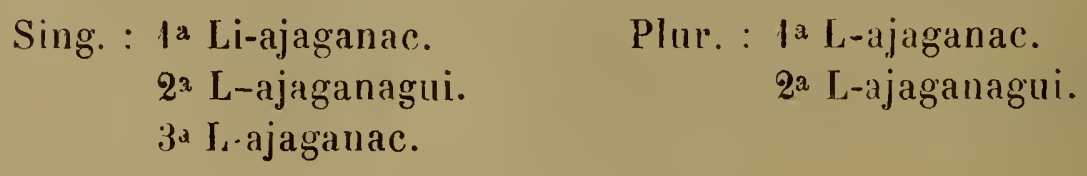


La falta de particula de phuralidad en la 1 persona se advierte en éste, como en otros ejemplos, y sin duda resulta de que dice: nuestra risa. La confusion con la $3^{a}$ del singular desaparecería en la frase.

A esta declinacion debería atribuirse el siguiente ejemplo, i pesar de sus anomalías:

\section{Cililat. plural Caalcilte: brazo}

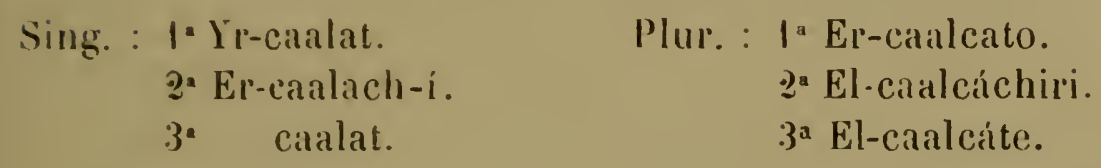

Plur. : Ia El-caalcato. 2 El-caalcúchiri. $3^{\text {a }}$ El-caalcáte.

lin Mocovi hallamos: Coiorii, abrazos.

En Toba hallamos: Aloik (L.), brazo derecho.

In ejemplo como éste nos enseña que puede infijarse la particula de pluralidad ca así plural la Er-caral-ca-te de Ir-carlit.

\section{OBSERYACIONES GENERALES}

De las Posesivaciones se ha tratado largamente en el tomo en que se publicó el manuscrito del Padre Tavolini sobre la lengua Mocoví, páginas LXVI y siguientes; no es necesario, pues, reproducir aquí lo que allí se dijo.

La impresion que nos deja el Abipon es la de mayor sencillez en su mecanismo; pero eso no obstante, con rastros de todas las complicaciones del dialecto hermano.

En Ibipon como en Incoví, la posesivacion típica es esta:

$$
\begin{aligned}
& \text { Singular: 1 } 1^{\text {a }} Y \ldots \text {. } 2^{\text {a }} G r \ldots i: \quad 3^{\text {a }} L \ldots \\
& \text { Plural: } 1^{\text {a }}(i) \ldots p l ; 2^{a} G r \ldots i i ; 3^{a} L \ldots p l \text {. }
\end{aligned}
$$


Mocoví: $G r=R D$.

Con la sola excepcion de Iligat, faltan ejemplos de la posesivacion Mocoví que corresponde a esta fórmula:

Singular: $1^{\text {a }} Y \ldots ; \quad 2^{\text {a }} C \ldots i ; \quad 3^{a} L \ldots$

Plural: $1^{\text {a }} C o \ldots p l .: 2^{\text {a }} C a \ldots i t ; 3^{\mathrm{a}} L \ldots p l$.

En las Posesivaciones con refucron tenemos séries de afijos comunes á los dos idiomas:

Primera série

Abipon

Sing. : 1a $\tilde{X}_{\ldots} \ldots$

Q⿱a $\mathrm{Gn}$ ó N...i.

$3^{\mathrm{a}} \mathrm{N} \ldots$

Plur. : $1^{\text {a }} \mathrm{Gll} \ldots \mathrm{pl}$.

2a (ill... ií.
Mocovi

Sing. : 1a $^{\mathrm{N}}, \tilde{\mathrm{N}} \mathrm{i}, \mathrm{N}, \mathrm{Y} \tilde{\mathrm{n}} \ldots$

$2 \mathrm{~s}$ N...i.

$3^{\mathrm{a}} \mathrm{N} \ldots$

Plur. : 1a Arn...pl.

ia Arn...ii.

Segunda série

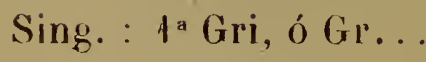

2a Gr. .í.

$3^{a} \mathrm{Gl}^{*} \ldots$

Plur.: $\{$ a Gr...pl.

2a Gr...ii.

3a Gr...pl.

Sing. : $1^{\text {a }} \mathrm{Di} \ldots$

$2^{a}$ Rd...i.

3a D...

Plur. : la Rd...pl.

2a Rd...ií.

Tercera série

Sing. : ta Li...

2a L ó Gl...i.

$3^{\mathrm{a}} \mathrm{L}$...

Plur. : 1a L...pl.

ga L...íf.

Sing. : fa II, Lii...

ga L.. i.

$3^{\text {a } ~ L . . . ~}$

Plur.: 1a Arl...pl.

$2^{\text {a }}$ Arl ...ii. 
Obsirves: que ell estas tres series la $\mathbf{C}=\mathbf{R}, \mathbf{y}$ que por faltalr los plurales en el Abipon no se da lat articulacion de ese numero en Crl, que sin duda algnuna existía.

Conviene repetir la advertencia que en los prefijos $G=$ Airl.

$$
(i=R \text { Y } R=1)
$$

Esta posesivacion que parece ser favorita en Abipon es algo excepcional en Mocoví; pero el ejemplo dado por má: de un concepto nos enseña la íntima correlacion que existe entre los dos dialectos ó idiomas.

Con lo dicho, la tabla completa de posesivaciones en el Apendice, el capítulo sobre los pronombres y sus partículas, y el artículo Posesivacion, en el Arte Mocoví, podrá el estudiante de estas lenguas tener idea cabal de lo que es este mecanismo curioso y variado en los idiomas del Chaco, tipo Guaycurú. Preciosa es la obra de Dobrizhoffer, pero aquí se ha demostrado con ejemplos del P. José Brigniel, que aquella no alcanza a explicar todos los misterios de la articulacion posesivada.

No está de más consignar aquí que en ese dialecto llamado por Hervas, Mbayá, Guaycurú ó Eyiguayegi, la articulacion típica es esta:

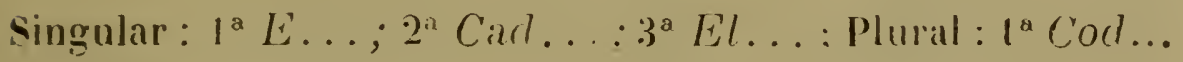




\section{CAPITULO VI}

\section{OBSERVACIONES SOBRE LA ARTICULACIÓN POSESIVA}

EN ABSOLUTO

Al primer golpe de vista llama la atencion la diferencia que se observa entre el Abipon y Mocoví, puesto que aquella lengua carece casi por completo del índice $\mathrm{C}$ de $2^{\mathrm{a}}$ persona que alterna con $\mathrm{D}$ en la posesivacion de ésta.

La clave de todas estas articulaciones se halla en el Mocoví (pág. 9). Ellas resultan de estos pronombres posesivos en absoluto :

Mocoví: Es mío, es tuyo, etc. Es mio, es nuestro. Son mios, son nuestros.

Sing. : 1a A $\mathrm{m}$.

2a Cadamî.



Plur. : la Codam.

$22^{a}$ Cadamti.
Sing. : fa Aimî.

$2^{\text {a }}$ Cadami.

$3^{a}$ Alamî.

Plur. : la Codamî.

2a Carlamtî.

La morbosidad del sonido ( $\quad$ o $K$ se ha establecido en todas estas lenguas y las ecuaciones :

$$
\text { C ó } \mathrm{K}=\mathrm{G}=\mathrm{H}=\mathrm{J}=\mathrm{S}=\text { una aspiracion }
$$

nos encuentra á cada paso, lo que no excluye la posibilidad de su reaparicion cuando exigencias de eufonía la impongan. A lo que se vé el Mocoví ha podido conservar su sonido $\mathrm{C}$ en ciertos temas posesivados mientras que el Abipon ha conver- 
lido su prefijo $\mathbf{C}$ ó $\mathbf{k}$ en (i al herir una $\mathrm{R}=\mathbf{n}$ ) (Mocovi) con b; mas como el Mocuvi no siempre conserva ileso el sonido C. $\dot{o} \mathbf{K}$, en estos se atiene á sólo la $\mathbf{~})=\mathbf{R}$ (Abipon). Lo que ha sucedido pues es esto :

ORIGEN DE LAS a RTICULACiones

Abipon

Sing. : $1^{\text {a }}(\mathrm{A})-\mathrm{i}-(\mathrm{m})$. $2 a c-(a)-(d-(a m) \cdot i$. $3^{a}(\mathrm{~A})-1-(\mathrm{a} m)$.

Plur. : fa $C_{2}-(0)-(1-(a m)$. $22^{a} C \cdot(a)-(d \cdot(a m t)-i i$.
Mo:ovi

Sing. : $1^{a}(\lambda)-i-(m)$. 2a $C-($ a) $v \cdot 1 \mathrm{D}-(\mathrm{am})-\mathrm{i}$. $3^{a}(\mathrm{~A})-\mathrm{I}-($ a $\mathrm{aI})$.

Plur. : $f^{\text {a }} \mathrm{A}-\mathrm{R}-\mathrm{D}$ (am). $2 a+R-D-(a n t) \cdot i$.

Resulta, pues, que mientras el Abipon se quedó con Cad mediante una sincopacion, $C d$, que por razones foneticas se trocó en $G r$, el Mocoví optó por dos formas; en la una hacia entrar el indice $\mathrm{C}$, en la otra el indice D, reuniéndulos recien en el plural bajo la forma sincopada $I i d$. que las mas de las reces por razun de eufonía se muda a la otra $A$ rd.

De que la $\mathrm{K}$ se muda a $\mathrm{G}$ al herir una $\mathrm{R}=\mathrm{D}$ ) se ve en esta expresion $F^{\circ}$ Dios ( $=\mathrm{G}$ Rios) à Dios, en que G es la preposicion nuestra à ó para; de suerte que cuando el Abipon usa la combinación had, forzosamente la convierte en Gr, que equivale a $R d$ Mocoví. Sin duda por esto es yue muchos plurales y segundas personas, en la poseri iacion mudan á $R$ sonidos que arrancau de una $\mathrm{K}$ ó $\mathrm{C}=\mathbf{G}$.

En resumidas cuentas, el Abipon, no nos ofrece ejomplos de la posesivación de segunda persuna ron $\mathrm{C}$, porque en lugar de furmar unos temas con preliju D y otros con C, en todos estos casos usa el pretijo dnble $G R$, que representa una combinacion de la $C$ con la $D$, es decir que se sirve de uno y otro índice á la vez.

Casi no hay anoniclía en las articulaciones que no encuen- 
tre su explicación en esta tabla de pronombres posesivos en absoluto que se da arriba. Allí se ve la razon por qué se puede introducir un afijo A cuando la $\epsilon$ fonía así lo exigiere antes ó despues de los índices de persuna.

Esa $m$ que no falta en ninguno de ios ejemplos que cita Tavolini trae á la memoria el $m i$ (es. está, hay) del Quíchua; porque es de advertir que el autor citado da frases completas. Si fuese ésta una analogía aislada, podríamos dejarla del lado; pero es el casoque son muchas, como se ha hecho notar ya en éste y en otros estudios. Por otra parte, es muy ajustado á experiencia, que en los pronombres se conserven rastros de abolengos lingüísticos perdidos ya en lo demás del idioma ; por ejemplo: el subfijo oa hace plural de pronombres pero no así de otros temas.

Para la tabla completa de Posesivaciones, véase el Apéndice $\mathbf{A}$ al fin del Arte.

\section{GAPITULO VII}

DEL DIMINUTIVO

Los diminutivos se forman, dice Dobrizhoffer, con los subfijos Avalk, Aole ú Olek, ex. gr.:

Ahepegak, caballo.

Oénék, muchacho.

Huáye, muchacha.

Pay', parre de misa.

Káëpak, palo.
A hëpegeraválk, caballito. Oénékacalk, murhachito. Haayáole, muchachita.

Payolek, padrecito.

Kaeperáole, rosario (palitos).

En este último ejemplo, que dice palitos, se ve cómo en plural se usa la terminacion de femenino. 
En Mocoví se usa tambien la terminacion olek de masculino, olé de femenino y plural. L.o propio puede decirse del Toba.

Como Ios demas indios, son muy amigos de emplear diminutivos, y hasta le dan el valor de un superlativo. Igual cosa sucede entre nositros criando decimos buenito para expresar que lo es en sumo grado.

\section{CiApl'TULO VIII}

UEL A DJETLVO

El adjetivo precede al sustantivo. Ex. gr. : Naaye graegaeca. malas (nuestras) costumbres (Pater Noster, Brigniel).

GOMPARACION

Para expresar que el tigre es peor que el perro hacen uso de este rodeo:

Nétegink chik naà, oagan nihirenak la naà. El perro no malo, pero tigre ya malo.

De otro modo:

Netegink chi chi naá, yágám dihirenak. El perro no no malo, como el tigre.

El superlativo se perifrasea de varios modos:

Nihirenak lamerpeëàoge kenoàoge nà̀.

El tigre más allá de todas cosas malo. 
0 así :

$$
\begin{array}{ccc}
\text { Nihirenak } & \text { chit keoà naà. } \\
\text { El tigre } & \text { no hay mala. }
\end{array}
$$

i.e. : Que el tigre no hay cosa peor.

En el Vocabulario de Brigniel hallo este ejemplo :

$$
\begin{gathered}
\text { Lam yalanc quenà, quirijà lajoà. } \\
\text { Mas derecho (es) este, que ese otro. }
\end{gathered}
$$

De aquí se ve que no es imposible expresar este pensamientı en Abipon como en romance: tienen ellos el Lam ó Nam (mas), lo demás es fácil. Verdad es que nada tiene de superior al otro modo de decir: Esto derecho, aquello no derecho.

Tambien significan el grado de comparación segun la intensidad de la voz. Esto mismo acostumbra la gente en Catamarca, ex. gr., cuando dicen lejos: la distancia se regulará segun la duracion que se dé á la primera sílaba.

\section{CAPITULO IX}

DE LOS NUMERALES, ETG.

Los Abipones sólo cuentan hasta tres:

1. Iñitara, uno (este solo).

2. Iroaka, dus (uno en plural).

3. Iñoaka yekaini, tres

4. Geyenk ñaté, cuatro (dedos de Surí). 
Neenhalek, cinco (piel de s. colores).

5. Hanámhegem, cinco (dedos de una mano)

10. Lanám rihegem, diez (dedos de dos manos).

20. Lanamrihegem cat gracherhaka anamichirihegem, veinte (todos los dedos de pies y manos).

\section{CAPITULO $\mathrm{X}$}

DE LOS PRONOMBRES

Los primitivos son:

Sing. : 1 Aym, Yo.

2a Akamí, Tú.

Mocovi

Sing. : 1' Aim, Yo.

2a Accami, Tú.

Plur. : fa Occom, Nosotros.

2 a Accami, Vosotros.
Plur. : 1a Akâm' $\left({ }^{*}\right)$, Nosotros. 2a Akamyí, Vosotros.

Toba

Sing. : 1a Ayin ó Ayem, Yo.

2a Akam ó Ham, Tú.

Plur. : $1^{2}$ Comi, Nosotros.

2a Cami, Vosotros.

En mi tratado sobre el Mocoví se verála tabla completa de estos pronombres en todos los idiomas afines.

El pronombre de tercera persona varía segun el modo de estar de la persona á que se refiere.

\section{El}

Presente......... Eneha

Sentado............ Hiñiha

Acostado.......... Hiriha
Ella

Anahá

Hañiha

Háriha

(1) M' es $m$ con acento. 


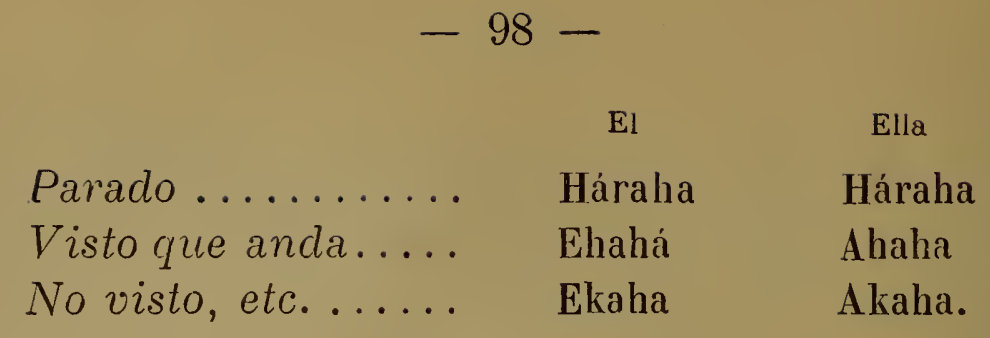

Lástima es que no se da la forma del plural; pero en Brigniel hallamos esto:

$$
\begin{aligned}
& \text { Enajá, Este } \\
& \text { Enoujá, Estos } \\
& \text { Ennoássó, en Mocoví. }
\end{aligned}
$$

Es decir, pues, que el infijo ou =oa es la partícula de pluralidad en estos casos. Dadas las equivalencias fonéticas puede reducirse á un va, ba ó pa.

Todos estos pronombres son susceptibles de recibir el subfijo tará, ó tára, solo, ex. gr.:

Aymatára, Yo solo

Akamitará, Tú solo

Akam ákalé, Nosotros solos.

(De esta variante nada observa Dobrizhoffer.)

Inítarà, Él solo, sentado.

Iritara (así), Él solo, acostado.

Echátára (asi), El solo, andando.

Ekàtará, Él solo, ausente.

Eràtàra (así), Él solo, parado. 


\section{CAPITLLO MI}

DEL CASO REGIMEX HE LOS PRONOMBRES

Lo que suele llamarse transicion en la flexion verbal de las lenguas indias se expresa en Abipon, como en tantas otras, por medio de unos afijos y partículas allegadizas muy curiosas.

Tomemos el verbo Ricapit (amo) en que Capit es la raíz, y $R i$ el prefijo de primera persona. Si queremos decir yo te amo, se modilicaría el tema Ricapit así: Rikapichieroá, que se descompone como sigue: $P i$, yo; kapit, querer ; ch, chicheo de $t$ al herir una $i$; ieroà, te, caso régimen.

Eu esta combinacion los casos régimen (subfijos) son:

$1^{a}$ Me, ... ioa. Mocoví ivà.

$2^{\text {a }}$ Te, ...ieroa. Mocoví arvá.

$3^{a}$ I.o, ... aé. Mocoví ló.

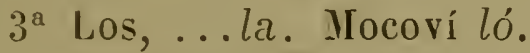

$1^{a}$ I mi mismo, matni...alta. Mocoví altá.

$2^{\text {a }}$ A tí mismo, ni...alta. Mocoví âltá.

$3^{\text {a }}$ Se, á sí mismo, ...áatá.

La segunda serie es esta (subfijos):

$1^{\text {a }}$ Me, ...iigé.

$2^{a}$ Te, ... yegarigé $\left(^{1}\right)$.

$3^{\mathrm{a}}$ Lo, ...egé ó gé.

$1^{\text {a }}$ Nos, ... yegarik.

Unos à otros, ...etaá.

$1^{a}, 2^{a}, 3^{a}$ llismo, ...altáa.

(1) En Brigniel está Lanichuinigargui, ya te conozco. 
La tercera serie (prefijos) es esta :

$$
\begin{aligned}
& 1^{\mathrm{a}} \mathrm{Me}, \mathrm{Né} \ldots \quad \text { Yo me. } \\
& \left.1^{\mathrm{a}} \mathrm{Me}, R i \ldots \text { Tú me. }\right\} \text { Moc. Di. } \\
& 1^{\text {a }} \mathrm{Me}, R i \ldots \quad \text { Él me. } \\
& 1^{\text {a }} \text { Nos, ...etá. Unos á otros. }
\end{aligned}
$$

La cuarta serie (subfijos) es ésta :

$$
\begin{aligned}
& 1^{\text {a }} \text { Мe }, \ldots i i . \text { Moc. ...i } \\
& 2^{\text {a }} \text { Te }, \ldots \text { r'ari. Moc. ....arrî. }
\end{aligned}
$$

\section{CAPITULO XII}

\section{DE LOS POSESIVOS}

Cuando se pregunta á quien pertenece cualquier cosa, en Abipon hay que distinguir entre lo que tiene vida (animal ó vegetal) y lo que carece de ella.

Si se trata de ser animal ó vegetal la pregunta se hace así :

$$
\text { ¿Cahami lelá? ¿De quién es esto? }
$$

y la contestacion que corresponde será ésta:

$$
\text { Ilá, mío; Grelé, tuyo; Lelá, suyo ; }
$$

mas si la cosa es sin vida se dice:

$$
\text { ¿Kahami kalam? ¿De quién es esto?. }
$$

y se responde: 
Aim', mio; karami, tuyo; halam, suyo;

karam', nuestro, etc.

En Mocoví tenemos una forma muy parecida:

Aim, mio; Cadami, tuyo; Al-lam, suyo.

Codam, nuestro; Cadamti, vuestro.

De las partículas ó afijos de posesivacion ya se ha tratado en los capítulos V y VI.

\section{CAPITULO XIII}

DE LOS RELATIVOS

El relativo en Abipon se expresa con la voz Eknam; plural Enonam. Ex. gr.:

Dios, eknam Kaogarik.

Dios, el que es Criador.

Hemokáchin nauáchieká, enonam Yapochi.

Estimo los soldados, los que (son) valientes.

Puede suplirse el relativo con un participio ó adjetivo, ex. gr.:

Riákayá netegingá oakaika, kach quenó ahamr'aeka Aborrezco los perros que muerden, y álos que son muertos. 


\section{CapITUlo XIV}

\section{DEL VERBO}

El mecanismo de la conjugacion Abipona es, como en Mocoví, Toba, etc., de lo más complicado. Adelung no da sino una idea remota de ella y lo que nos cuenta Dobrizhoffer es incompleto. Recien después de cotejar lo que consigna este. autor en su De Abiponibus con lo que se conserva en los manuscritos del Padre Brigniel es que nos podemos formar una idea cabal de la flexion verbal de esta interesante lengua y de su perfecta concordancia con las formas análogas del Mocoví.

Por varios motivos es conveniente arrancar de lo que al respecto nos dice Dobrizhoffer, que por fuerza tiene que ser la base de todo estudio sobre este idioma; por otra parte, es tan corto que bien merece que se reproduzca, dada su idoneidad para las comparaciones posteriores.

Como se verá, las conjugaciones se clasifican por su importancia numérica, y desde luego no corresponden en su órden al de las Mocovíes; pero hasta esto mismo puede ser materia de observacion á su tiempo, desde que á ello responde esa preferencia de una serie de afijos á otra, segun el idioma.

En Mocoví la serie favorita de partículas es :

$$
1^{\mathrm{a}} S \ldots\left(^{1}\right) ; 2^{\mathrm{a}} \ldots i ; 3^{\mathrm{a}} Y \ldots \text {; }
$$

en Abipon lo es esta otra $\left(\begin{array}{l}2 \\ : .\end{array}\right)$ :

$$
1^{\mathrm{a}} \operatorname{Ri} \ldots ; 2^{\mathrm{a}} G r \ldots i ; 3^{\mathrm{a}} N \ldots \text {, }
$$

(1) Los puntos suspensivos indican raíz ó tema.

$\left({ }^{2}\right)$ Segun Dobrizhoffer. 
que correspoude al Mocovi :

$$
1^{a} \text { Di...; } 2^{n} D \ldots i: 3^{n} \quad \Lambda \ldots
$$

\section{PRIMERA SÉRIE}

\section{Articulacion}

Sing.: 1 $^{a} R i \ldots ; 2^{a} G r \ldots i ; 3^{a} N \ldots$

Plur.: $1^{a} G r \ldots a k ; 2^{a} G r \ldots i i ; 3^{a} N \ldots e ́$.

\section{Ejemplo :}

\section{Amar.}

Sing. : Ia Ri-kapit. 23 Gr-kapich-i. $3^{\text {a }} \mathrm{N}$-kapit.
Plur. : la Gr-kapit-ak. 2a Gr-kapich-ii. 3a N-kapit-é.

Nota. - El cambio de $t$ en ch resulta del chicheo de la $t$ por contacto con la $i$.

Esta conjugacion corresponde á la reforzada con $\mathrm{D}$ del Mocoví, clase II. (Ver Mocovi, pág. CLxvı).

$$
1^{\mathrm{a}} \text { Di...; } 2^{\mathrm{a}} D \ldots i ; 3^{\mathrm{a}} N \ldots
$$

Otros ejemplos de Dobrizhoffer :

II. Temer

1 a Ri-etachá. 2a Gr-etach-i. $3^{\text {a }}$ N-etacha.
III. Desear

1 a $R(i) \cdot$ ihé. 2a Gr-ih-í. $3^{a}$ N-ihé.

Brigniel: Gr-etechiyam, habeis Brigniel : Grija naic, deseo code ser temerosos.

Mocoví : Di-octió, con temor. Mocoví: D(i)-issi-á, con deseo.

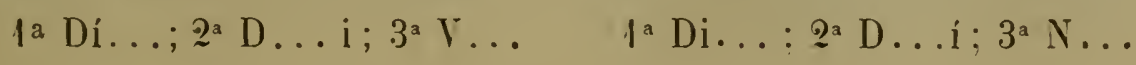


IV. Vomilar

1a Ri-emale-tapék.

2a Gr-emal-i-tapék.

$3^{\text {a }}$ N-emale-tapék.

Tapek equivale á nuestro gerundio en endo, ando.

VI. Obedecer

1 a Ri-ahepét.

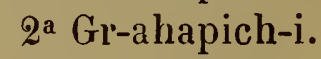

$3^{\text {a }} \mathrm{N}$-ahapét.
V. Estar abochornado

1a Ri-pagák.

2a Gr-pagak-é.

$3^{\text {a }} \mathrm{N}$-pagak.

Brigniel : Gri-pagyác, yo tengo vergüenza.

VII. Tener pereza

1 a Ri-aál. 2a.Gr-aal-i. $3^{\mathrm{a}} \mathrm{N}$-aal.

Por desgracia, la serie de los verbos en el manuscrito de Brigniel es incompleta, y, como se verá despues, la importancia que aquítiene esta conjugacion no le corresponde en realidad. Con excepcion de dos, los temas estos faltan en el Vocabulario (Brigniel); he aquí lo que hallo en éste :

Ama él : Er-capitá

Amala : Er-capich-i

Quiero: $\operatorname{Gr} r(i)$-igé

Quieres: Gr-igié

Quereis: Gr-igiye

¿Quiéres? ¿ Marigichi?

En este último ejemplo el prefijo $M a$ es de interrogacion, y el infijo ch es por chicheo de la partícula auxiliar te á que hace referencia Dobrizhoffer, y que no altera el valor del tema verbal.

Brigniel confundía $G r i$ con $R i$ de primera persona: sin duda así le sonaría á él, á veces; y la verdad es que la lógica de los respectivos fonetismos exige que sea Gri, más bien que $R i$; porque $d$ Mocoví, como aumento pronominal, corresponde á $g r$ del Abipon. 
SEGUXDA SERIE

Articulacion

Singular: $1^{a}$ Ri...; $2^{\star} G r \ldots i ; 3^{*} Y \ldots$ Falta el plural.

Ejemplos :

\section{Conocer}

Is Ri-araigé.

Qa Graraigé.

$3^{\text {a }} \mathrm{Y}$-araigé.

En Brignel esta : $1^{\text {a }}$ Arem, sé; 2a Ariñi, sabes; Aariñam, sabreis.

Mocoví : Saden, con.

1a $S \ldots ;$ ?a $\ldots i ; 3^{\mathrm{a}} Y \ldots$

En transiciones :

Pedro Diaden, Pedro me conoce.

"Dadini, Pedro te conoce.

¿ Yaden, Pedro lo conoce.

El modo transitivo de conjugar este rerbo corresponde exactamente al ejemplo de arriba, y no es imposible que Dobrizhoffer haya estado tras cordado.

\section{Apresurarse}

Ia Ri-hahagalgé.

2a Gr-ahalgali.

$3^{a}$ Y-ahágalgé.

En Brigniel está : Abreviar con Aim, etc.
Sing. : I Ajalalachi.

2a Ajalalachichi.

$3^{\text {a }}$ Yajalalachi.

Plur. : fa $\mathrm{Gr}$-ajalalàchi. 2a Griajala!âchichi. $3^{\text {a }}$ Y-alachite.

El enredo de letras es curioso, pero parece que se trata de raíces idénticas.

III. Morirse

1. Ri agá

2a Gl'egachí.

$3^{a}$ I-igá.

Brigniel da : Ya murió, Luigá;

Murais, Gregachi.

En Mocoví, Morir :

fa Di el-leu.

$2^{a}$ D-il-livii.

$3^{\text {a }}$ Y-el-leu.

La arliculacion es la misma, las raíces diferentes.

IV. Ahogarse

1 a Ri-igarañi.

2a Gr-egachañi.

$3^{a}$ Y-garañi. 
Brigniel da : Yo ahogo, Egar- Brigniel : Yhout, fuerte. gatañi. Ahogarse :

$1^{a}$ Gri-garañi.

VI. Estar sano

2a Gr-agach-añi.

$3^{\text {a }}$ Y-garañi.

1 a Ri-oamkatá.

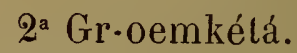

Aquí se ve que ri de $1^{\text {a }}$ persona era lo mismo que gri para este autor.

$A \tilde{n} i$ es complemento de tema, no de raíz, por eso se infija la $i$ de $2^{\text {a }}$ que de $r$ hace ch.
V. Esiar fuerte
$1{ }^{\text {a }} \mathrm{Ri}$-ahot.
2a Gr-ihochi.
$3^{\text {a }}$ Y-hot.
Brigniel : Grí-oancatañi,pronto estoy.

VIl. Avaluar

fa Ri-apategé.

2a Gr-pachiigé.

$3^{\text {a }} \mathrm{Y}$-apategé.

Este es el último de esta série.

\section{TERCERA SÉRIE}

Articulacion

Singular: $1^{\mathrm{a}} R i \ldots ; 2^{\mathrm{a}} R \ldots i ; 3^{\mathrm{a}} R \ldots$ Falta el plural.

Ejemplo único:

Saltar

Abipon

Mocovi

1 a Ri-ahat.

2a Rahachi.

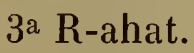

a $\mathrm{Y}$-assot.

2a D-assoct-i.

$3^{a}$ L-assot.

Este ejemplo es de suma importancia para establecer las ecuaciones :

$$
1^{\mathrm{a}} \mathrm{R}=\mathrm{D} ; 2^{\mathrm{a}} \mathbf{R}=\mathrm{L}
$$


Lo curioso es que en Mocoví se usa tambien la serie:

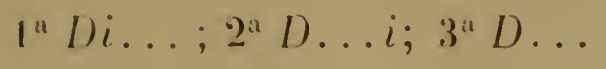

CUAlTA SÉRIE

Articulaciones

Singular: $1^{a} H \ldots ; 2^{a} H \ldots i ; 3^{a} Y \ldots$

Esta corresponde á la conjugacion típica del MIocoví:

$$
\text { I } S \ldots: 2^{a} \ldots i ; 3^{a} Y \ldots \text {. }
$$

mediante la sibilación de la primera $\mathrm{H}$ y desaparicion de la segunda. Véase: Fonología Mocovi.

Ejemplos :

\section{Enseñar}

1a Hápagr'anatr'an.

Эà Hapagr'anatr'añi.

$3^{3}$ Yapagr'anatr'an.

En Brigniel : Enséñame, Griapagañi.

En Mocoví : Sapparinactagan, con esta articulacion :

1a $S \ldots ; 2^{\mathrm{a}} \ldots$ i ; $3^{\mathrm{a}} \mathrm{D} \ldots$

II. Apuntar al blanco

$1^{\text {a }}$ Hatenetalgé.

2a Hachinitalge.

$3^{2}$ Yatenetalge.

En Brigniel : Apunto con fle- cha, Ñaten. La raíz es Aten, por eso se infija la $i$ de l $^{\text {a }}$ persona que asimila la $e$ anterior.

III. Recordar

$1^{\text {a }}$ Hacaleent.

2a Hacaleénchi.

3a Yacaleént.

Brigniel con .tim etc. :

1a Acalenetan.

2a Acalenetañi.

$3^{a}$ Acalenetan.

La anomalía que se nota en la falta de la $Y$ inicial aún está por explicarse. 


IV. Hacer
$1^{\text {a }}$ Haét.
$2^{a}$ Eichí.
$3^{a}$ Yaet.

Brigniel da :

1a Aoe.

2a Aoee.

$3^{\text {a }}$ Aoe.
En Mocoví :

$1^{\text {a }}$ S'oet.

2. Oictí.

$3^{\text {a }}$ Yoet.

$$
\text { V. Azotar }
$$

1a Hamelk.

2a Hamelgí.

$3^{a}$ Yamélk.

Brigniel : Namílgánát, azote.

\section{QUINTA SÉRIE}

Articulacion

Singular : $1^{\text {a }} H \ldots ; 2^{\mathrm{a}} H \ldots i ; 3^{\mathrm{a}} R \ldots$ Falta el plural.

\section{Ejemplos :}

\section{Dar coces}

1a Hachák. 2a Hachar'é. $3^{\text {a }}$ Rachak.

En Brigniel, Cocear :

Sing. : $1^{\text {a }}$ Achac.

$2^{a}$ Achague.

$3^{a}$ Yachac.

Plur. : 1a Acagac.

2a Achaguí.

$3^{a}$ Yachaga.

Como se ve, segun Brigniel, corresponde este verbo á la $4^{a}$ serie.

II. Comer

1 a Hakeñe. 2a Kinigí.

$3^{a}$ Rkeñe.

En Brigniel : Lajaquiñica, $v a$ mos á comer. Maquiini? ¿has comido?

Moc. : $1^{\text {a }}$ S-quee. $2^{a}$ quii. $3^{\text {a }}$ Lquée.

Las articulaciones son idénticas mediante la ecuación $\mathrm{R}=\mathrm{L}$.

III. Dormir

la Aaté.

2a Aachi.

$3^{a}$ Roaté.

En Brigniel : Aachii, duerme. 
SIXTA SÉRIE

Articulacion

Sing : $1^{a} R \ldots ; 2^{a} G r \ldots i 3^{a} L \ldots$ Falta el plural.

Ejemplo :

\section{Borracho estar.}

Abipon

Mocuri

a Rkihoget.

2a Grkihogichi.

$3^{\text {a }}$ Lkilıget.

La raiz $k i$ les es comun á los dos ejemplos nieel es beber, en ambas lenguas.

Sıng. : 1a Quinniequéte. 2a Quinniect.

$3^{\mathrm{a}}$ Quinniaguéut.

Plur. : 1a Aruinniagueut.

2a Aruinniectiu.

$3^{\text {a }}$ Quinniectó.

En Brigniel : Niichi, bebe tú.

La anomalía de esta $\mathrm{L}$ de tercera persona tal vez deba explicarse mediante la ecuación $\mathrm{L}=\mathrm{Y}$; en cuyo caso esta conjugacion correspondería á la Clase III, con refuerzo D del Mocoví :

$$
1^{\mathrm{a}} D \ldots ; 2^{\mathrm{a}} D \ldots i ; 3^{\mathrm{a}} Y \ldots
$$

SÉPTIMA SÉRIE

Articulacion

Sing.: $1^{\text {a }} \tilde{N}(=N i) \ldots ; 2^{\text {a }} N \ldots i ; 3^{\text {a }} N \ldots$ Falta el plural.

I. Acordarse

fa Netúnetá.

2a Nichuñiitá

\section{$3^{a}$ Netunetá.}

En Brigniel :

Sing. : 1a Ñieteui. 
2a Nichiuiñi.

$3^{a}$ Netui.

Plur. : $1^{a}$ Neteunc.

2 a Nichiiun yi.

3. Ñeteune.

II. Beber

$1^{\text {a }}$ Ñañam.

2a Nañami (Ñ ?).

$3^{\text {a Nañam. }}$

En Brigniel : Niichi, bebe tú.

Mocovi

Sing. : fa Nieet.

$2^{\text {a }}$ Nictii (sing.y plur.).

$3^{\text {a }}$ Neet.

Plur. : 1a Niectácca.

3a Neecté.

III. Volar

$1^{\text {a }}$ Natahegem ( $\tilde{N}$ ?) 2a Natachihegem.

$3^{\text {a Natahegem. }}$.

En Brigniel: Eetapec,Fugitivo.

Mocovi (Huir).

1 a Aim Es-et.

$2^{\mathrm{a}}-》$ iichi.

$3^{a}-»$ eet.

IV. Venir

$1^{a}$ Ñaué.

$2^{a}$ Nauichí,

3a Naué.

En Brigniel : Lanegue main, ven conmigo.

Mocovi

1 a Sannák.

$2^{\mathrm{a}}$ aqquii.

$3^{a}$ anıák.

\section{GAPITULO XV}

SIGUE EL VERBO

Hasta aquí los verbos de Dobrizhoffer. Ni él, ni ninguno de los que han dejado algo escrito sobre la materia, acertaron á clasificar los verbos por conjugaciones segun sus afijos personales de flexion, y la tabla que da el Padre Misionero no tenía otro objeto que hacer conocer la variedad de estas partículas. Por cierto que le faltó mucho para enterar la cuenta de esa misma variedad que él invoca ; así que si sólo contásemos con el material que él nos ha reunido no se hubiese podido completar la clasificacion. Gracias á los manuscritos del 
P. Brigniel y a lo que por analogia colegimos del trabajo del P. Tarolimi,hoy mos hallamos en el caso de poder reducir el Abipon y Mocoví a reglas como hicieron los Padres de la Compañia yotros con las lenguas de los Chiquitos, idiomas igualmente enmaranados en su mecanismo de posesivacion y llexion verbil.

Al tratar de los verbos que nos conserva Brigniel volveré sobre este punto. Mhora conviene reproducir lo que Dobrizhoffer nos cuenta de la conjugacion en general por sus Modos y 'liempos.

MODO INDICATIVO

El Presente ya lo hemos visto.

Pretérito

Amé : Rikapit kan ó kanigra.

Pluscuamperfecto

Había amado: kanigra gehe rikapitó Rikapit kanigra gehe; porque de los dos modos lo escribe Dobrizhoffer.

Futuro

Para este tiempo se subfija la partícula am, el $\delta$ del Mocoví, así: Grkapichiam: amarás.

IYPERATIVO

La segunda persona de presente ó de futuro sirve de imperativo, así :

Eichi: Haz.

Grkapichiam: amarás.

A reces se prefija la partícula $T a c h$ para segunda y $T a k$ para tercera persoua, ex. gr. : 
Tach grahàpichi: obedece.

Tach grakatrani: di.

Tak hanek: que venga.

La negacion se hace con futuro y Tchik ó Chige inicial, así:

Chit kahamatrañiam: no matarás.

Chit noaharegraniam: no mentirás.

Todos estos ejemplos están también en Brigniel con la correspondiente diferencia fonética; lo que prueba que este manuscrito, sea ó no del autor á quien se lo atribuyo, no era el original que le sirviera á Dobrizhoffer.

\section{OPTATIVo $\quad \mathrm{Y}$ SUBJUNTIVO}

Estos modos y tiempos se forman con ciertos afijos que pueden ser iniciales, ó finales.

Chigriek: ojalá; ex. gr. : Chigriek grkapichi G'Dios, eknam kdogarik: ojalá amases á Dios el que es Criador.

Kët (si) que corresponde al Quet Mocoví, y que puede ser inicial o final; ex. gr. : Kët greenr'ani, G'Dios grkapichi kët: si fueses bueno á Dios amarías.

Amla, despues que; Om y Oma en Mocoví, ex. gr.: Amla grapichi g'Dios, Dios lo nkapichier'oàm: despues que hayas amado á Dios, Dios te lo amará á tí.

Ehenhà, donec, hasta que, mientras que; ex. gr.: Ehenhà na chigrkapichi g'Dios, Chit gihé groamketapekam: mientras no quieras á Dios nunca te hallarás tranquilo.

Amamach: cuando, eso que; ex. gr.: Amamach rikapichier'oa lo grkà pichioam: cuando me quieras yo te lo querré.

Kët mat (si); ex. gr.: Kët mat nkapichirioà, la rikapitlo kët: si me amasen yo los querría. 
Tach, para que; ex. gr.: Tach grkapichoa, rikapichier'oam: Amame, yo te amaré. Así estí en Dobrizhoffer; pero se ve que el Tach no es más que el refuerzo de imperativo.

MODO INFINITIVO

Cuando nosotros ponemos un verbo despues de otro en infinitivo los $A$ bipones rigen á éste con la partícula $m^{\prime}$ prefijada, ex. gr.:

$$
\begin{aligned}
& \text { Là rihete m'hakéñe } \\
& \text { Ya quiero comer. }
\end{aligned}
$$

donde el hakéñe está tambien en primera persona del presente de indicativo ; tambien :

\section{Haoahen m'ahik.}

No puedo ir.

Locuciones que suplen al Infinitivo, Supinos y Gerundios. En lugar de decir Puedo ir, expresan la idea así:

\section{Lahikam. Chigeeka Loaik. \\ Ya iré. No hay dificultad.}

ó ¿Mañigà loaik? ¿Hay dificultad?

Yoamkatà kët lame

Justo es si ya vas (debes ir).

Mich grehech miame. ¿Acaso quieres irte?

vel Oagan chik yoamk.

Aunque no es justo (no debes ir).

En lugar de decir: “¿Qué bien sabe nadar este hombrel» 
el Abipon se expresa así: "iQué nadador es este hombrels Kemen alar'ankachak yóale.

VOZ PASIVA

No la conocen y á nuestras oraciones de pasiva ellos las expresan por activa. Cuando algo se ha muerto ó perdido dicen ellos que la cosa ha perecido así:

Yúihak oaloà: el buey pareció.

Yúihak chitlgihe: el buey ya no aparece.

Chigat yaraigé: no sabe, por: no se sabe.

Chigat yaik: no (lo?) come, por: no se come.

Chigat eigà: no (lo?) toca, por: no se toca.

Machka chigat nkehayape enó ahëpega, maoge oaloéra: porque no cuido los caballos, por eso desaparecieron, por : no fueron cuidados.

Chigichiekil nakatñi eer'gr'ae: No hay cuente las estrellas, por las estrellas son innumerables.

Am chigat yaraige, chigichiekal yaratapekam : cuando no sabe no hay lo contará, por: cuando no se sabe no debe contarse.

PARTiCipios

Estos se forman así y pueden posesivarse:

De Rikapit: Yo amo.

Masculino

1a Ykapicher'at, mi amado.

2a Grkapicher'achi, tu amado.

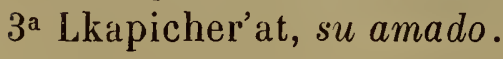

Femenino

1 a Ykapichkaté, mi amada. 2a Grkapichkachi, tu amada. 3a Lkapichkaté, su amada.

Lkapicheraté kenuaraoge: yo soy querido por todos.

Kapicher'a: amor; Ykapicher'a: mi amor; Kapichier'aik: el que ama, amante. 
De Rikáuagé: Yo compadezco.

Ykáuagrat: compadecido por mí.

Ykáuagr'a: mi compasion.

Kauagrankachac: compasivo.

Yhaúaget: compadecido por mí.

Grkauagigi: compadecido por tí, etc.

Kauagrankate: instrumento, modo, lugar de la compasion; la compasion misma.

De Hapagr'anatr'an: Enseño.

Napagr'anatr'ak: el que enseña, maestrọ.

Napagr'anaték: el que es enseñado, discípulo.

Napagr'anatr'anr'ek: enseñanza, lección.

Napagr'anatr'ankaté: la anterior que á otro se enseña, escuela, etc.

\section{CAPITULO XVI}

DE LOS VERBOS SEGUN BRIGNIEL

Ya hemos visto lo que dice Dobrizhoffer á propósito de los verbos. Este autor nos indica algunas reglas y nos da sus ejemplos; mas ello no puede considerarse el arte completo de la lengua Abipona, ya que sabemos lo que han dejado escrito los Padres Brigniel y Tavolini, éste de la Orden de San Francisco.

Brigniel, al fin de su Vocabulario, agrega una serie de verbos con su flexion completa, hasta donde él creyó necesario completarla y de allí se ha compulsado lo que va en seguida.

Como en todos los casos en las lenguas del Chaco de este 
tipo, los grupos y clases de verbos se arreglan segun su importancia numérica, y á primera vista se verá que esta clasificacion concuerda muy bien con lo que se ha observado en el Mocoví.

Para mayor claridad sólo se dará un ejemplo de cada tipo, reservando para un cuadro al fin la tabla completa de los verbos con sus notas y observaciones.

\section{GRUPOS Y CLASES}

En Abipon, como en Mocoví, los verbos, en sus conjugaciones, fácilmente se dividen en dos grandes grıpos : el uno sin refuerzo, el otro con él. Cada grupo de éstos se divide en clases y subclases.

$1^{\text {er }}$ Grupo. Sin refuerzo

CLASE $1^{\text {a }}$

Articulacion típica

Singular: $1^{\mathrm{a}}(A, E$ ó $Y) \ldots ; 2^{\mathrm{a}}(A, E$ ó $Y) \ldots i ; 3^{\mathrm{a}} Y \ldots$ Plural: $1^{\mathrm{a}} A, E$ ó $\left.Y\right) \ldots c a ; 2^{\mathrm{a}}(A E$ ó $Y) \ldots i i ; 3^{\mathrm{a}} Y \ldots e$.

\section{En Mocoví :}

$$
\begin{aligned}
& \text { Singular: } 1^{\text {a }} S \ldots ; 2^{\text {a }} \ldots i ; 3^{\text {a }} Y \ldots \\
& \text { Plural: } 1^{a} \text { S...́ácca; } 2^{a} \ldots i i ; 3^{a} Y \ldots e ́ \text {. }
\end{aligned}
$$

Nota. - La articulacion es idéntica en ambos casos dadas las ecuaciones

$$
\mathrm{S}=\mathrm{H} \text { ó Aspiración } ; \text { Aspiracion }=\text { Aspiracion. }
$$

Ver'S y H en Fonología Mocovi. 
Ejemplo :

\section{Ablandar}
Sing. : I Aim Aligat. 2a Acami Nligachi. $3^{n}$ Eroja Yaaligat.
Plur. : Ia Acam Aaligatca. $2^{\mathrm{a}}$ Acamii Aaligatchii. $3^{\mathrm{a}}$ Erouja Yaaligáte.

CLASE $2^{\circ}$

\section{Articulacion típica}

La misma de la anterior sólo que la $\mathbf{Y}$ de la tercera persona se sustituye con $\mathrm{R}$ ó GR, á veces con algun prefijo vocal, sin duda por eufonía.

En Mocoví la clasificacion es la misma, sólo que hallamos D por GR, como era de esperarse.

Ejemplo:

\section{Llorar}

Sing. : $1^{\text {a }}$ Eoca. 2a Eogai. $3^{\text {a Greoga }}$
Plur. : la Eogai.

$2^{a}$ Eogaii.

$3^{\mathrm{a}}$ Greoagai.

De esta clase tenemos unos seis verbos, dos de los cuales corresponden en tema y articulacion á los ejemplos Mocovíes. Véase la tabla completa de los verbos, al fin, Apéndice B.

CLASE $3^{\mathrm{a}}$

Articulacion tipica

Singular: $1^{\text {a }} A$ (ó nada) $\ldots ; 2^{\mathrm{a}} \ldots i ; 3^{\mathrm{a}} \ldots$

Plural: $1^{\text {a }} A$ (ó nada) $\ldots i ; 2^{\mathrm{a}} \ldots i i ; 3^{\mathrm{a}} \ldots$ é ó te. 
En Mocoví hallamos la S de primera persona. En el Apipon el prefijo puede faltar en todas tres personas de ambos números.

Ejemplo :

\section{Abrazar}

Sing. : $1^{\text {a }}$ Acaalgue.

2 a caaligue.

$3^{a}$ calgue.

Plur. : Ia Acaalegue.

$2^{a}$ caaligue.

$3^{\mathrm{a}}$ caaltegue.

La raíz es Caal y con gue se forma tema compuesto, por eso se infijan los subfijos.

Brigniel consigna unos 17 verbos que pueden incluirse en esta clase.

CLASE $4^{\mathrm{a}}$

Articulacion típica

Singular: $1^{\mathrm{a}} A j a \ldots ; 2^{\mathrm{a}} A \ldots i ; 3^{\circ} Y \ldots$

Plural: $1^{\mathrm{a}} A j a . . . a ; 2^{\mathrm{a}} A \ldots y i ; 3^{\mathrm{a}} Y \ldots r i$.

En Mocoví:

Singular : $1^{\text {a }} A s \ldots ; 2^{\mathrm{a}} O \ldots i ; 3^{\mathrm{a}} \quad Y \ldots$

Plural: $1^{\mathrm{a}} A s \ldots$ acca; $2^{\mathrm{a}} O \ldots i ; 3^{\mathrm{a}} Y \ldots e ́$.

Ejemplo :

\section{Sentarse}

Sing. : 1a Ajañiguigan. Plur. : 1a Ajanaguigan.

$2^{\text {a }}$ añiguii.

2a Anyiguigan.

3a Yñiguii.

$3^{\mathrm{a}}$ Yñiriguigan.

La terminacion guigan no es más que complemento de tema. 
La ecuacion $\mathrm{A}=0$ reaparece en el Abipon s Mocoví. Siempre estoy en que esta $A, \dot{o}$ sea $O$, nace de la ecuacion siguiente :

$$
\Lambda \mathrm{M}=\mathrm{\Lambda} \mathrm{u}=\mathrm{O} \text { vel } \mathrm{\Lambda} \text {. }
$$

En Toba es frecuente el prefijo Aude segunda persona. Naturalmente, ma articulacion como ésta dele cotejarse con los prefijos prouominales del Mataco-Mataguapo: Noj, $A, L$; sobre todo si se tiene en cuenta cierta confusion de $\mathrm{I}_{4}$ con $\mathrm{Y}$ que asoma en todas partes.

Los verbos de esta clase son unos 4 ó 5, y más, si incluimos algunos de la primer'i, cuya primera persona usa el prefijo A que desaparece en la segunda.

Véase el cuadro completo de los verbos, Apéndice B.

\section{CLASE $5^{\circ}$}

\section{Articulacion típica}

Singular: 1 ${ }^{\text {a }} E J \ldots ; 2^{\text {a }} E \ldots i ; 3^{\text {a }} E Y \ldots$

Plural: $1^{\text {a }} E J \ldots ; 2^{\mathrm{a}} E \ldots y i ; 3^{\mathrm{a}} E Y \ldots r i$.

\section{En Mocoví :}

Singular: 1a $E S \ldots$; 2a $E \ldots i ; 3^{\text {a }} E Y \ldots$

Plural: $1^{\text {a }} E S \ldots$.. acca; $2^{\text {a }} E \ldots i ; 3^{a} E Y \ldots e ́$.

\section{Ejemplo :}

Alcanzar

Sing. : fa EJ-añiguigam. 2ะ E-añiguigam. $3^{\text {a }}$ EY-añiguigam.
Plur. : 1a EJ-añiguigam. 2a E-añiguigam. $3^{\text {a }}$ EY-anriguigam.

Sólo un verbo de esta clase encontramos entre los que nos 
conserva Brigniel; pero él basta para el cotejo con el Mocoví. Es curioso que ambos idiomas hayan conservado tal uniformidad en tan complicadas series de articulaciones.

Otro punto digno de ser señalado es, que el Toba no conserva estas variadas flexiones; al menos no se pueden establecer del material con que contamos. En mi concepto resulta de que el Toba es un dialecto mucho más degenerado del idioma original.

$2^{\circ}$ Grupo. Con refuerzo

CLASE $1^{a}$

Con prefijo N. - Articulacion típica

Singular: $1^{\mathrm{a}} \tilde{N} i \ldots ; 2^{\mathrm{a}} N \ldots i ; 3^{\mathrm{a}} N \ldots$

Plural: $1^{\mathrm{a}} \tilde{N} i \ldots c a ; 2^{\mathrm{a}} N \ldots i i ; 3^{\mathrm{a}} N$...e.

En Mocoví tenemos la misma serie. En Abipon se advierte que en muchos casos este prefijo se usa con temas reflexivos; pero no en todos; ex gr.: Ñiamilg, afrentar.

\section{Ablandarse}

Sing. : 1 a Niaaligat.

2a Naatigachi.

$3^{\text {a }}$ Naaligat.
Plur. : $1^{a}$ Ñiaaligatca.

2a Naaligachii.

$3^{a}$ Naaligate.

De esta clase da Brigniel unos 17 buenos ejemplos que se verán en el cuadro completo. 
CLASE $2^{*}$

Con prefijo R. - Articulacion tipica

Singular : $1^{\mathrm{a}} R$ Ri...; $2^{\mathrm{a}} R \ldots i ; 3^{\mathrm{a}} R \ldots$

Plural: Ri...(ca); $2^{a} R \ldots i i ; 3^{\mathrm{a}} R \ldots(e)$.

Falta el plural en el manuscrito.

En Mocoví la série es la misma mediante la ecuacion $\mathbf{R}=\mathbf{D}$. Ejemplo:

\section{Saltar ó bailar}

Sing. : 1a Riahat. $\quad 9^{\text {a }}$ Rahachi. $\quad 3^{\text {a Rahat. }}$

Este ejemplo es sacado de Dobrizhoffer porque la lista de Brigniel no lo proporciona; pero desde que Baile es grahatca en este autor, y Bailador, grahataic, sabemos que segun él mismo, Grahat sería "él baila», tema que se ajusta á la articulacion de arriba.

\section{CLASE $3^{\mathrm{a}}$}

Prefijo $D$ con $N$ de $3^{a}$ persona. - Articulacion típica.

Singular : $1^{\mathrm{a}} \mathrm{Ri} \ldots ; 2^{\mathrm{a}} G r \ldots i ; 3^{\mathrm{a}} N \ldots$

Plural: $1^{\text {a }} G r \ldots a k ; 2^{a} G r \ldots i i ; 3^{a} N \ldots e$.

\section{Eu Mocoví :}

Singular: $1^{\mathrm{a}} D i \ldots ; 2^{\mathrm{a}} D \ldots i ; 3^{\mathrm{a}} N \ldots$

Plural $1^{\mathrm{a}}$ Ard...; 2a $D \ldots i ; 3^{\mathrm{a}} N$...e. 
Ejemplo:

$$
\text { Amo }
$$

Sing. : 1a Ricapit. $2^{\mathrm{a}}$ Grkapichi . $3^{a}$ Nkapit.
Plur. : 1ªrkapiták. $2^{a}$ Grkapichii. $3^{\text {a }}$ Nkapité.

Aquí tambien tenemos que suplir la lista de Brigniel con ejemplo sacado de Dobrizhoffer.

En el Vocabulario, etc., de Brigniel hallo estas expresiones:

1. Er-capitaá, yo amo.

2. Er-capichi, ámala.

3. Er-capitá, ama él.

Esto nos daría un ejemplo de la clase anterior.

Hallo esto tambien :

1. Grigé, quiero.

2. Grigié, ¿quieres?

3. Grigiyé, ¿queréis?

Este verbo en Dobrizhoffer corresponde tambien á esta clase, $i$. e. lleva $\mathbf{N}$ de tercera. Otro tanto sucede con Temer que en el Vocabulario está representado por Netachga, miedo, derivado de Netacha, tiene miedo.

Compárense estas otras interequivalencias :

Dobrizhoffer

1 a Naal, es perezoso.

2a Npagak, tiene vergüenza.
Brigniel

fa Naálga, pereza.

2a Mpayagá, vergüenza.

En el segundo caso sabemos por el Vocabulario que Gripáyac es tener vergüenza (yo).

Resulta, pues, que entre el Vocabulario y los datos de 
Dobrizhoffer, podemos incluir cinco verbos conocidos en esta clase.

Véase el cuadro completo: allí se darán ejemplos anảlogos del Mocoví.

$$
\text { CLASE } 4^{\mathrm{a}}
$$

Prefijo D con $Y$ de $3^{\text {a }}$ persona. - Articulacion típica

Singular: $1^{\text {a }} G r i \ldots ; 2^{\text {a }} G r \ldots i ; 3^{n} Y \ldots$

Plural: $1^{\mathrm{a}} \mathrm{Gri} \ldots ; 2^{\mathrm{a}} \mathrm{Gr} \ldots i i ; 3^{\mathrm{a}} Y \ldots$...

En Mocoví como el anterior con Y por N. Ejemplo:

$$
\text { Darse prisa }
$$

Sing. : fa Griajalat.

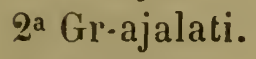

$3^{\text {a }}$ Yajalat.
Plur. : 1a Gr-ajalat (?).

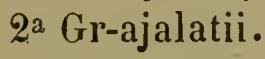

$3^{\text {a }}$ Y-ajalate.

Dos son los verbos conocidos que corresponden á esta clase, pero sin duda debe haber más; porque en Mocoví son seis por la parte que menos. Véase el cuadro completo al fin.

CLASE $5^{\mathrm{a}}$

$$
\text { Prefijo } L[=Y(?,] \text {. - Articulacion tipica }
$$

Singuldr: $1^{\text {a }} L i \ldots ; 2^{\text {a }} L \ldots i ; 3^{\text {a }} L \ldots$

Plural: $\quad 1^{\text {a }} L i \ldots c ; 2^{a} L \ldots i i ; 3^{a} L \ldots$.

Tal vez el Mocoví:

Singular : $1^{\text {a }} Y$ ó $L L \ldots ; 2^{\text {a }} D \ldots i ; 3^{\text {a }} L$ ó $Y \ldots$

Plural: $\quad 1^{\mathrm{a}} Y \ldots$ acca ) $2^{\mathrm{a}} D \ldots i ; 3^{\mathrm{a}} L \ldots$. e Ard...; $\left.\quad 3^{a} Y \ldots\right\}$ 
Ejemplo :

\section{Abstenerse}

Sing. : $1^{\text {a }}$ Liapim.

$2^{\mathrm{a}}$ Lapiñi.

$3^{\text {a Lapin. }}$

Plur. : 1a L-apino.

$2^{\mathrm{a}} \mathrm{L}$-apiñi.

$3^{a}$ L-apine.

De Brigniel son cuatro los verbos que se pueden incluir en esta clase, fuera de Laniague, acostumbrarse, que en singular prefija la $\mathrm{L}$, pero que la omite en plural.

Esta curiosa anomalía sólo se explica por aquella otra igualmente curiosa del Mocoví,que reproduce la articulacion de los nombres.

\section{CLASE $6^{\text {a }}$}

Sólo dos verbos se incluyen en ésta por no caber en otra parte.

$$
10 \text { Acuchillar }
$$

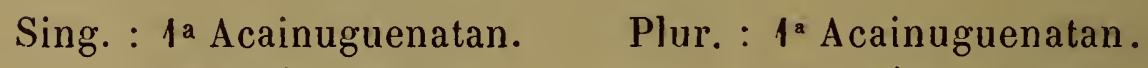

$2^{\mathrm{a}}$ Acain-y-usue.

$3^{\text {a }}$ Nacainugue. $2^{\mathrm{a}}$ Acain-y-ugue.

$3^{a}$ Nacainugue.

La $\mathbf{N}$ intrusa de $3^{a}$ es la única anomalía en este ejemplo.

\section{$2^{\circ}$ Alimentar}
Sing. : 1a Aquiñi gâm.
2a Nquiñi guiñiam.
$3^{\text {a }}$ quiñi gam.
Plur. : $1^{2}$ Aquiñi gamc.
$2^{a}$ quiñi ganyi.
3a Yquiñi gam.

Este ejemplo en realidad corresponde al primer grupo, clase $1^{\mathrm{a}}$ ó $4^{\mathrm{a}}$.

Un estudio posterior podrá modificar en algo estas clasificaciones, pero, en general, se verá que son bastante exactas 
y del cotejo con el Mocoví resulta que las reglas establecidas tienen base cientílica. Repito que el orden responde á la importancia numérica unicamente; que al dar el primer lugar a los temas sin refuer'zo nada se prejuzga, ni se da por ahora importancia alguna a la preferencia que se asigna á éstas.

El estudiante de estas lenguas hará bien de repasar cuanto se ha dicho de los verbos y sus flexiones en mi Mocoví.

\section{CAPITULO XVII}

EL VERBO CONJUGADO POR BRIGNIEL

En el Capítulo XV se ha reproducido lo que Dobrizhoffer nos dice acerca de la flexion verbal, que si se quiere basta para hacer comprender lo que ésta debería ser. Brigniel, sin dar regla alguna, conjuga sus ejemplos, unos con más detalles que otros, prro sin decir nada acerca de las partículas con que sintácticamente se entera la cuenta de nuestras Voces, Modos, Tiempos, etc. La verdad es que todo hace falta para formarse idea cabal de lo que es el mecanismo de esta lengua; con un autor sin el otro sólo la conocemos á medias.

Antes de proceder más allá debe establecerse que los Abipones, por lo general, prefijan sus pronombres personales A im, yo, etc.; pero en esta reseña no es necesario repetirlos. 


\section{Abrir}

\section{Modo indicativo}

\section{Tiempo presente}

Sing. : $1^{\text {a }}$ Gijoutougue.

2 a Gijouchi-ugue.

$3^{a}$ Yjoutougue.

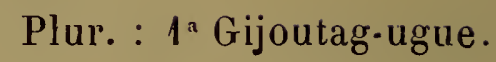

2 a Gijouchii-ugue.

$3^{\text {a }}$ Yjoutro-ugue.

Pretérito: He abierto

Sing. : 1a La-G-ijoutougue. $\quad$ Plur. : $1^{\text {a }}$ La-G-ijoutagugue.

$2^{a} \quad$ L-ijouchi-ugue. $\quad 2^{a} \quad$ L-ijouchi-ugue.

$3^{\mathrm{a}}$ La-Yjoutougue. $\quad 3^{\mathrm{a}}$ La-Yjoutrougue.

Futuro

Sing. : $1^{\text {a }} G$-ijoutoucam. $2^{\mathrm{a}} \mathrm{G}$-ijouchi-ucam. $3^{\mathrm{a}} \quad$ Yjoutoucam.
Plur. : 1a G-ijoutagucam. 2a G-ijouchi-ucam. $3^{\mathrm{a}} \quad$ Yjoutroucam.

Varias cosas se advierten al tomar el conjunto de los tres tiempos que no constan en ninguno de ellos por separado. $1^{\circ}$ La articulacion es ésta :

Sing.: $1^{\mathrm{a}} \mathrm{G}=\mathrm{H}=\mathrm{S}$ Moc.

$2^{a} \mathbf{G}=\mathbf{H}=$ Aspiracion insensible, probado en el Pretérito, Lijouchiugue.

$3^{a} \mathbf{Y}=\mathbf{Y i}$, por sincopacion de prefijo con $i$ radical.

Plur.: $1^{\mathrm{a}}$ G...ag, en que $a g=a c$.

$3^{\mathrm{a}} \mathrm{Y} \ldots r$, en que $r$ medial sustituye á é final como afijo de pluralidad. Ve Erouja.

$2^{\circ}$ Que la raíz verbal es Yjout, duro, fuerte. El ugue es terminacion de movimiento. 
$3^{\circ}$ Que la $t$ de la raíz produce chicheo con la $i$ final de la segunda persona; y que la infijacion de este subfijo nos hace ver cual es la raíz del tema verbal; en otras palabras, que éste es un verbo compuesto.

$4^{\circ}$ Que así como los subfijos personales son finales de la riíz, el subfijo am de futuro es final del tema.

$5^{\circ}$ Que el adverbio $L a$, ya, que hace pretérito puede sincoparse como en la segunda persona.

Entre las frases está este participio: Yijoutogué, abierto.

\section{CAPITULO XVIII}

\section{EL VERBO EN SU FLEXION TRANSITIVA}

Aquí precisamente tenemos que volver á Dobrizhoffer, que nos da los ejemplos que tanto me han servido en mi Mocoví. Es verdaderamente, como él lo dice, un "laberinto" que sólo con baqueano se puede andar : con el buen Padre, con los capítulos a! respecto en mi Mocovi, queda ya el camino trillado para los que vengan despues. Véase el Capítulo XVI ( $\left.{ }^{1}\right)$ y * Arte Mocoví ».

\section{Ricapit: amo.}

I. Ri-kapich-i-er'oá, yo te amo. Ri, sujeto; Kapit, tema verbal; $i$ subfijo personal de segunda; eroa, terminacion de caso régimen de segunda.

II. Gr-kapich-ioà, tú me amas. Gr, sujeto; kapit, tema; $i$, con terminación oá, caso régimen de primera persona.

III. $N$-kapich-ioá, él me ama. Como el anterior. $N$, sujeto.

(1) Dobrizhoffer, tomo II, pág. 161, De Abiponibus. 
IV. N-kapich-ier'oá, él te ama. Como el I, con $\mathbf{N}$ de sujeto.

V. Gr-kapita-é, nosotros lo amamos. Gr-a (=ak), articulacion del sujeto nosotros; kapit, tema; $e$, caso régimen de tercera en singular.

VI. Gr-kapit-la, nosotros los amamos. Como el V, con el caso régimen de tercera en plural.

VII. Mat-ni-kapit-alta, sí que me amo á mí mismo. Mat, partícula de afirmacion seria; $n i$, me, caso régimen de primera; kapit, tema; alta, terminacion reflexiva mismo: sirve para todas las personas.

VIII. Ni-kapich-i-alta, te amas á tí mismo. $N i$, parece que es caso régimen de segunda. En Dobrizhoffer el $N i$ del VII tiene acento, éste no; kapichi, tema de segunda persona; alta, mismo.

IX. Gr-kapitá-atá, nos queremos unos á otros (el nacu del Quíchua). Grkapitá por Grkapiták, tema de primera persona en plural ; atá, desinencia recíproco-reflexiva.

Habiendo explicado la articulacion pasemos á compararla con la Mocoví :

Abipon

(1 á 2) Rikapichier'oá.

(2 á 1) Grkapichioá.

(3 á 1) Nkapichioá.

(3 á 2) Nkapichir’oá.

(1 pl. á 3 s.) Grkapitaé.

(1 pl. á 3 pl.) Grkapitla.

(1 á 1) Nikapitalta.

(2 á 2) Nikapichialta.

(1 pl. entre 1 pl.) Grkapitaatá.
Mocovi

Ysinniappeguá (decir).

Ynniappiivá (decir).

Ncoictivá.

Ncoictarvá.

Ñagarncá (oir).

Ñagayarnarló (oir).

Ñagayanltá (oir).

Doqquialtá (aborrecer). Falta.

(Véase "Mocoví ", cap. LXXXII, pág. CLXXXIX et seq.)

Como dice Dobrizhoffer, si no fuese más que esto lo que hay que andar, nada fuera ; pero es el caso que, como con 
las articulaciones de posesivo y de llexion verbal, las séries de partículas son varias y su uso, a lo que parece, algo caprichoso.

2a SERIE DE ARTICULACIONES TRANSITIYAS

Rikauagé: Tengo lástima, compadezco.

1. Ri-kauág-yégarigé, yo te compadezco. $R i$, sujeto; kauág, tema; yegarigé, caso régimen de segunda persona.

No es necesario seguir con las explicaciones, baste con lo dicho en el anterior caso.

No está del todo averiguado cuál sea la equivalente articulaciou del Mocoví, pero como hipótesis sẹ ofrece ésta:

Abipon

(1 á 2) Ri-kauág-yegarigé.

(2 a 1) Gr-kauag-iygé.

(2 á 1 pl.) Gr-kauág-yegarik.

(3 á 1) N-kauag-iygé.

(3 á 2) N-kauag-yegarigé.

(3 á 3) N-kauág-egé.

(1 pl. á I pl.) Gr-kauageká pegetaá (unos ó otros).

(1 á 1) Ñi-kauákaltaá.
Mocovi

Ñ-oyernal-léh (llorar).

N-oyinni-iléh (2 plur.á 1 s.). N-oyinn-iarléh (2pl. á 1 p.). N-oinn-iléh $(l=l-l$.$) .$

N-oyinn-irarleh (3 pl. á 2): N-oyen-deel-leh.

No acaban aquí las variantes, y esta otra série es, si se quiere, aún más ingeniosa. Un tema que corresponda al grupo que conjuga el prefijo $\mathrm{H}=\mathrm{S}$ Mocoví de primera persona hace caso régimen de primera con $N i$ ó $R i$ inicial. Obsérvese que las desinencias tr'an y tapek son partículas de flexion como nuestro $n d o$, etc. 
$3^{a}$ SÉrIE DE ARTICULACIONES DE TRANSICION

Hapagr'anatr'an: yo enseño

Abipon Mocovi

(1 á 1) Ne-apagr'an.

(1 pl. á 4 pl.) H-apagr'an- cir). katápegetá.

(1 á 2) H-apagrani.

(2 á 1) Ri-ápagr’anic (').

(3 á 1) Ri-apagr'an.

(3 á 3) Y-apagr'an.

N(i)-ischioennelta (maldeFalta.

S-ischinniapéh.

D-ischinni .

D-ischoennapéh.

Y-schoennapé.

No puede darse un más bonito ejemplo de analogías, con las correspondientes variantes fonéticas. Adviértase que en el primer caso, yo me enseño, equivale á yo aprendo. En ambos idiomas se deja ver que $\mathrm{Ne}$ ó $\mathrm{Ni}$ es prefijo reflexivo, en estos casos, mientras que $R i$ ó 1$) i$ es caso régimen.

Obsérvese tambien cómo el cambio de una série de articulaciones á otra, es decir, de la propia á la ajena, introduce el régimen de transicion, que llaman, en la accion del verbo.

Dos ejemplos más da Dobrizhoffer, que reproduzco aquí; pero que corresponden á las mismas séries $3^{\mathrm{a}}$ y $2^{\mathrm{a}}$.

\section{Hamelk : Castigo}

H-amelgi, yo á ti.

Ri-amelgi, tú á mí.

Ri-amelk, él á mí.

Gr-amelgi, él á tí.

Y-amélk. él á él.
Hakleenté : Acordarse.

H-akleenchitapegr'ari.

H-akleenchitapegii.

Y-akleentetapegii.

Tanto en el Abipon, como en el Mocoví, se verá que la $r$ en estas partículas de transicion indicé segunda persona en

(1) En Brigniel: Griapagañi, enséñame. 
ambos números y primera de plural; lo que no debe causarnos sorpresa, descle que igual cosa sucede con las articulaciones de posesivo y de flexion verbal: el prefijo Gr es comun á las tres personas citadas y su determinacion exacta depende de otr:ts circunstancias.

Hay que advertir que el verbo va acompañado del pronombre personal, de suerteque lo que á veces parece anfibología en los casos de arriba, no lo es; por ejemplo, la falsa concordia que encierra aim hamegli, yo te castigo, sujeto de primera, tema de segunda persona, no deja duda acerca del sentido.

Repartidos entre las frases que da Brigniel se encuentran algunos ejemplos de estas transiciones, y no está demás citarlos:

No entiendo: Chiga oagipatá.

No te entiendo: Chiga oagipat-eigó.

¿Entiendes? ¿ Moagipat? (t?)

¿Me entiendes? ¿Ioagipachiyó?

¿Entendeis? ¿ Moagipachi?

¿.Me entendeis? ¿IIoagipachiyó?

El fonetismo de Brigniel no es el de Dobrizloffer : la $g$ es siempre una $r$ posible.

En el Acto de Contricion está esto:

Ya te quiero mucho: La-Ricapich-igo.

Me has de ayudar: Gri-atoñ-am $(\tilde{\mathbf{n}}=\mathbf{n i})$.

Ev la Salve:

Yo te saludo: Ñiquiñi-oagoa. 


\section{GAPÍTULO XIX}

\section{DEL VERBO SUSTANTIVO $Y$ OTROS}

$$
\text { CONJUGACION DEL ADJETIVO. }
$$

El Abipon carece del verbo ser ó estar como del verbo haber, dice Dobrizhoffer.

Todo adjetivo es susceptible de ser conjugado mediante el arrimo de la articulacion pronominal, que para este caso es la serie:

$$
1^{\mathrm{a}} R i \ldots ; 2^{\mathrm{a}} \mathrm{Gr} \ldots i ; 3^{\mathrm{a}} Y \ldots
$$

ex. gr. :

$$
\begin{aligned}
& 1^{\text {a }} \mathrm{Ri} \text {-apót: soy valiente. } \\
& 2^{\mathrm{a}} \mathrm{Gr} \text {-apochi: eres valiente. } \\
& 3^{\mathrm{a}} \mathrm{Y} \text {-apót: es valiente. }
\end{aligned}
$$

El plural es probable que sea éste:

$$
\text { 1a Gr-apot-ca; 2a Gr-apoch-ii; } 3^{\text {a }} Y \text {-apot-é; }
$$

pero falta en el texto.

\section{Haber}

Este verbo se suple con otras partículas; ex gr.: Tengo muchos caballos: Ayte yla ahépega. i. e. Muchos míos los caballos.

De sospechar es que este la sea un pronombre de tercera que corresponda por su colocacion á nuestro el de, de suerte que yla diría el de mi, los de mi, etc. La y es el posesivo de Aim, yo. 
En este ejemplo se verá que Dobrizhoffer estuvo dormitando cuando Jo apuntó (véase su Cap. XVII). Dice el autor: Habeo multus pulices, pero el Abipon expresa Canis habet, etc.

Netegink loapakate eno Pop: las pulgas del perro ellas son nuchas.

Chitcaeká lpabé: no tengo carne; tal vez corresponda más bien á este otro romance: no hay carne, expresion que explica mejor el modo de pensar de los indios. Así cuando en Bolivia se pregunta si hay carne, pasto, ó lo que sea, la contestacion es mana canchu ( $i l$ n'y en a pas), no hay ; seda el fraucés para que se comprenda el valor del $c h u=p a s$. Dobrizhoffer cuenta que heka es el equivalente del romance hay, y que su plural es ekoa, si es negativo, Chigekoa.

¿Hay carne? ¿ Meka kanák?

De ejemplos como éste y el otro (¿ M-ayte nauachieka? ¿Qué no son muchos los soldados?) deducimos que hay verbo sustantivo y que una de sus formas es eka ó $k a$. Por otra parte, esta Hinnerkam, será, y los subfijos kán, de tiempo pasado, kam, de futuro. Es la raiz ca tan conocida en Quíchua, etc.

\section{ALGUNAS OTRAS ESPECIALIDADES DE LOS VERBOS}

Los Abipones, como todos, forman sus verbos compuestos, y para ello se ajustan inconscientemente á reglas. De los siguientes ejemplos se verá el modo de proceder.

Menetañi, es, si se quiere, el verbo que corresponde á nuestro estar en el sentido de existir; arrimándole subfijos se modifica su significado.

Con Hegen: arriba :

Dios Meneta-hegem kien hipigém.

Dios está arriba en el cielo. 
Con $A \tilde{n} i$, abajo:

Menetañi ken aloá.
Está abajo en la Tierra.

Con Hagam, agua :

$$
\begin{aligned}
& \text { Meñetahagám ken enar'ap. } \\
& \text { Vive acuáticamente en el agua. }
\end{aligned}
$$

Aui: seguir

Con Aigit, alrededor: Hauiretaigit, sigo al que viene.

Con Aä: Hauirad́, sigo al que se va.

Con Añi, abajo: Hauirañi: sigo con la mano lo que está abajo de mí.

Con Hegem, sobre ó arriba: Hauirihegeméege, sigo con la mano lo que está arriba de mí.

\section{OBSERVACIONES GENERALES SOBRE EL VERBO}

Al cotejar el Verbo Abipon con su flexion en Ios otros codialectos se notan muchas diferencias, las que sin duda motivaron ciertas apreciaciones erróneas de los que antes han tratado sobre la materia; mas no todas ellas son verdaderas diferencias, por mucho que lo parezcan. Por ejemplo: no es diferencia la $R$ en lugar de $D$, ni la $G r$ en lugar de $A r d$ en Abipon y Mocoví, porque estas responden á diferencia de fonetismo únicamente, y salvadas las ecuaciones del caso resulta identidad. El Padre Sanchez Labrador, el Padre Jolis, etc., podrían fundarse en tales ejemplos para poner en duda la identidad de orígen entre dos ó más de estos idiomas; nosotros, empero, conocemos que hay igualdad absoluta por esta parte.

Es por otro lado que se llama nuestra atención, no obstante que ya en mi Mocoví había yo dado por establecida la prueba de que la $\mathbf{S}$ de aquel idioma debía buscarse en la $\mathbf{J}=\mathbf{H}=$ 
simple aspiracion. Siempre esta subsistente la pregunta ¿por qué entra la S, ó sus equivalentes, como prefijo de primera persona en la flexion verbal de estos idiomas?

El verdadero indice de primera es una I ó $\mathrm{Y}$, sola ó reforzada, la que encontramos en los nombres y en los verbos; mas donde se presenta la $\mathrm{S}$ verbal, ó una de sus equivalencias desaparece todo rastro de la I. Esto algo nos dice, y ese algo es, que la I puede suplirse con la $\mathrm{S}$, ó sus degeneraciones, ó sea, que la $\mathbf{S}$, etc., contienen en sí lit idea pronominal de primera persona. Ln examen de la articulacion pronominal de las lenguas limítrofes confirma esta hipótesis.

No es mi propósito por ahora instituir una comparacion entre los afijos pronominales del $\mathrm{Abipon} \mathrm{y} \mathrm{grupo} \mathrm{Guaranítico,}$ porque prefiero esperar que salga á luz la obra del señor Lucien Adam sobre esta interesante familià de lenguis. Sin duda alguna él establecera los canones fonéticos de todos esos idliomas y sus variaciones dialécticas, con lo que nos será facil instituir parangones; pero sin este trabajo preliminar, nada acertado podría resultar; hacerlo aquí sería desviarme demasiado de los límites de este trabajo.

Una cosa podré establecer, que la $R$, afijo pronominal en el Abipon, mucho se parece á la $\mathbf{R}=\mathrm{T}$ que con igual carácter hallamos en el Guaraní. ex. gr.: en Che-R-obá, mi cara; nde-R-obá, tu cara.

D'Orbigny, en su L'horrme américain, arranca su “Raza Pampeana " de los Chiquitos y la acaba en los Tehuelches ó Patagones. Efectivamente, en la lengua de los Chiquitos encontramos la I, la $\tilde{\mathrm{X}}$ y la $\mathrm{Z}$ como prefijos de la primera persona en la flexion verbal; $y$ debe notarse que en este idioma el paradigma de afijos pronominales es un laberinto tan enmarañado como el de nuestro Abipon, etc.

En Lule de Yachoni, lengua que geográficamente estaba en contacto con las del Chaco, tipo Abipon, etc., hallamos la $s$ final en Quis, yo, y la $c$ tambien final como indice de primera persona en la flexion rerbal, así: Amaici-ç, yo amo. 
En otros trabajos he sugerido la hipótesis que el grupo Guaycurú (Mocoví, etc.) del Chaco procede de Andahuailas, en el Perú, adonde se llamaron Chancas, y en mérito de esta suposicion, se puede instituir comparacion tambien con el Aimará, lengua en que el $h a$ es una partícula pronominal que equivale al romance mío, que en plural haría ssa. Por supuesto esta partícula se subfija en Aimará, mientras que la correspondiente partícula se prefija en Abipon, Mocoví, etc., pero asi el inglés dice un bueno hombre, cuando nosotros diríamos un hombre bueno.

Que algo debe haber en esto de pedirse prestadas las articulaciones unas lenguas á otras se ve en el subfijo verbal $n i$ del Quíchua, que reaparece como prefijo $\tilde{N}$ ó $N i$ ó $\tilde{N} i$ en Abipon, Mocoví, etc. Yo supongo que estos Chaquenses de ser vecinos de los del Cuzco y La Paz se largaron al Chaco, y allí es un hecho que dieron con tribus quichuizantes.

La verdad es que por donde quiera hallamos un orígen posible de esa $\mathbf{S}=\mathbf{H}$ prefijo pronominal de primera persona para verbos. Ahí está el Mataco, vecino inmediato de todos estos idiomas, con su

$$
\text { Nuslam }=\text { Nujlam : } Y_{O} .
$$

De donde se ve mejor la posible analogía en los afijos entre Aimará y Abipon-Mocoví es en la $4^{\mathrm{a}}$ y $5^{\mathrm{a}}$ clase.

\begin{tabular}{|c|c|c|}
\hline Abipon & Mocoví & Aimará \\
\hline ing.: $1^{a} A j a-\ldots$ & $1^{a} A s-\ldots-$ & $1^{*} \ldots-t-h a$ \\
\hline $2^{\mathrm{a}} A-\ldots-i$ & $2^{a} O-\ldots-i$ & $.-t-a$ \\
\hline $3^{2} Y-\ldots$ & $3^{a} Y-\ldots$ & $3^{a} \ldots-i\left(^{2}\right)$ \\
\hline ur. $1^{a} A j a-\ldots$ pl. $\left(^{1}\right)$ & $1^{\mathrm{a}} A s-\ldots-\mathrm{pl} .\left(^{1}\right)$ & $1^{\mathrm{a}} \ldots-\mathrm{pl} .\left(^{1}\right) t-h a$ \\
\hline $2^{a} A-\ldots-i i$ & $2^{\mathrm{a}} O-\ldots-i$ & $2^{\mathrm{a}} \ldots-\mathrm{pl} .\left(^{1}\right) t-a$ \\
\hline $3^{\mathrm{a}} Y-\ldots-\mathrm{pl} .\left(^{1}\right)$ & $3^{\mathrm{a}} Y-\ldots-\mathrm{pl} .\left(^{1}\right)$ & $3^{\mathrm{a}} \ldots-\mathrm{pl} . \quad i\left(^{2}\right)$ \\
\hline
\end{tabular}

(') Diferentes partículas de pluralidad.

${ }^{(2)}$-Sincopacion de la última vocal con la $i$. 
Dada la ecuacion $0=\Lambda$ hay identidad en los afijos, con la diferencia que en aqquellos casos se prefijan, en éste se subfijan.

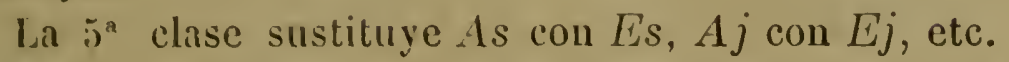

Así como en este ('aso las analogías están entre el Aimará y las lenguas del Chaco, tipo Guaycurú, en este otro las hallaremos eutre éstas mismas y la lengua del Cuzco.

Abipon Mocovi Quichua

\begin{tabular}{|c|c|c|}
\hline Sing.: $1^{a} \quad i i-$ & $1^{\text {a }} \mathrm{Ni}-\ldots$ & $1^{a} \ldots-n i$ \\
\hline $2 N-\ldots-i$ & $2^{\mathrm{a}} N^{\top}-\ldots-i$ & $2^{\mathrm{a}} \ldots-n q u i$ \\
\hline $3^{\text {a }} N-$. & $3^{a} N-\ldots$ & $3^{a} \ldots-n$ \\
\hline$\left.: l^{\mathrm{a}} \bar{N} i-\ldots p \mathrm{pl} .{ }^{1}\right)$ & $1^{\mathrm{a}} \tilde{N} i-\ldots-\mathrm{pl} .\left(^{1}\right)$ & $1^{a} \ldots-n$ pl. $\left(^{1}\right)\left(^{2}\right)$ \\
\hline $2 N-\ldots-i i$ & $2^{\mathrm{a}} N-\ldots-i$ & $2^{a} \ldots-n q u i$ pl. $\left.{ }^{1}\right)$ \\
\hline $3^{a} N-\ldots-p l .\left({ }^{1}\right)$ & $\left.3^{\mathrm{a}} N-\ldots-\mathrm{pl} .{ }^{1}\right)$ & $3^{a} \ldots-n$ pl. $\left(^{1}\right)\left(^{3}\right)$ \\
\hline
\end{tabular}

Que el subfijo nqui se abra así, $n$-qui, para recibir el tema como una intercalacion se comprende; como tambien que el qui así separado degenere en $i$.

Para mí estus son, ó verdaderos rastros de un orígen comun, ó de no ejemplos milagrosos de omofonías casuales con la más exquisita lógica en todos sus accidentes; yo me inclino á la primera hipótesis.

Empero no es esto todo. Hemos visto que el Quíchua refuerza sus temas verbales con $\mathrm{N}$ y que otro tanto sucede er Abipon, etc.; mas el Aimará los refuerza en primera y segunda persona con T. En Guaraní la T y la $R$ se intercambian ó sustituyen como demostrativos, en IIojo la $\mathbf{T}$ y la $\mathbf{R}$ igualmente son demostrativos y complementos de temas pronominales. Ocurramos al Abipon y de allí encontramos que se usa el refuerzo inicial $R$ precisamente como el Aimará usa el refuerzo final (de la raíz) $\mathrm{T}$.

(1) Diferentes partículas segun el caso.

$\left.i^{\S}\right)$ Se prescinde de las formas exclusivas é inclusivas.

( $\left.{ }^{3}\right)$ No siempre con partícula de plural cu. 
Abipon

Sing. : 1a R-i-tema.

$2^{a}$ R-tema-i.

3a Y-tema.
Aimará

Sing. : la Tema-T.ha.

2a Tema-T-a.

3a Tema-i ( $\left.{ }^{1}\right)$

Este es un modo; mas como en Quichua el refuerzo $\mathrm{N}$ en la tercera persona puede ser refuerzo ó índice de tercera persona, hallamos que en Abipon tambien puede asegurarse lo mismo de esa clase en que la $\mathbf{R}$ sustituye á la $\mathbf{Y}$ como prefijo de tercera persona. Ver Glase II con prefijo R. Sustitúyase $\mathbf{R}$ con $\mathbf{D}$ y lo dicho tiene aplicacion al Mocoví.

¿Qué significan estas variantes en la fiexion verbal ? Para mí son todas ellas pruebas de una raza con tendencias camaleónicas en su lenguaje : raza con un oido inclinado á apropiarse idiomas ajenos siempre con su dosis del hablar propio.

Por supuesto al usarse el refuerzo $\mathbf{R}$ fallaba el sonido que indicase primera persona y razones de eufonía ó de lo que se fuere excluiría la $\$$; fuerza era, pues, recurrir al índice ó infijo $i$ de esta persona: ingenioso mecanismo que reduce un grupo importante de verbos á la gran familia de los que emplean la I de primera persona.

Tiempo vendrá en que se pruebe cómo ese subfijo $\mathrm{Ca}$ chiquitano de primera y segunda persona ha podido ser el origen de ese mecanismo Abipon:

1. $\mathrm{H}=\mathrm{S}$ Mocoví;

2. $\mathbf{H}=$ Nada Mocoví.

En estas monógrafías vamos caminando hacia el mejor conocimiento de cómo se encadenan ciertas lenguas americanas unas con otras, y esto naturalmente sucede por el lado de la articulacion pronominal, verdadera piedra de toque de las Gramáticas Indias, sobre todo en las lenguas del Chaco

$\left.{ }^{1}\right)$ Con sincopacion de la vocal que precede. 
del tipo Abipon; vencida la dificultad de los afijos de persoua lo demis es sencillo.

No hay que dejarse enganar con las complicaciones fonéticas: ellas naturalmente imposibilitan la adquisición de la lengua para hablarla y escribirla con nuestros signos; pero prescindiendo de esto podemos conseguir conocimientos bastante exactos de todos estos idiomas, establecer ciertas reglas que nos sirvan de guía si andando el tiempo damos con otros grupos que puedan incluirse en esta gran familia.

Cuando este estudio se suplemente con los que corresponden alMbayá ó Guaycurú yLengua ó Payaguá,podremos decir que se ha completado el gran Grupo típico del Chaco, y veremos que, como el Toba y el Abipon confirman lo escrito sobre el Mocoví, los tres se ilustrarin $\mathrm{y}$, comprueban al compararlos con los codialectos que aún nos quedan que examinar, y que tan insuficientemente se analizan en las obras de Hervas y Adelung. Bajo este punto de vista no es perdido el tiempo y espacio que se dedica á cada uno de estos idiomas como partes de un todo que aún está por descubrirse.

\section{CAPÍTULO XX}

PARTículas, VOGES Y EXPRESIONES QUE LLAMAMOS ADVERBIOS, PREPOSICIONES, CONJUNGIONES É INTERJECCIONES

Para evitar confusiones se pone todo en órden alfabético como para facilidad de referencia. Lo que importa es tener el cuadro á la mano para cuando se ofrezca el cotejo con otros idiomas y dialectos.

A. Preposición. Men, mek, ken. Abajo. Erpeiañi.

En kerá, hácia. Ver $\operatorname{En}(\mathrm{D}$.$) . Abajo. Añi (D.).$ 
Acaso. Origeena. Ver : Morigi, en preguntas.

¿Acaso? $M$, prefijo. La $h$ ó $n$ de los temas se suprimen. Mocoví, $\boldsymbol{M}$.

¿Acaso ? Men prefijo (D.). Ver interrogacion. ¿ Men leerá? es verdad ? Klevá, es verdad. Chigera, no es cierto.

¿Acaso? (num, lat.). Mik y Mik mich.

Adentro. Erpeiava. Toba Panó (L.).

¿Adonde está? Eguém mevaé. Agua. Hagam (D.), como subfijo de verbo, estar en, etc., menetá.

Afuera. Ouge (D.). Toba Auék (L.).

Ahí está el plato. Ená laqui$q u i$.

Ahora.Quité,Enequite, Quitam. Toba Nagi. Mocoví Ennegui idi.

Ahora.Kite(D.).Moc. Enneguí. Ahora fué. Kutekan (D.).

Ahora luego será. Kitam (D.). Ahora, ya, hoy. Kitnéoga (D.). Alguna vez. Aoequem.

Antes. Ayaggui é Quegé.

Aquí. Enaja. Toba Enná.

Por aquí. Quenaja.

Arriba. Hegem (D.).

Asi como. Men men. Ex. gr. : Mennetá, men naetar'at: asi como (es) el padre, así (es) el hijo. Mocoví Minni.

Atras. Nacal. Toba Loek (L.).

Aún no. Chigahek (D.).

Aunque. Klatum keen. Ver Oagan (D.).

Ayer. Guenaamú, Gnaamá(D.). Kan, part. de pasado. Moc. Tóm.

Casi. Ver Cerca.

Cerca, á punto de, casi. Latám (D.). Latam riohamat yiuihák: el buey casi me mató. Toba Yak. Moc. Layam.

Como. Eguem meem. Mocoví, Meêm.

Como también. Meeram, Gueem clatqué.

¡ Cómo eres de! Kemen ó Kimili (D.).

Como (si fuese). Yágámsicut. Rocehá yágám Metegink : atropello como si fuese perro (D.).

Con (instrumental). Haraá. ex. gr.: Yóale yahamat nihirenak naraá lohèlete : el indio mató el tigre con la lanza (D.).

¿Cuándo? Egmalquiam? Toba Malagí.

¿Cuándo? (de pasado). Hegmalagé? (D.). Moc. Nomal. ¿Cuándo? (de futuro). Hegmalkam (D.).

Despues. Amla, Amà, Amlayerge (D.). Moc. Om, Oma. Toba Tocomelé.

Muchodespues. Chitlkihe(D.). $\measuredangle$ De donde? Eguem?

¿Por donde? Egmeoe. 
En. Ken (D.). Men, ex. gi.: Men hipigem : en el Cielo.

Encima. Por la superticie. Alye ó Elge (D.). Tubat Laléli (L.).

Por eso (ideo). Maroge, ex. gr. : Tun ayle apalúye lien nepark máoge chik cuitelian : porque unuchos mosquitos en el campo por eso no dormí.

Que en fin. Hegmi pref. (D.).

Por fin. En resumen. Mal ó Gramachlia, ex. srr.: Eneha mat yaole: éste si que es hombre. Gramachla Abipon yapochi: en fin, los Abipones son valientes (D.).

Al fin. layám.

Hasta. Aicaña.

Hasta aqui. Laicaña.

Hoy. Eneogá. Toba Nagui. Mocoví Ennegui.

Léjos. Ayaque. Toba Cayagé. Moc. Aguinium.

Luego.Después. Amblá. Amblá quiñi locagic: luego que coma me voy. Moc. Oma.

Mañana. Am richigni (D.).

Mas. Nam. Moc. Lam.

Medio día. Neogata.

Mucho. Ait (pl. e). Moc. Oictêu.

IIuy. Ait ipi.

No. Chiga, pref. Chiga arem: no sé. Chit vinyilá : no repiques. Chieem: no es así. Tannachit? \& por qué no?

No. Ygná Iná (D.). Toba Ay.
No obstante. Oagan (D.). Ver Pero.

No. Chik, Chil, Chichi (ne Lat.) pret. verb. (D.).

¿Pilra qué? ¿ Por qué? Yyuri?

Pasado mañana. Amckére lahaua (D.).

Porque (quia Lat.). Tan. Ver Maoge (D.).

¿Por qué? ¿Por qué causa? Eurigri, Eorat, Miekaenégen. Moc. Quennege? ¿Cuál? Toba Quolarien.

- Por qué razon? Miguenegueaoé. Moc. Quenneguc ¿Qué? id.

¡Qué! kemen. Moc. Meen, ¿ Cómo? id.

Sino. Amachiga.

Si (de hombres). Héé (D.).

Si (de mujeres). Háá (D.). Toba, shá.

Si quiero. Ee grige.

Por todas partes. Ciecó grachieoé.

A la tarde. Am. Nnema (D.). Moc. Nomanagata.

Y. Katchka, Kach, Kat (D.). Moc. Char.

Ya. La, prefijo verbal.

Ya (de pasado). Nehegetoé(D.). Ya (de presente). Haketemal (D.).

Ya (hoy, ahora). Kitnéoga (D.). Ya (esta noche). Kitnenegin, Kilnehaoe (D.).

Yi me roy al campo. Sahik lien nepárk. 


\section{CAPITULO XXI}

De las partículas ó afijos verbales, etc.

Llegamos ya al capítulo de las partículas allegadizas, tan importantes en toda lengua americana, porque no sólo revelan su mecanismo gramatical, sinó tambien sirven de rastros para buscar el encadenamiento de todos estos idiomas entre sí.

Dado el valor de estos párrafos se reproducirán íntegros de la obra de Dobrizhoffer con esta señal (D.) para distinguirlos de las observaciones posteriores.

De las articulaciones pronominales de nombre y de verbo ya se ha dicho lo bastante en este y otros trabajos (Mocoví, Toba y Mataco, etc.).

IA

La (va, inicial), se arrima á todo verbo; ex gr.:

La reókatarí cachergayé : ya está llorando la vieja. La rielk: ya estoy asustado.

La nañam: ya bebo (D.).

También puede ser de pasado como en estas frases :

Laoaod́: ya se murió.

Loquec: ya se fué.

En el mismo (Dobrizhoffer) encontramos: La hâui, ya seguí (alcancé á entender); á la par de: La hàui kan.

En Mocoví y Toba es tambien prefijo de tiempo pasado. Debe compararse con el ña (ya Quíchua) y la terminaci $^{\text {on }}$ rka de pretérito que sustituye las partículas $L a \quad y$ 
kan. De que esta $n$ final uada tiene de orgánica se advierte en su forma de futuro kám. Se me dirá que por idéntica razon la idea de tiempo pasado se buscaria en la $n$ y no en la $k$; pero a esto se contesta que la $n$ final se suple con la $l=r$ inicial: sustitución muy conocida en el Chaco; ex. gr. : Nam = Lam, más.

TAPEK Ó TARI

Subfijos que allegados á la última sílaba del verbo significau acción que se esta haciendo; ex. gr.:

Hakiriogrian : aro la tierra.

Hakiriogr'ane-tapek: ahora estoy arando.

Haoachin: estoy enfermo.

Haoachinetari: actualmente estoy enfermo.

Ambas partículas se usan en el Mocoví y es probable que en todos los demás codialectos de este grupo. Su uso es muy general, como que el modo de hablar gerundivo conviene à estos idiomas.

Ejemplos del Mocorí :

Ñagayarncactápeh : estamos escuchando.

Ichocactarni : confesarse.

KACHIT (face en romance, como final de verbo; $\nabla . g .:$ Satisface)

De Ar'air'aik ahëpegak: manso caballo.

Ar'air'aikachit ahëpegak : manso hago al caballo.

De Rielk: tengo miedo.

Rielkachit nihírenák: el tigre me acobardó.

De Ayerhégemegé: cosa alta.

Ayercachihegemegé: enaltezco una cosa, la pongo

en alto (D.). 
Este subfijo parece que corresponde al Mocoví Oicti de Oêt, hacer. El ca es partícula de verbo activo, etc., en muchos de estos idiomas, y el chi subfijo de verbo transitivo en Quíchua. A parte de esto está el subfijo verbal te ó ti tan en uso en Mocoví y Abipon, y que no hace más que alargar el tema; ex gr. : Rihe = Rihete, quiero (volo).

R'AT ó R’AN (más ó menos lo que kachit hace á otro, etc.)

Se usan con algunos verbos y significan lo que el anterior kachit; ex gr. :

$1^{\circ}$ Rpaé enar'ap : caliente agua Hapaer'at enar'ap: caliento agua.

$2^{\circ} L a a ́$ : grande, extenso. Laar'ar'at: extiendo, agrando

$3^{\circ}$ Lenechi: pequeño, chico. Lenechitar'at: achicar.

$4^{\circ}$ Haoaté : duermo. Haoacher'an akiravalk: hago dormir al niño(D.)

En el ejemplo $3^{\circ}$ se ve cómo el afijo ta puede agregarse ó no. Igual cosa sucede con tapek. Ta, segun parece, en estos idiomas es una especie de verbo ser ó estar.

Las correspondientes partículas en Mocoví son: Gât, Gân ó Gôn; ex. gr.:

Agât : manifestar.

Avoagn: castigar, etc.

$$
\text { KEN (subfijo frecuentativo) }
$$

Este subfijo hace que el tema verbal sea frecuentativo, y significa costumbre ó hábito ; ex gr. : Roélakiken, tiene cosumb re de pelear, es peleador (D.). 
Este subfijo arrimado a los sustantivos Lahérek, trabajo, o, Yaar'air'ék, saber, tambien significan costumbre; ex. gr.: Néoga latenk nañametapek: lo mis del día está bebiendo.

Gramachlia Laheerekaage: en fin ya esta en el trabajo. Mat yaar'air'ék aaye: en fin sabe (= suele) (I).).

Sospecho que esta partícula pueda ser el ogué ó augué del Mocoví, como Ocoyart-i-ogué, tú aflojas, tal vez tú acostumbras ó sueles allojar. La infijacion de la $i$ de segunda persona nos demuestra que la terminacion ogué no es orgánica de la raiz; desde luego que es un simple subfijo que modifica al tema. Los respectivos fonetismos confirman la cumparacion que aquí se hace.

\section{IT (del material)}

Este subfijo significa el material de que se hace una cosa; así, Nichigeherit es un manıo cosido de pieles de putria que los Abipones llaman Nichigehé.

Káepérit: pisada,estacada; de Káepdk: palo, madera (D.).

En Iocoví tenemos la misma partícula ; ex gr.: Ncoipadit: corral; de Ncoippá: leña, palo.

HAT (lugar en que crece algo;

Esta partícula final tambien señala el lugar en que crece cualquier arbol ó fruta; ex. gr.:

Nebokehat: palmar; de Neboke: especie de palma.

Nemelkehat: maizal; de Nemelk: maiz (D.). 
En Mocoví sat ó sacte, como en los siguientes ejemplos:

Ectonessácte: pencanal; de Ectoniqque,penca(Opuntia). Nocolalatelsat : cañaveral.

Confirmo aquí mi hipótesis de que este sat pueda explicar el Sacat ó Sacate, pueblo, del Sanavirona ó lengua de Córdoba.

IK (terminacion de nombres de árbol)

En $I h$ terminan casi todos los nombres de árbol; ex . gr.:

Apéke: fruta del chañar; Apekik: el Chañar (Gorliea decorticans).

Oaik: algarruba blanca; Oaikik: algarrobo blanco.

Roak: algarroba colorada; Roaikik: su árbol (D.).

La correspondiente partícula Mocoví es $i k$ o $i h$; ex. gr.:

Naccalmaih: ombú.

Dudasnik: durazno.

Appiguinik: ñandubay.

$R^{\prime} \mathrm{EKI}$ (vaso continente)

El subfijo R'eki significa el lugar, cosa ó vaso en que algo se encierra, guarda ó contiene ; ex. gr.:

Nañamr'eki: copa, vaso; de Nañam : bebo.

Neetr'ki: vaso; de Ñeet: bebo(D.).

En Mccoví y Toba, se usa tambien esta partícula; ex gr.:

Ennerarnaqqui: tintero. Assoctarqui : cincha. 
EnToba :

Lahi o Uicchigui: vasija.

Charqui: vejiga.

Ossoatarqui: faja.

En Mataco es muy conocido este subfijo en su forma $h i$.

LȦYT (receptáculo)

Casi tiene la misma significacion que la anterior, y tambieu se pospone; ex. gr. :

Yabogek layt: tabaquera.

Ahëpegrlayt: ccrral.

Eu Mocoví, Layı̂ es sepultura, segun la cita dudosa que conservo en el Vocabulario.

LAN $\dot{A}$ (sirve para)

Voz de aplicacion general, sobre todo en boca de los que no son muy espertos en el idioma y se hallan al fin de sus recursos: se usa como subfijo. Las viejas mascan las hojas de tabaco con sal y así preparadas las llaman "medicina"; pedido pues el Tabaco, su medicina viene en seguida:

Ta ch kâue achibir'aik neotá laná : dame tambien sal para remedio.

Tach kàue latar'an lpagé laná: dame cuchillo para la carne.

ALAR'ANR'AT (subfio verbal)

Con esto de un verbo se hace el nombre del instrumento que produce los efectos de la accion que expresa dicho verbo ; ex. gr.: 
Noetarén: curar; Noetarenatar'anr'at, medicina, aquello con que se cura.

Rietachá: tengo miedo; Netachkatr'anr'at: objeto que espanta, comola cara embijada de Indio, en facha de guerra (D.).

Dice Dobrizhoffer que con esta variedad de giros varía su hablar el que conoce las galas del Abipon, y que Laná es recurso de los aprendices.

Se deja ver que aquí están complicadas las partículas $r$ 'an y r'at (quas vide) y la desinencia participial $t$.

$$
\text { KATÉ (subfijo de instrumento) }
$$

Este, como el anterior, es el modo elegante de sustituir ese Laná vulgar (cosa para); ex gr.:

Hakiriogran: aro ; Kiriogrankaté : arado. Nahategr'an: tusar, trasquilar; Ahategkaté: tijeras.

(Ver Alar'anr'at).

El Mocoví lo usa tambien; ex.gr.: Aqquil-lelcaté, tijeras.

$$
\text { LATÉ (lugar de accion) }
$$

Esta partícula se subfija á las voces é indica el lugar donde se ejecuta la accion indicada por el verbo. Suple al Laná, como sucede en Katé y Alar'anr'at, etc.; ex. gr.:

Géhayá: miro ; Geharlaté: espejo.

Quiñii (B.): alimentarse; Kiñier'alaté : lugar en que se cume, ergo, mesa (D.).

Véase Occolalaté (caña) en Mocoví. Parece que dice: cosia que crece en lugar húmedo. 
IN (particula final de nobleza)

Hombres y mujeres que han side elevados a la clase noble usan un modode hablar especial. En primer lugar los nombres de los primeros tienen que acabar en in, de las segundas en en; y los mismos subrijos hay que arrimar a nombres y verbos si se habla con ó de ellos; ex. gr.:

Este caballo es de un Abipon cualquiera; sería: lela, es de; pero Hëcheri lilin, es de Hëcheri, de la clase noble.

1 plebeyo se le saluda así : ¿Lá nauichi? ¿Ya llegaste? y contesta: La naué: ya llegué.

El primer Lá me suena á $L a ́$, adios, ó salud.

Si el que llega es noble se dice: Lá náuirin? ¿Ya llegaste? (_.ya llegó su Merced”) y él cou mannificencia y la boca llena contesta: La nauerinkie así. "Ya me tiene usted de llegadan, porque el Latin no lo explica.

Para los del pueblo la madre es Laté, el hijo Laetar'at; para los nobles Lichiá é Illalek respectivamente.

Con mucha razón dice Dobrizhoffer que ellos en su ensenanza se atuvieron a la lengua del pueblo. 


\section{APÉNDICE A}

CUADRO COMPLETO DE LOS NOMBRES SEGUN SU ARTICU LAGION

POSESIVA. (Ver vocabulario y capitulos)

\section{GRUPO $1^{0}$}

Sing. : $1^{\text {a }} Y \ldots ; 2^{\text {a }} G r \ldots i ; 3^{\text {a }} L \ldots$

Plur.: $1^{\mathrm{a}} G r \ldots ; 2^{\mathrm{a}} G r \ldots i ; 3^{\mathrm{a}} L \ldots i g a, L \ldots$ te.

I. N-aripá : El amigo

Singular

1a Y-aripá (mi amigo).

2a Gr-aripé (tu amigo).

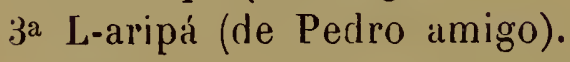

\section{Plural}

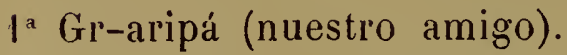
2ar-ari cchi (vuest. amigo).

Toba. : Hidik.

Notas. - 1a En 2a persona $\dot{e}=a ́ i$.

2a En segunda del plural subfijo cchi anómalo.

II. N-agíc : Cara

Sing. : $1^{\text {a }}$ Y-agic.

2a Gr-aguigui. $3^{a}$ L-agíc erajá.

Plur. : 1a Gr-agic. 23 Gr-agi-yi. $3^{3}$ L-agi-iga.

Notas. - $1^{\text {a }}$ Ablándase $c$ en gui.

$2^{\text {a }}$ Cámbiase $c$ en $y i$.

$3^{\text {a }}$ Para plural cámbiase $c$ en iga.

Moc. : Cassigui: Tu carâ. fa $Y \ldots ; 2^{\text {a }} C \ldots i ; 3^{\text {a }} L \ldots$

Toba : Lassik.

III. N-iic : Casa

Sing. : $1^{\text {a }} \mathrm{Y}$-icqui.

2a $\mathrm{Gr}$.iiggui.

$3^{\text {a }}$ L-iicqui.

Plur. : 1 a Gr-iícqui.

2a Gr-iicquirigüi.

$3^{a}$ L-iicqui-te. 
Yotas. - Mocovi Vó. I Y...; Moc.. Accannimni, tragadla. 2a Ca...ri; 3a La...

Toba : Nohic, Lacó.

\section{II}

VII. L. iilet: IIijo muerlo. Plı-ral : 1.-iilit-é.

Sing.: Lapaanat-ec (discípulo). Pl.: Lapaanat-ca (discípulos).

Sing. : 1a P-apaanatec. $2^{2}$ Gr-apaanatigu-i. $3^{3} \mathrm{~L}$-apaanatec.

Plur. : 2a Gr-apaanatagu-i.

Notas. - $1^{a}$ Asimilación de $e$ con $i$ en la $2^{\text {a }}$ persona.

əa Cambio de $i$ por $a$ en $2 \mathrm{a}$ de plural.

Moc.: Apparinactagan, Enseñar.

Toba : Apagrgaguém.

$$
\text { V. X-atáp : Frente }
$$

Sing. : la Y-atáp. 2a Gr-atáp-i.

Mocovi : Naactápe, con pret. 1 ${ }^{\text {a }}$. . ; 2a $C a \ldots i ; 3^{\mathrm{a}} L a \ldots$

Toba : Latap ó Lotap.

VI. Acauichigá : Garganta

Sing. : la Y-acauichigá. 2a Gr-acauichigu-é.

Notas. - Todo regular.

Sing. : fa Y-ilet.

2a Gr-iilich-i.

$3^{\text {a }}$ L-iilet (Pedro L...).

Plur. : la Gr-iilet.

$2^{a}$ Gr iilich-irii.

$3^{a}$ L-iilet-e.

Así dicen cuando alguno se les ha muerto.

Notas. - Ia Obsérvese asimilacion de la é con $i$.

Q a tambien el chicheo de $t$.

Moc.: Yal-lek, con prefijo. $\left.\right|^{\mathrm{a}}$ $Y \ldots ; 2^{\text {a }}$ Cact...i; $3^{\text {a } Y l . . . ~}$

VIII. Hijo viro

Sing. : $1^{\text {a }}$ Y-aital.

2a Gr-aitach-í.

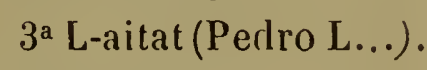

Plur. : 1a $\mathrm{Gl}^{\circ}$-aicat.

2a Gr-aicach-ií.

$3^{a}$ L-aitat-e.

Dicen Pedro y María cuando no se les murió ninguno.

Hija mujer

$f^{\text {a }} \mathrm{Y}$-aitcate.

2a Gr-aitcach-í. 
Notas. - Plural de Cat por Tat, en primera y segunda.

IX. N-aoenc : El marido

Sing. : fa $Y$-aoenc. 2a Gr-auinyí. 3a L-anenc (Anija L...).

Notas. - Ia 0 que se ruelve $u$ ante $i$ por $e$ en la segunda persona.

Moc. : Ová, con la $Y \ldots$; 2a D...i; $3^{\text {a } L \ldots}$

Toba : Louva.

X. N-egargá : La muerte

Sing.̀. : 1a Y.gargá .

2a Gl'-egararg-é.

$3^{a}$ L-egargà̀ (Pedro L.).

Plur. : 1a Gr-egargá.

2a Falta.

$3^{a}$ L-eguergá .

Notas. - 1a Sincopacion de $e$ en primera persona.

2a Tercera persona plural anómalo.

Ifoc. : Nélaoga con pref. $1^{a}$ $Y \ldots ; 2^{\text {a }} D \ldots i ; 3^{\text {a }} L \ldots$

XI. L-atéta : Muslo

Sing. : $1^{\text {a }}$ Y-atéta. 2a Gr-atechi. 3a L-atéta (Pedro L.).

Plur. : Ia Gr-atretri. 2a Gr-atretri-í. $3^{\mathrm{a}} \mathrm{L}$-atretri.

Notas. - El plural es doble, nuestros muslos.

Moc. Octel-lecta, plural Octelectari con $1^{\text {a }} Y \ldots$; 2a $D \ldots i$; $3^{\mathrm{a}} L \ldots$

Toba : Yotelta ó Telectá.

XII. N-ajapi : Nalgas (Ver Culo, XL)

Sing. : 1a Y-ajapi. 2a Gr-ajapi.

Nота. $-I$ por $i i$ en $2^{\text {a }}$.

Moc. : Ossâp, Asentaderas. Con $1^{\mathrm{a}} Y \ldots ; 2^{\mathrm{a}} D \ldots i ; 3^{\mathrm{a}} L \ldots$

XIII. N-aclataoé : Nombre

Sing. : fa Y.aclataoé. 2a Gr'-aclatauichí. 3a L-aclataoé(Ped.L.).

Nота. $-U$ por 0 en $2^{\text {a }}$.

XIV. N-atoete : Ojos

Sing. : la r-atoeté. 2a Gi-atoich-i. $3^{\text {a }}$ L-atoeté.

Plur. : I ${ }^{\mathrm{a}} \mathrm{Gr}$-atoete. 
a cir-atoichirigui.

3a L-aloeté eroujá.

Nota. - Todoregrular, menos segunda persona del plul'al.

Moc. : Iii corle.

XV. N-apé: Nalura de la mujer

$$
\begin{aligned}
& \text { Sing.. : la Y-apé. } \\
& \text { ga Gip-apí. } \\
& \text { 3 L-apé. }
\end{aligned}
$$

Nura. - No sería extraño que esta série pueda atribuirse al habla mujeril.

Mocoví : Ap, boca, con la , 1y...; 2. Cad...i; $3^{\mathrm{a}} \mathrm{Al}-\mathrm{l}$...

\section{Y-aacatéc : Palabra}

Sing. : fa Y-aacatec.

$2 a \mathrm{Gr}$-aacatiguí.

$3^{a} \mathrm{~L}$-aacatec.

Plur. : fa Gr-aacatéc.

2a Gr-aacatiguií.

$2^{2}$ L-aacategue.

Notas. - fa Falta de chicheo en 2 a persona.

2a Desinencias de 2 a $3^{\text {a }}$ en plural.

Moc.: Vacratéh, con prefijo.
Ia $1 . . . ; 2^{a} \quad D \ldots i ; L .$.

Toba: Vacalac, Nkakkí (I.).

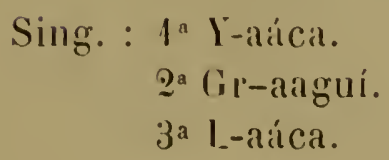

NotA. - Moc: Naak, pariente. Con la I...; 2a D...i; $3^{\text {a } L \ldots . .}$

XVIII. N-oalouge: Pecado; plural Noalougete

Plur. : fa Gr-aolougete. 2a Gr-oalougichiriguí.

Notas. - la Nuestros pecados.

2 a Forma de la 2 a persona.

Moc.: Nassoak. (Ter Arte Moc.). 小 $^{\mathrm{a}} \ldots$; $2^{\mathrm{a}} D \ldots i ; 3^{\mathrm{a}} L \ldots$

XIX. N-oala : El pecho

Sing. : fa Y-oala. 2a Gr-oale. $3^{\text {a L-Oala. }}$

Nota.-Todolegular. Hoc. : Oal-là, Estómago. la $Y \ldots ; 2^{\mathrm{a}}$ D...i; $3^{\mathrm{a}} \mathrm{L} \ldots$... 
XX. N-uichí : Pedo

Sing. : fa Y-uichí.

2a Gr-uichi.

$3^{\text {a }}$ L-uichí.

XXI. N-etaigc : $E l$ pelo

Sing. : 1 a $\mathrm{Y}$-taigc.

2 a Gr-etaiggui.

$3^{a}$ L-etaigc.

Nota. - Sincopación de e de' ${ }^{a}$ persona, que es eufónica.

XXII. N-aarenatanat : $E l$ pensamiento ; plural, Naarenatancate.

Sing. : 1a Y-aarenatanat. $2^{a}$ Gr-aarenatanachi. $3^{\text {a }}$ L-aarenatanat.

Plur. : fa Gr-aarenatancate. 2a Gr-aarenatancachi .

Not八s. -- 1a Nuestros pensamientos.

2 Todo regular.

Moc.: Adenactarni, pensar.

XXIII. N-achagec: $E l$ pié ; plural, N-achajáca

Sing. : $1^{\text {a }}$ Y-achagec. 2a Gr-achagiguí. $3^{a} \mathrm{~L} \cdot$ achagec

Plur.: 1 a Y-achajáca (mis piés). $2^{\text {a }} \mathrm{Gr}$-achajágayí.

3a L-achajáca.

Otra forma :

$1 G r-a c h a j a ́ c a$ (nuestros piés, etc.).

$2^{a}$ Acamii Gr-achajáca.

3a Gr (?)-achajáca erouja.

Moc.: Actáuh (se fué). Actavegue (anda).

XXIV. Niichi : La pierna

Sing. : fa Y-ichi.

(2a Gr-ichi.

Gr-ichi-li (tus piernas.

$3^{\text {a }}$ L-ichi (de Pedro).

Plur. : $1^{\text {a }}$ Gr-ichi (nuestras). 2a Gr-ichi-lii.

$3^{\mathrm{a}}$ L-ichi eroujá (déél).

Mocoví : Icti, con pref. fi $Y \ldots ; 2^{\mathrm{a}} D \ldots i ; 3^{\mathrm{a}} L \ldots$

XXV.L-ichigáric : La pobreza.

Sing. : $1^{\text {a }}$ Y-chigáric.

$2^{a} \mathrm{Gr}$-ichigarigui.

$3^{\mathrm{a}} \mathrm{L}$-ichigaric.

Plur. : la Gr-ichigárica.

$2^{\text {a }}$ (Falta).

3 L-ichigárica. 
Notas. - Ver ga persona del singular con más una $i$.

Iloc.: Ygorisca (¡Pobrecito!)

Toba : Tiogodik (Pobre).

XXVI. N-outíl : Él pueblo

Sing. : I Ý-oetá.

2a Gir-vetachi.

Plur. : la Gr-oeta.
Plur. : fa Gir-iliouquete.

2a Gr-ilionquechirii.

3a L-iliouquete eroujá.

Moc. : Yliaqui (póngalo). C-Cocti (rodillia). la $Y \ldots$; $2^{\mathrm{a}}$ D...i: : 3 a $L$...

Toba : Likté (L.).

XXIX. I-igilalca : La ropa

Toba: Mohik, (L.) Naiguelli.

XXVII. L-ajanı: La puerta; pl. L-ijam-i.

Sing. : I $\mathrm{Y}$-ajam.

2a Gr-ajam-i (de la iglesia).

$3^{\text {a }}$ L-iitaqui Lajami (del cielo).

L-ajamí ipîm.

Ioc : Lasóm, con plet. Ia $Y \ldots ; 2^{\mathrm{a}} D \ldots i ; 3^{\mathrm{a}} L \ldots$

Toba : Lasom.

XXVIII. N-iliouquete : Rodilla ó Rodillas

Sing. : fa $Y$-iliouquete. Q2 Srp-iliouquichi. $3^{\text {a }}$ L-iliouquete(Ped.).
Sing. : fa $Y$-gilalca. 2a Gr-igilalcaí. $3^{\text {a }}$ L-igilalca .

Nota. - Palece tema de plural.

XXX. N-auiga : La sangre

Sing. : fa Y-auiga.

') Gr-auiga chí.

$\mathrm{s}^{\mathrm{a}}$ L-auiga.

Moc. : Nevó. la $Y \ldots ; 2^{a}$ D...i $; 3^{\mathrm{a}} L \ldots$.

Toba : Elagó.

XXXI. N-oegegga : La sarna.

Sing. : fa Y-oegegga. 2a Gr-oegeggui.

Toba : Quesagá. 
Moc.: Neleagá, con $1^{\text {a }} Y \ldots$;

XXXII. N - achajagalate : $E l$ zapato. La escalera

2a $D . . . i ; 3^{\text {a }} L \ldots$

Toba : Calcolagaték.

Sing. : fa $\mathrm{Y}$ achajagalate. 2a Gr-achajagalichí. $3^{\text {a }} \mathrm{L}$-achajagalate.

(Ver XXIII).

XXXVI. N-aoé : El diente

Sing. : la Y-aoé. 2a Cr-auí. $3^{\text {a }} \mathrm{L}$-aoé.

XXXIII. N-añaquí : La silla

Sing. : $1^{\text {a }} \mathrm{Y}$-añaquí.

2a Gr-añaqui -chí.

$3^{a} \mathrm{~L}$-añaqui .

XXXVII. N-aoel: Las entrañas

Moc. : Innecta (estar sentado).

Moc.: Ové, con 1 a $Y \ldots ; 2^{a}$ $D . . i ; 3^{\mathrm{a}} L \ldots$

Toba : Oré.

XXXIV. N-etapegé: $E l$ sombrero

Sing. : fa Y-aoel.

2a Gr-auili.

Mocoví : Al-lot, con 1 a $Y . .$. ; $2^{\text {a }}$ Cact...i; 3a L...

Toba.: Dilahuel.

Sing. : $1^{\text {a }}$ Y-tapegé.

2a Gr-etapigí .

$3^{\mathrm{a}} \mathrm{L}$-etapegé.

XXXVIII. N-aal . El nieto, la nieta

XXXV . N-eleigáa : La vida

Sing. : Y-aal.

Gr-aali .

Sing. : fa Y-leigá.

2a Gr-eleigué.

Moc.: Avál-l (nieto). Plur.

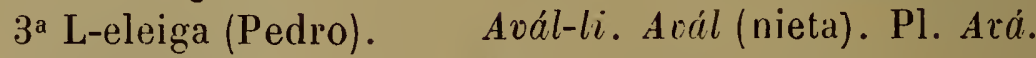

Plur. : 1a Gr-eleigá.

1a $Y \ldots ; 2^{a} C \ldots i ; 3^{a} L \ldots$

2a Gr-eleigueyí.

3a L-eleigá eroujá. 
Hoc. : Lai, con 1 a 1...; 2.

XXXIX. Noalouge : Culpa;pl.

Noalougete (Ver Pecado, IVIII).

D...i; $3 “ L \ldots$
Tobat : Yoyji (I..), Layi.

ILII. Mano derecha

Sing. : I Y Y-oalouge. Qa Gr-oalougichí.

3a L-Oalouge.

Sing. : Y-alaic.

Toba: (L.) Aloik (brazo (?) derecho).

XL. Lajapi: Culo

Anómalo. Canac: Comida.

Moc.: Losscip (Asentaderas). la $Y \ldots ; 2$ D...i; $3^{\mathrm{a}} L \ldots$

Sing. : fa Anac.

2 a Cinague.

$3^{a}$ Alac.

ILl. Luii : Lado

Plur. : fa Canác.

2a Canayí.

3a Alága.

Sing. : fa Y-uii.

2: (Falta).

Moc. : Annocó, Naiqque.

?3 $\mathrm{L}$-uii.

Toba: Connok, Nalik (L.).

GRUPO $2^{\circ}$

Singular: $1^{\text {a }} Y \ldots$; 2a $A r . . . i(?) ; 3^{\text {a }} Y l \dot{0} E l$.

Plural: $\quad \quad^{\text {a }} A r \ldots ; 2^{a} A r \ldots i($ ? $) ; 3^{a} Y l$ ó $E l$.

I. Il-quigi : El ánima



$2^{2}$ Ar-quigil.

Sing. : 1a Y-quigí.

2 Ar-quigi.

3a Yl-quigi Pedro.
Moc. : Nquii (alma) con $f^{a}$ $Y \ldots ;$ 2a $A r \ldots i ; 3^{\mathrm{a}} L \ldots$.

Toba : Hiquihi. 
II. Quiriouganate : El arado

Sing. : $1^{\text {a }}$ Y-quiriouganate. 2a Ar-quiriouganate. $3^{a}$ Il-quiriouganate.

Toba : Lacegancaté.

III. Quetal : Oreja ; pl. Quetela

Sing. : 1a Y-quitila (mis orejas). 2a Ar-quetalí (tus orejas).

$3^{\mathrm{a}}$ El-quetala (sus orejas).

Plur. : 1a Ar-quetala.

$2^{\text {a }}$ Ar-quetala, acamii. $3^{a}$ El-quetala, eroujá.

Moc.: Quel-lá, con pref. $\uparrow^{a}$ $Y \ldots ; 2^{\text {a }} R \ldots i ; 3^{\text {a }} L \ldots$

Toba : Quetelá (L.), Telá.

\section{Sub-clase de las anteriores}

IV. Caalat : Brazo; plur. Caalacate

Sing. : 1a Yr-caalát. 2a Gr-caalachí. $3^{\mathrm{a}}$ caalat.

Plur. : Ja Er-caalcate (mis brazos). $2^{\mathrm{a}}$ El-caalcáchiri.

$3^{a}$ El-caalcáte.

Moc.: Coiorii (abrazos). Toba : Aloik (L. derecho).

GRUPO $3^{\circ}$

Singular : $1^{\mathrm{a}} Y l \ldots ; 2^{\mathrm{a}} C a c h \ldots i ; 3^{\mathrm{a}} Y l \ldots$

I. Iligat: Miembro del varon

Sing. : 1a Yl-igat.

2a Cach-igach-i.

3a Yl-igat erajá.
Mocoví: Annéglet, con $1^{\text {a }}$ Ai... ; 2a Cast...i ; 3 ${ }^{\mathrm{a}}$ Al... 
GRUPO $4^{\circ}$

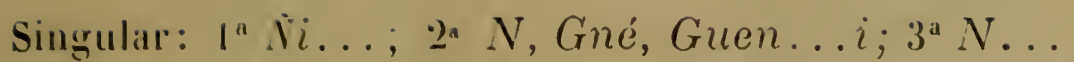

Plural: ${ }^{a} \mathrm{~N}$, Gan, Guen...ca; $2^{a} \mathrm{~N}$, Gan, Guen...ii;

$3^{\text {a }}$. ...e.

I. Aagát : Boca ; plur. Gannaacate

Sing. : la X̃i-agat.

2a N-aagachí.

$3^{a} \mathrm{~N}$-agát.

Plul. : la Gannaacate.

$2{ }^{a} \mathrm{~N}$-aachirií.

$3^{3} \mathrm{~N}$-aacate.

Moc.: Yol.legarnagál (lengua). 1 $Y . .$. ; פa $D . . . i$; 3a $L \ldots$

Toba: Paragtani (boca abajo estar) (L.).

II. Elpage : Carne

Sing. : fa İ-oaic.

2 a $\mathrm{N}$-oaigui.

$3^{\text {a }}$ -oait erajá.

Plur. : fa N-oayaca.

2a $\mathrm{N}$-oayagayi.

$3^{a} \mathrm{~N}$-oayaca eroujá.

Tuba : Lapát.
III. Até : Vedo

Sing. : la Nii-até.

2a Gn-achi.

3a N-até.

Plur. : la Gn-até (dedos). 2a Gn-achí (dedos).

Moc.: Lpalacaté (dedo). $1^{\text {a }}$ $Y \ldots ;$ 2a $L \ldots ; 3^{\text {z } \ldots . ~}$

1V. Noanerma : Hermana

Sing : fa Ni-oanerma. פa $\mathrm{N}$-oanerme.

$3^{a}$ N-oanerma Pedro.

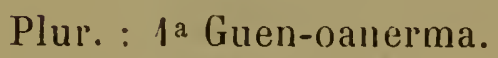

2a X-oanerme.

$3^{\text {a }} \mathrm{N}$-oanerme Pedro y (cachque) Juan.

V. Hermana mayor

$1^{\text {a }}$ Ni-oanerma nanqueí.

2a $\mathrm{N}$-oanerme namqueí. 
Hermana menor

I $\mathrm{Yi}$-oanerma nam aoenec.

2. $\mathrm{N}$-oanerme nam aoenec.

VI. Neınàgc: IIano izquierda

$1^{\text {a }}$ Ni-mágc, etc.

VII. Nagipi : Labio

Sing. : $1^{\text {a }}$ Ni-agípi.

2a N-agipchi.

$3^{a} \mathrm{~N}$-agipe Pedro.

Mocori: Al-lappi, con pref. 1 a $A y \ldots ; 2^{\mathrm{a}} C a d \ldots i ; 3^{\mathrm{a}}$ Al-l... Toba : Nacip (el (le arriba).

VIII. Mano

Sing. : la Ñi-apequena.

2a N-apequene.

$3^{a} \mathrm{~N}$-apequena Pedro.

Plur. : faGuen-apequena (manos).

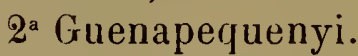

$3^{a} \mathrm{~N}$-apequena.

Natacqueuit (de los Tobas).

Moc.: Nappoquenná (muñeca). 1 a $\bar{N} . . ; 9^{\text {a }} N \ldots i ; 3^{\mathrm{a}} N \ldots$
IX. Mano izquierda

Sing. : $1^{a}$ Ñi-mac.

$2^{a}$ E-eniague.

$3^{\text {a }} \mathrm{N}$-emac.

Toba : Emak.

X. Noacará : Señor

Sing. : $1_{\text {a }} \tilde{N}$-oacará.

2a N-oacaré. 3a N-oacará.

Plur. : 1a Gann-oacará. 2a Gann-oacarií. 3a N-oacará eroujá.

XI. Naagagaquí : Sepultura

Sing. : Ñi-alagagaquí. 2a N-aagagagui.

Toba: Lavác (L.), Lauatchqui.

XII. Napaquenalaoel : Palma de la mano

Sing. : la Ni-apaquenalaoel. 2a Guen-apaquenelavel.

(Ver atras : VIII, Mano). 
Sub-Clase $\Lambda$

XIII. Nañalejoa : Hermano

Sing. : Ni-añalejóa.

2a An-añalejoa.
Plur. : 1 A An-añalejóa.

2a An-añalejorii(nos).

\section{Sub-Clase B}

XIV. Npaagnago : Enemigos

Sing. : 1a Ñi-paagnagòu.

2a El-paagnagòchi. Mocoví Npaguennará (ene$3^{a}$ El-paagnagòu Ped. migo), con la $\tilde{N} . . . ; 2^{a} N \ldots i ; 3^{a}$

Plur. : la Am-paagnagòu.

$2^{\text {a }}$ Al-paagonaurigui.

\section{GRUPO $5^{\circ}$}

Singular: 1 a $G r i \ldots ; 2^{\text {a }} G r \ldots i ; 3^{\text {a }} G r \ldots$

Plural: $\quad \quad^{\text {a }} G r \ldots ; 2^{\text {a }} G r \ldots i i ; 3^{\text {a }} G r \ldots e$.

I. Acan : Barriga

Toba : Tahám (L.), Dahám.

Sing. : $1^{\text {a }}$ Gr-Acan $\left({ }^{1}\right)$

2a $\mathrm{Gr}$-Acam-i.

$3^{a}$ (Falta).

Plur. : 1a Gr-Acan ( ${ }^{1}$ ).

2a Gr-Acam-ií.

3a Gr-Acall-yí.

II. Graré : Pestañas

Sing. : 1a Gri-aré.

2a Gr-arí.

3a Gr-aré.

Moc.: N-occoppagá (ham- Mocoví : Diadé, con $1^{a} D i . . . ;$ bre). 2a $R d \ldots i ; 3^{\text {a }} D \ldots$

(') Así en mi copia del uśnuscrito se ve que dele ser Gri. Puede resultar de un descuido. 
$2^{\mathrm{a}}$ Gr-acami.

III. Acám : Vientre

Toba : Cadahán(L.), Dahám.

Sing. : 1a Gri-acám.

GRUPO $6^{\circ}$

Singuldr: $1^{\text {a }} L i \ldots ; 2^{\text {a }} G l \ldots i, L \ldots i ; 3^{\mathrm{a}} L \ldots$

Plural: $\quad 1^{\text {a }} L \ldots ; 2^{\text {a }} L \ldots i i$.

I. Lachigat : Lengua

Sing. : $1^{\text {a }} \mathrm{Li}$-achigat. 2a Gl-achigachí.

- Toba : Latiagat (L.), Uachagat.

II. Oachiat : Orina

Sing. : 1 a Li-achiat. 2a Gl-oachiachí.

$3^{\mathrm{a}} \mathrm{L}$-oachiat.

Toba : Utiagáth.

III. Lajaganac : Risa

Sing. : 1a Li-ajaganac.

2 a L-ajaganagui.

$3^{a}$ L-ajaganac.

Plur. : la L-ajaganac acam.

$2^{a}$ L-ajagaguii. 


\title{
APENDICE B
}

\author{
GRUPO $1^{\circ}$
}

Articulaciones

Singular: $1^{a}(H) \ldots ; 2^{a}(H) \ldots i ; 3^{a} Y \ldots$
Plural: $1^{a}(I I) \ldots c a ; 2^{a}(H) \ldots i i ; 3^{a} Y \ldots$ A vel $\dot{e}$.

Mocovi : Singular: $1^{\text {a }} S \ldots ; 2^{\text {a }} \ldots i ; 3^{\text {a }} Y \ldots$

Plural: (Falta).

3a Yapaguiñi.

I. Ablandar la cera

Plur. : la Apagañi.

2a Apaiiñi.

$3^{a}$ Japiiñi.

Sing. : fa Aim aaligat loapa.

Qa Acami aaligachiloa.

3a Eraja yaaligat loapa.

Plur. : la Acam aaligatca loa.

Forma reflexiva : $1^{\text {a }} \tilde{n} i$-apı-

guini, yo me tapo.

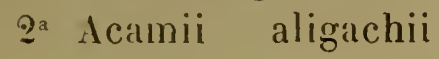
loapa.

En Mocoví, Taparse:

$3^{a}$ Erouja yaaligáte loapa.

Sing. : la Ñappoquiña. 2a Nappoiña. $3^{a}$ Nappoguiña.

Forma reflexiva $1^{\text {a }} \tilde{u}$-aaligat, go me ablando, etc. (Ver este ejemplo en los verbos.
1a X̃appogoña.
2a Nappoiña.
$3^{\text {a }}$ Nappoîñ.

II. Tapar (Ojo p. 12:3)

Sing. : la Apaguiñi. 2a Apiguiñi.

III. Abrir

Sing. : Ia Gijontougue. 
2a Gijouchiugue.

$3^{\mathrm{a}} \mathrm{Y}$-joutougue.

Plur. : 1a Gijoutag-ugue.

$2^{a}$ Gijouchí-ugue.

$3^{\text {a }} \mathrm{Y}$-joutrougue.

Otro modo :

Sing. : fa Yjoutougué.

2a Yjochiugué.

3a Yjotougué.

Plur. : 1a Yjotrougué.

2a Yjochiugué.

$3^{\text {a }}$ Yjoutrougué.

IV. Abreviar

Sing. : 1 Ajalalachi.

$2^{a}$ Ajalalachichi.

$3^{a}$ Y-ajalalachichi.

Plur. : 1* Gr-ajalalâchi.

2a. Sir-ajalalachichi.

$3^{\text {a }} \mathrm{X}$-alalachite.

V. Napatrañi : Abrigar

Sing. : 1a Apatañi.

¿a Apetañi.

$3^{a}$ Yapiñi.

Plur. : la Apaccatañi.

2a Napaitrañi.

3a Napatıañi.

Yo me abrigo. elc.

Sing. : fa Ñi-apagui.

2a N-apiguí.

$3^{a} \mathrm{~N}$-apagui.

Plur. : la Apagui (?).

2a N-apaiñi.

3a N-apatrañi.

VI. Yo acabo

Sing. : 1a Aim Aant.

2a Aanchi.

$3^{\mathrm{a}}$ Yaant.

Plur. : fa $^{\mathrm{a}}$ Aant.

$2^{a}$ Aanchii.

$3^{\mathrm{a}} \quad$ Yaanté.

En Mocoví :

Sing. : 1 a S-ommacte. $2^{\text {a }} \mathrm{L}$-ommactii.

$3^{\mathrm{a}} \mathrm{Y}$-ommacte.

Plur. : fa S-ommatácca.

2a L-ommactii.

3a Y-omınacté.

Otra forma :

Sing. : 1 a Somm'at, etc.

(Ver II y obsérrese la con-

VII. Acusar

fusión entre la forma activa y reflexiva).

Sing. : fa Aachi (sic). 


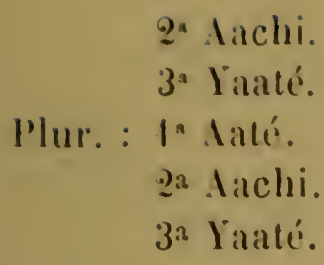

VIII. Adivinar

$$
\begin{aligned}
& \text { Sing. : fo Aarenapeque. } \\
& \text { פa Aarenapé. } \\
& 3^{\text {a }} \text { Y -arenapé. }
\end{aligned}
$$

Moc.: Sadinió (saber). (Ver Entender, Arte).

$$
\begin{aligned}
\text { Sing. : } & \text { I }^{\text {S }} \text { S-âdén. } \\
& 2^{\mathrm{a}} \text { àdiní. } \\
& 3^{\mathrm{a}} \text { Y-adén. }
\end{aligned}
$$

Plur. : 1a S-adenâcca.

2a âdini.

$3^{a}$ Y-âdéné.

$$
\text { IX. Afilar }
$$

Sing. : fa Egec grechiñi. 2a Egec grechiñi. $3^{\text {a }}$ Yegec grechiñi.

Plur. : $f^{\text {a }}$ Egec gretaim. 2a Egec grechiñi. $3^{\mathrm{a}} \quad$ Egec grechiñi.

X. Aflojar

Sing. : $1^{\text {a }}$ Ajalalgué. 2a djalaligné.

3a Yajalatgué.

Plur. : $1^{\text {a }}$ Njalalachitca.

2a Ajalalachí.

3" Yajalalachit.

En Mocoví :

Sing. : $1^{\text {a }} \mathrm{S}$-ocoyart-ogué.

$2^{a}$ occoyarti-ogué.

$3^{a} \mathrm{Y}$ - occoyarti-ogué.

Plur. : 1a $\mathrm{S}$-occoyarctavogué. $3^{a}$ Y-occovarti-ogué.

Obsérvese el fonetisino.

XI. Agradar

Sing. : fa Aoamam.

$2^{a}$ Aoamañi.

3a Y-oamam.

Plur.: fa Aoamanc.

$2^{a}$ Aoamañi.

$3^{\text {a }}$ Y.oamañi.

En Mocoví : Gustarle. A mi me gusta, etc.

Sing. : 1a Ñaman.

פa Namanni.

$3^{a}$ Namán.

Plur.: 1a Ñamannácca.

2 Namanní.

$3^{a}$ Namanné.

XII. Aguijonear

Sing. : 1a Aoaá. 
$2^{a}$ oxachí.

$3^{\text {a }}$ Y-oa.

Plur.: $1^{\text {a }}$ Aoaá.

$\AA^{\mathrm{a}}$ oarii.

$3^{\mathrm{a}} \mathrm{Y} \cdot$ oát.

XIII. Ahogar



$2^{a}$ Egargachañi.

3a Y-gargañi.

Plur. : 1 a Gregarañi.

$2^{a}$ Gregeriañi.

$3^{\text {a }}$ Y-grerañi.

Forma reflexiva: 1a Grigarañi: Yo me ahogo, etc.

XIV. Ahorcar

Sing. : 1a Avichil cajate.

$2^{\mathrm{a}}$ ichi-il.

$3^{\text {a }}$ Yuichiil.

Plur. : 1 a Auichiil.

$2^{a}$ ychiil.

$3^{\text {a }}$ Y...chiil.

Ahorca tú : Nuichiguigam.

XV. Ahuyentar

Sing. : 1a Apaanapéq.

$2^{a}$ paañapéq.

$3^{\text {a }}$ Ypaanapéq.

Plur. : 1` Apaaencapéq. $2^{a}$ paaiñíapéq.

$3^{\text {a }}$ Ypaanera.

XVI. Alejar

Sing. : 1a Ayatogué.

$2^{a}$ Ayachiugué.

$3^{\mathrm{a}} \mathrm{Y}$-ayatogué.

Plur.: $\left.\right|^{\mathrm{a}}$ Ayatogué.

2 a Ayachiugué.

3a Yayatrogué.

XVII. Hablar. Rezar

Sing. : Ia (Falta).

$2^{a}$ Ychi (habla).

En Mocoví (hablar):

Sing. : 1a Aim S-eectacá.

$3^{\mathrm{a}}$ D.eectacá.

XVIII. Volver

Sing. : la A-uiguilat.

$2^{a}$ uiguilaciri.

$3^{\text {a }}$ Y.uiguilat.

Plur. : 1a Auiguilate.

2 a uiguilachii.

$3^{\text {a }}$ Yuiguiláte.

XIX. var

Sing. : 1a Aat. 
2a Aachi.

$3^{\text {a }}$ Yaat.

Plur. : fa Latq.

2" Aachii.

$3^{\text {a }}$ Yaate.

En Ilocori :

Sing. : fa ES-an

2a E-anni.

3a EY-án.

Plur. : fa ES-annácca.

$2^{\text {a }}$ E-anní.

3a EY-anné.

XX. Pisar

Sing. : $1^{\text {a }}$ Achagañi.

2a Achacyguiñi.

3a Yachagañi.

Plur.: $1^{a}$ Achagagañi.

$2^{a}$ Achagaiñi.

$3^{a} Y$ achac iñi.

En Mocoví (andaré):

Sing. : la S'-ectoannó.

$2^{a}$ octaonnió.

$3^{\mathrm{a}}$ Y-octoannô.

Plur. : fa S-octoancó.

3a Y-octoanó.

XXI. Cocear

Sing. : $1^{a}$ Achac.

2 a Achague

$3^{a} \mathrm{Y}$-achac.
Plur. : Ia Acagac.

$2^{a}$ Achagui.

$3^{a} Y$-achaga.

(Ver anterior).

XXII. Álcanzar de arriba

Sing. : 1a Auiriguima.

2a Auichiguima.

$3^{\text {a }}$ Auiriguima.

Plur. : fa Auirguiguima.

2a Auiriguiguima.

$3^{\text {a }}$ Yauchiriguima.

XXIII. Confesar

Sing. : 1 a Ychat.

2a Ychachi.

$3^{\text {a }}$ Yichat.

Plur.: |a Ychatc.

2a Ychachii.

$3^{a}$ Yicháte.

(Ver Confesarse).

XXIV. Cortar

Sing. : fa Ychac.

2a Ychague.

$3^{\mathrm{a}}$ Yichac.

Plur. : la Ychagac.

2a Ychagui.

$3^{\text {a }}$ Yichaga. 
En Mocovi :

$\begin{aligned} & \text { Sing. : } \text { fa S ichâcá. } 2^{\mathrm{a}} \text { icharri. } \\ & 3^{\mathrm{a}} \text { ichacá. }\end{aligned}$

Plur. : 1a S ichar'sócco.

$3^{\mathrm{a}}$ icharé.

XXV Acompañar

Sing. : 1a Aqueya.

$2^{a}$ queyachi.

$3^{\mathrm{a}}$ queya.

Plur. : 1 a Aqueyarc.

$2^{a}$ queyarii.

$3^{a}$ Yqueyate.
En Mocoví :

Sing. : 1a S-coyá.

2a coyarí.

$3^{\mathrm{a}}$ coyá.

Plur. : $1^{\text {a }}$ S-coyarácca.

$2^{a}$ coyalí.

$3^{\mathrm{a}}$. coyacté.

Otro ejemplo :

Sing. : 1a Yiyá.

2a Divai.

3a $Y$-yá.

Plur. : 1a Ardeyá.

2a Diyaí.

3a Liyá.

GRUPO $2^{\circ}$

Articulaciones

Abipon : Singular: $1^{\mathrm{a}}(H) \ldots ; 2^{\mathrm{a}}(H) \ldots i ; 3^{\mathrm{a}} G r \ldots$

Plural : $1^{\mathrm{a}}(H) \ldots c ; 2^{\mathrm{a}}(H) \ldots i i ; 3^{\mathrm{a}} G r \ldots e ́$

Mocoví : Singular : $1^{\mathrm{a}} S \ldots ; 2^{\mathrm{a}} \ldots i ; 3^{\mathrm{a}} D \ldots$

Plural : (Falta).

I. Acrecento

Sing. : 1a Acagi anogué.

2a Acagi anogué.

3a IRcagi anogué.

Plur. : 1a Acagi anogué. 2a cagi inyugué.

3a 1Rcagi anogué.

En Mocoví (Santifico) :

Sing. : $1^{\text {a }}$ S·aguiá.

2a âqquiá. 
3* D-aguiá.

Plur. : I S-aqqquiagá.

शa ìcquiá.

3" D-aycuitau.

II. Alabar

Sing. : 1a Ienim.

ga lenañi.

$3^{\text {a }}$ Aenalle.

Plur.: fa Aentinc.

ga lenanyi.

$3^{a}$ Graenane.

III. Alimentarse

Sing.: $f^{\mathrm{a}}$ Aquene.

2a quinyi.

3a ERquene.

Plur. : la Aquiñic.

2a Yquinyi.

3a Tquiini.

gânam.

En Mocoví (comer) :

Sing. : fa Squeô.

$2^{\mathrm{a}}$ quiiô.

3a Lqueó.

Plur. : 1a Squiacô.

$2^{\mathrm{a}}$ quiió.

$3^{\text {a }}$ quẹèo.

IV. Saludar

Sing. : fa $^{\text {Yguinan. }}$
$2^{2}$ Ygnuinañi.

3agRiguinan.

Plur.: 1" Yguinan.

2a Yiguinayi.

3 a (iRiguinane.

En Mocoví :

Sing. : la S-iqquuin.

2a iqquuinni.

$3^{\text {a }}$ iqquîn.

Plur. : fa S-iqquînáca.

$3^{\text {a }}$ iqquînnê.

V. Confesarse

Sing. : $1^{a}$ Yclıacalan.

2a Ychacatañi.

$3^{\text {a GRichacatan. }}$

Plur.: 1a Ychacatanc.

2 Tchacatanyi.

$3^{\text {a GRichacatane. }}$

\section{En Mocoví :}

Sing. : fa Sichococtarn.

2a ichococtarnii.

3a Dichococtarn.

Plụr. : I Sichococtarnácca.

$2^{2}$ ichococtarni.

$3^{a}$ El Dichococtarné.

VI. Llorar

Sing. : $1^{\mathrm{a}}$ Eoca.

2a Eogaí. 
$3^{a}$ RGeoga.

Plur.: 1a Eoegaic.

$2^{a} \quad$ Eoagaii. 3a GReogai.

En Mocoví : Noyen, etc.

\section{GRUPO $2^{\circ}$ BIS}

(Ver grupo $11^{\circ}, \mathrm{n}^{\circ} \mathrm{VI}$, en que la $G r$ de la $3^{\mathrm{a}}$ persona se sustituye con $N$ ).

\section{Articulaciones}

Singular : $1^{\text {a }}(H) \ldots ; 2^{\text {a }}(H) \ldots i ; 3^{\text {a }} N \ldots$

Plural: $1^{\mathrm{a}}(H) \ldots(?) ; 2^{\mathrm{a}}(H) \ldots$ ?; $3^{\mathrm{a}} N \ldots$ (?)

GRUPO $3^{\circ}$

\section{Articulaciones}

Abipon : Singular : $1^{\mathrm{a}}(H) \mathrm{a} \ldots ; 2^{\mathrm{a}} \ldots i ; 3^{\mathrm{a}} \ldots$

Plural: $1^{\mathrm{a}}(H)$ a...c; $2^{\mathrm{a}} \ldots i i ; 3^{\mathrm{a}} \ldots t e ́$ ó é.

Mocoví : Singular : $1^{\text {a }} S \ldots ; 2^{\text {a }} \ldots i ; 3^{\text {a }} \ldots$

Plural $: 1^{\mathrm{a}} \mathrm{S} \ldots$ acca; $2^{\mathrm{a}} \ldots i ; 3^{\mathrm{a}} \ldots e ́$.

$3^{\text {a }}$ Ygaraoa.

I. Yo aborté ó malpari, con Plur.: $1^{2}$ (Falta).

Aim, etc. Nija (Ella)

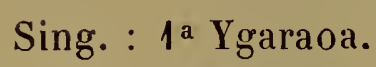

II. Abrazar

2a Ygarañi.

gracami.

Sing. : 1a Acaalgue. 
ga caligué.

$3^{a}$ caalgue.

Plur. : I leaalegue.

2" caaligue.

$3^{a}$ caaltegue.

III. Acepillar : Ejaloachichi ó

Egelocatan

Sing. : 1a Egelocatan.

2a Egelocatañi.

3" Egelocatan.

Plur. : Ia Egelocatanc.

2 E Eelocatañi.

3a Egelocatan.

IV. Acercarse

Sing. : la Acainnoá.

2a cainyoá.

$3^{a}$ cainnoá.

Plur. : la Acainnoá:

ga cainyoá.

$3^{a}$ cainnoá.

V. Acometer: Nialotan, Aim. etc.

Sing. : fa Aloutan.

2a Alouchan.

$3^{a}$ Aloutan.

Plur. : 1a Aloutan.

$\vartheta^{a}$ Alochian.

$3^{a}$ Yaloutan.
En singular de $3^{a}$, en pl. de 1?.

VI. Acompañar : Queyechi (Ver XXY del grupo 10)

VII. Aconsejar: Miniá (Ver Cachague)

Sing. : la Migi.

$2^{a}$ Migi.

$3^{\text {a }}$ Meem.

Plur. : 1a lìiginc.

2 a Meem.

3a Meem.

Otro ejemplo :

Sing. : fa Cachacatan.

2a Cachacatañi.

$3^{a}$ Cachacatan.

Plur. : 1 a Acachacatanc.

2a cachacatañi.

$3^{a}$ cachacatane.

VIII. Acordarse

Sing. : 1a Acalenetan.

2a Acalenetañi.

$3^{a}$ Acalenetan.

Plur. : 1a Acalenetanc.

2a Acalenetañigui.

$3^{a}$ Acalenetrn. 
IX. Acoseo: Yachacjagan

Sing. : $1^{\mathrm{a}} \operatorname{Achac}\left(1^{\mathrm{a}}, 2^{\mathrm{a}}, 3^{\mathrm{a}}\right)$.

Plur. : ta Achac jaganc. $2^{a}$ Achac jaganyi. $3^{\mathrm{a}}$ Achac jagan.

X. Advertir : Oacachapcan vel Ujactapcam

Sing. : 1" Oacatapeq. $2^{2}$ Oacachapilcan. $3^{a}$ Oacatapelcan.

Plur. : 1a Oacatapilcan. $2^{a}$ Oacachapialcan. $3^{\mathrm{a}}$ Oacatapialcan.

Otro ejemplo :

Sing. : fa Oajaetapeq. 2a Oajaitapeq.

\section{Afligir}

Sing. : $1^{\text {a }}$ Aitata. $2^{a}$ Aitatañi. $3^{a}$ Aitata.

Plur. : $1^{\text {a }}$ Aitata. 2 a Aitatii. $3^{\mathrm{a}}$ GRaitata.

En Mocoví (Afligirse) :

Sing. : $1^{\text {a }}$ S-atictactá. $2^{a}$ actictactá. $3^{\text {a }}$ Yactictactan.

Plur. : 1a Sactictarnácca. 2. actictactí. $3^{\text {a }}$ Yactictarctié.

XII. Aguardar ó Esperar

Sing. : 1a, $2^{\mathrm{a}}, 3^{\mathrm{a}}$ Caoate. Plur. : 1 $12,2^{\mathrm{a}}, 3^{\mathrm{a}}$ Coaoyate.

En Mocoví (Esperar y Aguardar) :

Sing. : 1a Sal-liaô. $2^{a}$ al-liao. $3^{\text {a }}$ Yal-liaô.

Plur. : 1a Sal-liacaô. $2^{a}$ al-liao. $3^{a}$ Yal-liraó.

XIII. Aguzar

Sing. : $1^{\text {a }}$ Apiloat. $2^{a}$ Apiloachi. $3^{a}$ Apiloat.

Plur. : 1a Apiloat. $2^{a}$ Apiloachi. $3^{a}$ Apiloati.

XIV. Alabar : Graenâm

Sing. : $1^{\mathrm{a}}$ Aenâm.

$2^{a} \quad$ Aenañi.

$3^{a}$ Aenanc.

Plur. : $1^{\text {a }}$ Aenanc. 
Qa . Ieninyi.

3* Grachane.

XY. Alegrarse: Netan

Sing. : 1 a Ayelgretapec.

2: Ayelgritapec.

3a A yelgretapec.

Plur. : $f^{\text {a }}$ A yelgritatapec.

: Avelgriitapec.

$3^{\text {a Avelgretapec. }}$

Otro ejemplo en Mocoví (Itan-netapeq) :

Sing. : fa Ni-íctoñ.

פa Neectoñi.

$3^{\text {a }}$ Neectoñ.

Plur. : fa Niictònácca.

2a Neectòni.

$3^{a}$ Necctoné.

En Mocovi (Reir):

Sing. : fa S-ayel-legré.

2a ayil-ligrí.

$3^{\text {a }}$ Dayel-legré.

Plur. : 1a Sail-ligriacca. $2^{a}$ ayil-ligui.

$3^{n}$ Dilyel-legré.

XVI. Hacer

Sing. : 1 a Aoe.

2 a Aoee.

$3^{\text {a }}$ Aoe.

Plur. : fa Aocque.

2 a Aoaye.

$3^{\text {a }}$ Aoate.

\section{En Mocoví}

Sing. : 1a 'Sòet.

2a ôicti.

$3^{\text {a }}$ Yôet.

Plur. : la Sòectácca.

2 a ôictí.

$3^{a}$ Yòecté.

XVII. Hacer asi

Sing. : 1a Ameligingue.

$2^{a}$ Ameliñigue.

$3^{\text {a }}$ Ameleengue.

Plur. : $1^{\text {a }}$ An aligingue.

2a Amaliiñigue.

$3^{\text {a }}$ Analeentegue. 


\section{GRUPO $4^{\circ}$}

\section{Articulaciones}

Abipon : Singular : $1^{\mathrm{a}} A j \ldots ; 2^{\mathrm{a}} \ldots i ; 3^{\mathrm{a}} Y \ldots$

Plural : $1^{\mathrm{a}} A j \ldots(?) ; 2^{\mathrm{a}} \ldots i i ; 3^{\mathrm{a}} Y \ldots$ (?)

Mocoví : Singular : $1^{\mathrm{a}} A s \ldots ; 2^{\mathrm{a}} \mathrm{O} \ldots i ; 3^{\mathrm{a}} \mathrm{E}$.

Plural: $1^{\text {a } A s . . . a c c a ; ~} 2^{\mathrm{a}} \mathrm{O} \ldots i ; 3^{\mathrm{a}} \mathrm{E} \ldots$. é

I. Sentarse

Sing. : 1a AJ-añi.

2 a añigni.

$3^{\text {a }} \quad Y$ ñigni.

Plur. : 1a AJanañi.

a Aanyiñi.

$3^{a} \quad$ Añiñi.

Otro ejemplo :

Sing. : la Ajañi.

$2^{a} \quad$ añigni.

$3^{\text {a }}$ Ynigni.

Plur.: $1^{a}$ Ajanañi.

$2^{a} \quad$ Aanyiñi.

$3^{\mathrm{a}}$ Yñiñi.

II. Levantarse

Sing. : 1a Ajañiguigan.

2a añigui-í. $3^{\text {a }}$ Y-ñiguií.

Plur. : la Ajanaguigan.

2a anyiguigan.

$3^{\text {a }}$ Yñiriguigan.

En Mocoví (Linnicsigôm):

Sing. : 1a Laassinsigôm.

2a L onnisium.

$3^{\text {a L Lnnissigom. }}$

Plur. : fa Laassinarsigom.

2a L onnisigóm.

$3^{\text {a }}$ LYnnissigôm.

III. Poner urriba

Sing. : 1a AJañiguigam.

$2^{\text {a }}$ añiguigam.

$3^{a}$ A Yañiguigam.

Plur. : 1a AJanaguigam.

$2^{a}$ anviguiçanı.

$3^{a}$ A Yanriguigam. 
En Mocoví :

IV. Acosturse

Sing. : 1" AJ-aluí.

ga aniini.

3a LI nigui.

Plur. : fa La Jauañi.

2a L auiñi.

$3^{a} \mathrm{~L}$ auinyan.
Singe. : fa Ni-namni.
2" Nemnanini.
$3^{\text {a Nemmani. }}$
Plur. : fa Ni-nnantmi.
qa Nennanini.
3a Nennani.

(Ver Nenannetañi).

GRUPO $5^{\circ}$

Articulaciones

Abipon : Singular : $1^{a} E j \ldots ; 2^{a} E \ldots \imath ; 3^{a} E y \ldots$

Plural : $1^{a} E j \ldots ; 2^{a} E \ldots y i ; 3^{a} E y \ldots r$.

M ocoví: Singular : $1^{\text {a }} E S \ldots ; 2^{a} E \ldots i ; 3^{a} E Y$.

Plural: $1^{a} E S \ldots a ́ c c a ; 2^{a} E \ldots i ; 3^{a} E Y \ldots e ́$.

\section{Alcanzar}

Sing. : $1^{\text {a }}$ EJ-añiguigam. 2a $\mathrm{E}$ añiguigam. $3^{a}$ EYañiguigam.
Plur. : fa EJ-aniguigam. 2a $\mathrm{E}$ - an ̣iguigam.

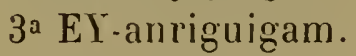




\section{GRUPO $6^{\circ}$}

\section{Con refuerzo $N$}

\section{Articulaciones}

Abipon : Singular : $1^{\mathrm{a}} \tilde{N} i \ldots ; 2^{\mathrm{a}} N \ldots i ; 3^{\mathrm{a}} N \ldots$

$$
\text { Plural: } 1^{\text {a }} \tilde{N} i \ldots c ; 2^{\mathrm{a}} N \ldots i i ; 3^{\mathrm{a}} N \ldots e \dot{e}
$$

Mocoví : Singular : $1^{\text {a }} \tilde{N} i$ ó $\tilde{N} i \ldots ; 2^{a} N \ldots i ; 3^{a} N \ldots$

P'ural: $\quad 1^{\text {a }} \Lambda^{\top} i$ ó $N i \ldots$ ácca; $2^{\mathrm{a}} N \ldots i ; 3^{\mathrm{a}} N \ldots$. é.

I. Ablandarse

Sing. : 1a Ñi-aaligat.

2a $\mathrm{N}$-aaligachi.

$3^{\text {a }} \mathrm{N}$-aaligat.

Plur. : fa Ni-aaligatca.

$2^{a} \mathrm{~N}$-aaligatchii.

$3^{\text {a }} \mathrm{N}$-aaligate.

Aaligat : Ablandar.

II. Taparse

Sing. : $1^{\text {a }}$ Ni-apaguiñi. 2a $\mathrm{N}$-apiguiñi.

$3^{a} \mathrm{~N}$-apaguíni.

Plur. : ^a Ñi-apagañí.

2a N-apaiiñi.

3a $\mathrm{N}$-apiiñi.

Apaguiñi : Tapar.
III. Abajar

Sing. : $1^{\text {a }}$ Ni-achiguiñi.

2a Naachiguiñi.

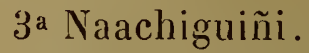

Plur. ; 1a Ñi-ataguiñi.

ஓa N-achiguiñi.

$3^{a}$ Naachiguiñi.

IV. Abrigarse

Sing. : 1a Ñi-apagui.

$2^{a} \mathrm{~N}$-apigui.

$3^{a} \mathrm{~N}$-apagui.

Plur. : f a $^{\text {apagui. }}$

2a N-apaiñi.

$3^{a} \mathrm{~N}$-apatrañi.

Apatañi : Yo abrigo. 
En Mocovi (Cortar) :

V. Acordarse: Nichiuiñi

Sing. : I Ňi-cteni.

2" $\mathrm{N}$-ichiuiñi.

3" N-eteni.

Plur. : fa $\bar{X}$-eteunc.

2. $\mathrm{N}$-ichininyi.

$3^{\text {a }} \mathrm{N}$-eteune.

VI. Acostarse: Nenannetañi

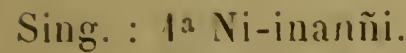

$2^{\mathrm{a}} \mathrm{N}$-cenanniñi.

$3^{a}$ N.eenanñi.

Plur. : fa Ni-inamnañi.

2a $\mathrm{N}$-eenanñiñi.

$3^{\text {a }} \mathrm{N}$-eenanก̃iñi.

En Mocoví :

Sing. : \{a Ni-naani.

2a $\mathrm{N}$-ennanini.

$3^{\text {a }} \mathrm{N}$-ennani.

Plur. : fa Ni-nnanârni.

2a $N$-emanini.

$3^{a}$ N-ennani.

VII. Acuchillar : Noaralta

Sing. : fa Ñoaralta.

$2 a$ Noachaltá.

$3^{a}$ Noaraltá.

Plü. : la Ñoacaltá.

2a Noachialtá.

$3^{2}$ Noaraltá.
Singr. : fa S-íchicá.

2a icharrari.

$3^{\text {a }}$ ichacát.

Plur. : fa S-icharsócco.

$3^{\text {a }}$ ichàré.

VIII. Adelantarse, tambien Adelantate tú.

Plural : Añitaogue.

IX. Adorar : Ñimamnachitooá

Sing. : 1 ${ }^{\text {a }}$ i-mamnachit. $2^{\text {a }}$ N-emamnachichi. $3^{a}$ N-emamnachit.

Plur. : $1^{\text {a }}$ Ñi-mamnachit. 2a $\mathrm{N}$-emamnachii. $3^{\text {a }} \mathrm{N}$-emamnachité.

Otro ejemplo :

Sing. : 1a Ncaôñapeq.

2 a caôñapéq.

$3^{\text {a }}$ caòñapéq.

Plur. : † $^{\mathrm{a}}$ caogancapéq.

$2^{\mathrm{a}}$ caogñiapeq.

$3^{a}$ caogñapeq.

X. Adornar : Lánoamatetá

Sing. : 1a Noamat.

$2{ }^{3}$ Noamachi.

$3^{\text {a }}$ Noamat. 
Plur. : 1a Ñoamât.

2a Noamachi.

$3^{a}$ Noamat.

XIV. Afrentar, castigar : Namilquetapéq

XI. Adquirir : Naammatanat

Sing. : $1^{\text {a }}$ Ni-ammatanat.

$2^{2} \mathrm{AN}$-ammatamachi.

$3^{\mathrm{a}} \mathrm{N}$-ammatanat.

Plur.: 1a N-ammatancate.

$2^{a}$ N-ammatancachi.

$3^{\mathrm{a}} \quad \mathrm{N}$-ammatancate.

XII. Afear : Lanaayapeq

Sing. : $1^{\text {a }} \tilde{\text { Naagan. }}$

$2^{\text {a }}$ Naañi.

$3^{a}$ Naagam.

Plur. : 1a Ñáagamc.

2a Naagamyi.

$3^{a}$ Naacné.

Sing. : 1a Niamilq.

$2^{a}$ Naamilgui.

$3^{\text {a }}$ Naamilq.

Plur. : 1a Ñamilq.

$3^{a}$ Namilgué.

XV. Ser afrentado

Sing. : $1^{a} \tilde{N} i$-amilca.

2a $\mathrm{N}$-amilguica.

$3^{\mathrm{a}} \mathrm{N}$-emilguetapéq.

Plur. : 1a Ñi-amilcatapéq.

2a $\mathrm{N}$-amilquitapéq.

$\delta^{a} \mathrm{~N}$-amilguetapéq.

XVI. Bajar la carne: Niacñi elpage

XIII. Afeitar : Lanaate lanareue, vel Najate.

Sing. : $1^{\text {a }}$ Niate lanareue. 2a Naachi lanareue. $3^{a}$ Naate lanareue.

Plur. : 1a Ñaatagá lanareue. $2^{a}$ Naachi lanareue. $3^{a}$ Naate lanareue.

Otro ejemplo :

Sing. : 1a Ñajact lañareue. $2^{a}$ Najachiqui lanareue $3^{\mathrm{a}}$ Najatege lanareue.

Sing. : $1^{a}$ Niacñi.

$2^{a}$ Naachiquiñi.

3a Naacñi Pedro elpage.

Plur. : $1^{\text {a }}$ Niactañi.

$2^{a}$ Naachiguiiñi.

$3^{a}$ Naachiñi.

XVII. Madrugar

Sing. : $1^{\text {a }}$ Naitetaguin. $2^{a}$ Naichitaguin. $3^{\mathrm{a}}$ Naitetaguin. 
Plur. I Naicatiguin (sic). פa Naichitaguiin. 3" Naitetragnuin.

En Mocovi (Lerantarse) :

Sing. : fa Laassinsigònn.

2a Lonnisium.

$$
\text { etc., etc. }
$$

Otro ejemplo, tambien en Mocoví :

Sing. : Ia Aschivinni.

$$
2 \text { a ovinni. }
$$

$3^{a} \quad$ iviguinni.

Plur. : 1 Assararni.

$$
2 \text { a orinni. }
$$$$
3^{\text {a }} \text { ivinni. }
$$

\section{Otra forma :}

$$
\begin{aligned}
& \text { Sing.: fa Aschinchim. } \\
& 2^{\mathrm{a}} \text { onnischiguim. } \\
& 3^{\mathrm{a}} \text { ymnischiguim. } \\
& \\
& \text { etc., etc. }
\end{aligned}
$$

XVIII. Estar sentado

Sing. : 1a Ñachicatañi. 2 Nachigiitañi. $3^{n}$ Nachicatañi.

Plur.: 1" Nachignuicatañi.

$2^{a}$ Nachiguiitañi.

$3^{\text {n }}$ Nachicatrañi.

En Mocoví (Estar sentado):

Sing. : $1^{\text {a }}$ (Sis)innectá.

$2^{a} \quad$ Linnictá.

$3^{\text {a }}$ ennectá.

Plur. : 1 a Siss inactá.

2a Liinictá.

3a ennectá.

XIX. Participo

Sing. : 1a Niaone.

$2^{a}$ Naoñie.

$3^{\text {a }}$ Naone.

Plur. : fa Ni-aoanigue.

2a Naoñigue.

3a Naoanta.

En Mocoví (Dar) :

Sing. : $1^{\text {a }}$ Esan.

2a Eanní.

$3^{\text {a }}$ Eyán.

Plur. : fa Esannacca.

2a Eanní.

$3^{\text {a }}$ Eyauné. 


\section{GRUPO $7^{\circ}$}

Con refuerzo D. Partícula $R(=D$ Moc.)

\section{Articulaciones}

Abipon : Singular : $1^{\mathrm{a}} R i \ldots ; 2^{\mathrm{a}} R \ldots i ; 3^{\mathrm{a}} R$;

Mocoví : Singular : $1^{a} D i \ldots ; 2^{a} D \ldots i ; 3^{a} D \ldots$

Plural : $1^{\mathrm{a}} D i \ldots a ́ c c a ; 2^{\mathrm{a}} D \ldots i ; 3^{\mathrm{a}} D \ldots \dot{e}$.

En Mocoví (Bailar) :

I. Saltar ó Bailar

Sing. : Ia Ri-ahat.

2 a R-ahachi.

$3^{a} \mathbf{R}$-ahát.
Sing. : $1^{\text {a }} \mathrm{Y}$-assot. $2^{a} \mathrm{D}$-assoctí. $3^{\text {a }}$ L-assot.

Plur. : 1a Y-assottáca. $3^{\text {a }} \mathrm{L}$-assocté.

\section{GRUPO $8^{\circ}$}

Con refuerzos iniciales $R$ y $N$ de la $3^{\text {a }}$

\section{Articulaciones}

Abipon : Singular : $1^{\text {a }} R i \ldots ; 2^{a} G r \ldots i ; 3^{a} N \ldots$

Plural : $1^{a} G r \ldots k ; 2^{a} G r \ldots i \ddot{i} ; 3^{a} N \ldots e ́$.

Mocoví : Singular : $1^{\text {a }} D i \ldots ; 2^{\text {a }} D \ldots i ; 3^{\text {a }} N \ldots$

Plural : $1^{\mathrm{a}} A r d \ldots ; 2^{\mathrm{a}} D_{\ldots} \ldots \dot{i} ; 3^{\mathrm{a}} N \ldots e ́$. 
I. $A m a)^{\circ}$

Sing. : fa Rikapit. Qa Grkípichi. 3a Nkípit.

Plur. : I Grkapiták. 2a Grkipichii. 3a Nkapité.

II. Temer

Sing. : fa Rietachá. 2a Gretachi. $3^{\text {a Netacha. }}$

En Mocoví :

Sing. : la Di-octiâ. 2 D-octiá. 3a N-octiá.

Plur. : fa Ard-octiá. 2a D-ôctiá. $3^{2}$ N-octità.

III. Desear

Sing. : 1 Rihé. 2a Grihí. $3^{a}$ Nihé.

En Mocoví :

Sing. : 1 a Di(i)ssiá. 9a D-issiá.

$3^{\text {a }} \mathrm{N}$-issia.

Plur. : fa Ard-issia.

ga D-issiá.

$3^{\mathrm{a}} \quad \mathrm{N}$-issité.

IV: Ser perezoso

Sing. : fa Ri-aal. 2a Gr'-aalí. $3^{\text {a }} \mathrm{N}$-aal.

\section{Tener vergüenza}

Sing. : 1 Ri-pagak.

2a $\mathrm{Gr}$-pagaré.

$3^{\mathrm{a}} \mathrm{N}$-pagak.

VI. Vomitar

Sing. : fa Ri-emaletapék. 2a Gr-emalitápék. $3^{\mathrm{a}} \mathrm{N}$-emaletapék.

VII. Obedezco

Sing. : $1^{a}$ Ri-ahapét. 2a Gr-ahapichi. $3^{\text {a }} \mathrm{N}$-ahapet.

En Mocoví :

Sing. : 1ª Assevel-lék. 
GRUPO $9^{\circ}$

Refuerzo inicial $R\left(=D\right.$ Moc.) y $Y$ de $3^{\mathrm{a}}$

\section{Articulaciones}

Abipon : Singular : $1^{\text {a }} G r i \ldots ; 2^{\text {a }} G r \ldots i ; 3^{\text {a }} Y \ldots$

Plural : $\quad 1^{\mathrm{a}}\left(\begin{array}{r}r \\ r\end{array} \ldots ; 2^{\mathrm{a}} G r \ldots i i ; 3^{\mathrm{a}} Y \ldots e^{\prime}\right.$

Mocoví : Singular : $1^{\mathrm{a}} D i \ldots ; 2^{\mathrm{a}} D \ldots i ; 3^{\mathrm{a}} Y \ldots$

Plural : $1^{\mathrm{a}} A r d \ldots ; 2^{\mathrm{a}} D \ldots i ; 3^{\mathrm{a}} Y \ldots e \dot{ }$.

\section{Abreoiar ó Darse prisa}

Sing. : 1a Gri-ajalat.

$2^{a} \mathrm{Gr}$-ajalati.

$3^{\text {a }}$ Y-ajalat.

Plur. : $1^{\text {a } G r-a j a l a t . ~}$

$2^{a} \mathrm{Gr}$-ajalatii.

$3^{\text {a }}$ Y-ajálate.
II. Ahogarse

Sing. : la Gri-garañi.

2a Gre-gachañi.

$3^{a}$ Y-gdrañi.

Plur. : 1a Gre-garañi. 2a Gre-gari-añí. $3^{a}$ Y-gregarañi.

\section{GRUPO $10^{\circ}$}

\section{Conjugaciones anormales}

\section{Articulaciones}

Abipon : Singular : $1^{\text {a }} Y \ldots ; 2^{\text {a }} G r \ldots i ; 3^{\text {a }} L \ldots$

Plural : $1^{\mathrm{a}} G r \ldots c ; 2^{\mathrm{a}} G r \ldots i i ; 3^{\mathrm{a}} L \ldots \hat{e}$.

Mocoví : Singular : $1^{\text {a }} Y \ldots ; 2^{\mathrm{a}} D \ldots i ; 3^{\mathrm{a}} L \ldots$

Plural : $\quad 1^{\mathrm{a}}$ Ard...; $2^{\mathrm{a}} D \ldots i ; 3^{\mathrm{a}} L \ldots$ 
1. Aborrecer

Sing. : 1a Yoetat.

2a Gr-oetachi.

3a L-oetat.

Plur. : I $^{\text {a }}$ ir-oetagt.

2a Gr-oetagchi.

3a L-oetágte.
III. Acostumbrarse

Sing. : 1a Macha-girq.

$2^{\text {a }}$ Gra-giriit.

3a Mach Lagirq.

Plur. : 1a Mach Gragiriq.

2a Mach Gragririq.

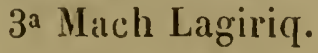

En Mocovi (Sospechar mal): $\quad=$ Ojo á la

Sing. : 1a LL-ovectá

$2^{\text {a }}$ D-ovecti-á.

3a Y-ovectá.

Plur. : 1a Ard-ovectá.

2a D-ovecti-á.

$3^{\text {a }}$ Y-ovectá.
Sing. : fa Mati-Yagirq.

2a Gragiriit.

3a Màti-Lagirq.

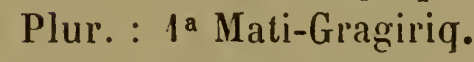

2a Mati-Gragiriq.

$3^{\text {a Nati-Lagiriq. }}$

GRUPO $11^{\circ}$

Flexiones anómalas

\section{Articulaciones}

Abipon. Singular : $1^{\mathrm{a}} L i \ldots ; 2^{\mathrm{a}} L \ldots$; $3^{\mathrm{a}} L \ldots$ Plural : $\quad 1^{a} L \ldots c ; 2^{a} L \ldots i i ; L \ldots$.

I. Abstenerse : Lapiñi

Sing. : $1^{\text {a }} \mathrm{Li}$-apim.

๑a L-apiñi. 3a L-apin.

Plur. : fa L-apínc.

2a L-apiñi.

$3^{\text {a }}$ L-apine. 

Plur. : $1^{\text {a }}$ Anacague. $2^{\text {a }}$ Anayague.
II. Acariciar : Laeoyan nachi- chi
$3^{a}$ Aneyeragué.

Sing. : $1^{a}$ Laeoyân nachit.

2 Leaoyàn nachichi.

$3^{\circ}$ leaayân nachit.

Plur. : 1a Leaoyân nachit.

$2^{\text {a }}$ y $3^{\mathrm{a}}$ como el singular.

III. Yo me rio

Sing. : $1^{\text {a }}$ Li-ajagan.

$2^{2}$ L-ajagañi.

$3^{a}$ L-ajagan.

Plur. : I' Li-ajaganc.

$2^{a}$ L-ajaganyi.

$3^{a}$ L-ajagane.

IV. Acortar: Larichi aolq

Sing. : $1^{\mathrm{a}}, 2^{\mathrm{a}}$ y $3^{\mathrm{a}}$ Larichi aolc.

Sing. : 1a Acainuguenatan

2a Acain-y-ugue.

$3^{\text {a }}$ Nacainugue.

Plur. : 1 a Acainugue.

$2^{2}$ Acainugue.

$3^{a}$ Nacainugue.

(Ver Grupo $2^{\circ} \mathrm{Bis}$ ).

VII. Alimentar : Aquiñi gâm

Sing. : 1a Aquiñi gâm.

2a Nquiñi guiñiam.

$3^{\text {a }}$ quiñi gam.

Plur. : 1a Aquiñi gàmc. $2^{2}$ quiñi ganyi. 3a Yquiñi gam.

Plur. : 1 ${ }^{\mathrm{a}}, 2^{\mathrm{a}}$ y $3^{\mathrm{a}}$ Larichi aolcá.

V. Acostumbrarse : Laniague

Sing. : $1^{2}, 2^{a}$ y $3^{\mathrm{a}}$ Laniague. 


\section{ORACIONES Y DOCTRINA CRISTIANA}

En seguida se reproducen las Oraciones y Doctrina Cristiana que contienen los manuscritos del Padre Brigniel. Ia traducción es la propia del origrinal. Por comcdidad se transeribe palabra por palabra, reservando las observaciones para notas al pié. Es conveniente hacer el cotejo de las voces con sus congéneres en el Léxicon.

\section{PADRE NUESTRO}

Gretá, Padre muestro

Cianime ', que estás

Quir ', en los

Ypiam, Cielos

Chigrica, ojalú (sea)

Traaguiam, respetaremo.s (ado)

Erá, ese ó él

Graclatauichi, tu nombre

Laneguimacam, vendrás á nosotros

Grigitam (que) querremos

Greequetegué, cumplir

Quena ${ }^{2}$, en la ó esia

Aloá, tierra

Quera ${ }^{3}$, como

Marigichmeem, tú quieres

Quera ${ }^{3}$, como

Yeequetegué, cumplen

Quecó ${ }^{3}$, los que

Quiñitaoat ${ }^{4}$, están contigo

Quír ${ }^{2}$, en él
Ypiam, Cielo

Queco naca, nuestra

Quená, comida

Noeyagá, del cuerpo

Cachaque, $y$

Ylquigi, del alma

Quenole ${ }^{2}$, de cada

Neotá, dia

Tat, también

Nañañiermam, darásnosle

Eneogá, hoy

Clach, tambien

Enam ercaoquela, tendrasnos lístima

Queno ${ }^{2}$, por (esas)

Naaye, no buenas (malas)

Gragir-ricá, nuestras costumbres

Quera ${ }^{3}$, como

Arcaoque, nos apiadamos

Queco ${ }^{2}$, de los 
Naquiatragoa, nuestros enemigos (que nos quieren mal)

Chit, no

Oaitalam, quieran escuchar

Amblayam, cuando

Grajañiñi, los quiera ocltear (nos?)

Queno, con los
Niloencatannacá, engaños

Hec, (ese ó) él

Namnaaquent, malo hichicero (mas m. h.)

Ychigroaammachipcam, nos has de guardar

Queno ${ }^{2}$, de los

Naaye, males.

Notas. - ${ }^{1}$ Cañime, parece una sincopación de Aham, tú, y Ená, ese ó el, con un subfijo que sirve de verbo estar de algun modo.

${ }^{2} Q$ el prefijo preposicional.

${ }^{3} Q$ prefijo usado como conjunción relativa en antecedente y consecuente.

4 Ver Cañime. La $Q$ aquí parece ser la preposición nuestra con, y el pronombre $i \tilde{n} i$ con $t a$, el verbo estar en forma participial. En la terninación oat suena algo de caso régimen de $2^{a}$ persona.

En forma de Apéndice se hallara un estudio comparado de esta oración con la de igual clase que reproduce Adelung de Hervas.

Los romances de Brigniel no siempre corresponden estrictamente al original; por ejemplo, la voz Abipona no dice malo hechicero, sinó más malo hechicero, ó sea, malísimo.

AVE MARIA

Ñiquiñioagoa, te saludo Maria Oaoapaití, llena

Queca, de la

Naim ${ }^{1}$, más

Gracia, gracia

Dios, Dios
Ñoacará, Nuestro Señor

Yuiaguí, tienes

Acamí ${ }^{2}$, tu vientre

Nemacaignate, venerada

Piitaogue, arriba

Queno, de (esas) las 
Nogue, Lodas

Queno, (esas) las:

Oanerma, mujeres

Clach yucem, y tambien como

Nemacaignate, es renerado

Ená, ese (el)

Graitachi, tu hijo

Jesus, Jesús

Santa Maria, Santa María

Dios, Dios (de) l.ate, madre

Ncaognapialcam, ruega por

Acám, nosotros

Oalouigrica, pecadores

(Quité, ahora

Cache, $y$

Amblayam, despues cuando

Arircae, llegue

Ecá, la

Grelougá, muestra muerte.A men

Notas. - ${ }^{1}$. Naim, mas, interpretación dudosa.

"Acami, adviértase que es tu vientre y no el pronombre que dice tí.

CREDO

Ajouetelgué ', creo

Quiñi, en el

Dios, Dios

Letá, Padre

Namachiga, que nada

Ecorionapec, dificulla

Naenatanc, Hncedor

Quir, de el

Ypiam, cielo

Cach, $y$

Quena, de la

Alóa, lierra

Ajouetelgué, creo en

Jesu Cristo, Jesu Cristo

Yñitara, único

Laetat, hijo suyo

Noacará Nuestro Señor

Nancaayangui ², se hizo (con canigi'a)
Yoalé, hombre

Canigra (antes)

Mach cace, dándolo el

Espíritu Santo, Espíritu Santo

Queiñiguiñi, nació (con cani-

gra)

Canigrá antes (con nació)

Mañiae, de la Doncella

II $^{\text {a }} \mathrm{S}^{\mathrm{ma}}$, Maria Santísima

Lichigrilatnec, padeció

Egem, cuando

Lichinatangue mandó

Poncio Pilato, Poncio Pilato

Noariguí, clavar

Canigra (hace claró de clacar)

Liquiinâñâlá, en la Cruz

Oaoa, murió (con can)

Canigrá (hace: murió de oaoa)

Niginini ${ }^{3}$, fué sepultado 
Quiquiquiñi ${ }^{3}$, bajó

Ylquigí, el alma

Queca, de la

Aloa, tierra

Laoachiñi, al centro (metido ya den(ro)

Naachigigam ${ }^{4}$, sacó

Loacalí, las almas

Eco, las que

Nanc, tuvieron

Ariaca, buenas

Lagir-rica, costumbres

Egem despues de (cuando fueron)

Leroaca, dos

Neotá, diạs

Catammatcara, al otro dia

Natatougué ${ }^{3}$, resucitó

Eco, de los

Eguergueicá, muertos

Matajaimec ${ }^{4}$, subió

Querá, á los (al)

Ypiam, Cielos

Yñi, allí

Lanachí catañi, está sentado

Quera, á la

Alaic, derecha

Quiñi, de el

Dios, Eios

Leta, Padre

Namachiga, que nada

Ecorionapec, dificulta

Clatque, $y$

Ychigueimecam, desde alli ha de venir
Amnajatagni, á preguntar

Queno, á los

Eleierá, vivos

Cach, $y$

Queno á los

Eguergueica, muertos

Ajouetelgue, creo en

Espíritu Santo, Espiritu Santo

S. I. C., Santa Iglesia Católica

Cach, $y$

Queno, en los que

Naoamnagoa, comen juntos

Eco, (esos) los

Nam, más

Elcaocate, queridos

Laicate, hijos

$\mathrm{Hec}, \mathrm{de}(e l)$.

Nancaori, Dios

Ajouetelgue, creo

Queca, en eso

Ancaogá, tiene lástima

Queno, de los

Naaye, no buenos

Groalougeté, nuestros pecados

Querá, en la

Latatgá, resurreccion

Eno, de los

Noeyagá, cuerpos

Cach, $y$

Queca, de la

Eleigá, vida

Nachitcatainñam, que no se acabará $(\sin$ fin $)$.

Ajoutelete, creo. Amen.

Notas. - ${ }^{1}$ Acordarse que la raíz es Ouetelgué; $A j$ es el prefijo de la persona en ciertos verbos. 
: Falta que se interprete el prefijo Nanc, acaso contenga la idea del todo.

"Falta aquí el canigra, tiempo ha.

i Sacarcí, porque la forma es de futuro.

\section{ACTO DE CONTRICION}

Ỹoacará, Señor mio

Jesu Christo, Jesu Cristo

Dios, Dios.

Cach, y

Ioalé, hombre

Acami, tú

Nancauiyi, por sois quien

Cach, y

Griiquiai, prosigo

Tanamach, por eso

Cacami, de lú

Greennammaraagui, ser tu tan bueno

Maoque, por eso

Laricapichigo ${ }^{1}$, te quiero mucho $(y a)$.

Lamerpeeiagué, sobre todas.

Queno, las

Aogue, cosas (todas)

Lanachigui, me pesa

Yavel, de corazon (mio)

Queno, por los que

Najaoeye ${ }^{2}$, he hecho

Yoalougeté, pecados

Nachiga, no

Asammotque, he guardado

Eno (los)

Grelatancachi, tus mandamientos.
Gleennetapiguí, pienso ya

Yavel, de corason (mio)

Lariennenanamquite, ser ya buena hora

Grieequetapilitan, he de cumplir.

Quenonàmach, porque ellas son

Graacatai, tus palabras

Cachit, no

Noennaltaam, me he de hacer burla (á mí mismo)

Amlate, cuando

Rigitam, quiera

Aoeye, hacer

Yoalougeté, pecados

Eco, esos

Netanetrayo ${ }^{3}$, que me están tentando

Gichataam, he de confesar

Eno, los que

Aoeye, hiciere

Yoalougete, pecados

Quiñi, al

Pai, Padre

Cach, y

Caoain, daré

Lageueté, payas (penitencia)

Ecá, eso que

Mgueicayo, me ha nombrado(?) 
Achiñagoam, mostraré Queno uich, con lo que Grigitam, he de querer

Lageueté, pagas (?) Queno nich, con lo que Grieennanacá, he de ser bueno Naoetam, aunque

Ychiguiric, mi pobreza

Latenc (es) grande

Oagam, pero

Clachqueem (tambien)

Tanachit, no hay

Canaaguí, con qué comparar(?)

Greennanae, tu bondad

Maogue, por eso

Apiitagoa, tengo esperanza

Mamorcaoquiicam, que me has de tener lástima
Cachque, $y$

Griatoñam, me has de ayudar Aoaltrocam, á arrojar

Eno, estas

Nachiga, no

Yalamberete, derechas

Yagirica, costumbres

Chachque, $y$

Aotam gracia, me has de dar gracia

Majá aoammatẻgue,para guar. dar

Grelatancchi, tus mandamientos

Auiraḋ, hasta que llegue

Ygargá, mi muerte.

Amen.

Notas. - ${ }^{1}$ Un buen ejemplo del igo, subfijo de caso régimen de $2^{\mathrm{a}}$ persona.

2 Ver Ncaoe, Vocabulario.

${ }^{3}$ Ayo ó yo, subfijo de caso régimen de $1^{a}$ persona.

\section{CATECISMO}

Yguem? Cuántos

Legaga, hay

Caorí, Dios?

Yñitara, Un

Nancaori, Dios.

Yguem? \& Dónde

Menaague, está

Aori, Dios ?

¿Menetajaimegué ${ }^{~}$, Está
Quiri, en el

Ypiam, Cuelo

Cachquena, $y$ en la

Alóa, tierra

Chieco, no hay

Grachiga, partes que no

Enae, esté.

Cami, ¿ Quièn

Laenatec, hizo 
Quipiatm, al Cielo

Cach, !!

Quena, la

Moa, lierra

Cach, y

Queno, il las

Aogué, cosus todas?

Hee, El

Nallcalori, Dios

Noacara, Nuestro Señor.

Miqui iñique, ¿Quién es

Iol'i? Dios?

La SSma Trid, La Santisima Trinidad.

Miqui iñique la, ¿Quién es la

S. Trinidad, Santisima Trinidad?

Dios Letí, Dios Padre

Dios Laetát, Dios Hijo

Dios Espíritu Santo, Dios Espíritu Santo

Queinnate, lres

Personas, personas

Yeequembretapichi, distintas

Yñital"ı, un

Inancaori, Dios nuestro.

Iñi, ¿El (es)

Letá, Padre

Me!at Aori ${ }^{2}$, es Dios?

Eé, Si

Clatque, también

Iñi, es $(e l)$.

Yñi, $E l$

Laetát, Hijo

Melat, es

Aori, Dios?

Ee, $S$ i

Clatque sñi, tambien es (él).
Iiii E. S., El Espiritu Sunto

Melat Aori, es Dios?

Ee, Si

Clatque ỹii, lambien es (él).

Maquegen ${ }^{3}$, EAcuso son

Yonate, tres

Aori, Dios?

Ygllit, No

Yùitara, $14 n$

Nancaori, Dios.

Egrmecá, ¿ Cuál

Queno, de estas

Queimnate, tres

Personas, personas

Aaviangui, se hizo (con can)

Yoale, hoinbre?

Canigra? (con Aayaugui)

Liñagec, La 2a

Laetat, Hijo

Laayangui, hecho

Yoalé, hombre

Canigra, (con Laay)

Laclataoe, se llama

Jesu Christo, Jesu Cristo.

Miqui iñigué, 6 Quièn es

Jesu Christo, Jesu Cristo?

Hec, $E l$

Nancaori, Dios mismo

Cach, $y$

Yoalé, hombre.

Yguem ? ¿ Dónde

Naneiquinyí, encarnó?

Lavel grate, Entrañas

María Santisima, María Santisima

Laenatec, haciéndolo

Espíritu Santo, Espiritu San-

to 
Namachac enetari, siempre Miqui irié, ¿Quién alli está lo mismo!

Maayé, doncella

Late, madre

$\mathrm{Hec}$, de el

Nancaori, Dios (mismo).

Migue negué ¿ Por qué

Maoé, causa

Manigitam, quiso

Miigá, morir

Jesu Christo, Jesu Cristo

Noacará, Nuestro Señor

Noaretaguí, clavado

Liquinánála? en la Cruz?

Tan, Porque

Nigitam, quiso

Grauiguigam, subirnos

Quiripiam, en el, Cielo

Acam, á nosotros

Oalouigueicá, pecadores.

Miqui irié, ¿Quién allí

Enetagui, está

Hostia Consagrada? HostiaConsagrada?

Enetaguí, Está

Nooyaga, el cuerpo

Hec nam, del (mismo)

Noacara, Nuestro Señor

Jesu Christo, Jesu Cristo.

Enetagui, está

Cañi, en aquel

Lecáct, metal

Amblaayamgué, despues de decir

Laaccaccá, las palabras

De la Consagracion, de la Consagracion?

Enetaguí ${ }^{3}$, Está

Jauigá, la sangre

Hec nam, del (mismo)

Noacara, Nuestro Señor

Jesu Christo, Jesu Cristo.

Yñi, El que

Yaaguit, recibe

Cañi, á esa

Hostia Corısagrada,Hostia Consagrada

Miqui irie, quién alli

Ychiit, recibe?

Ychiit, Recibe.

Yri, alli

Noeyagá, el cuerpo

$\mathrm{Hec}$, de (el)

Nam, mismo

Noacará, Nuestro Señor

Jesu Christo, Jesu Cristo.

I T'ema en que entra un infijo jaim ó jaime aún no determinado.

${ }^{2}$ Ver el verbo Estar. La $L$ puede ser una sustitucion de $N$.

${ }^{3}$ Maqueyen ¿́acaso son? Véase el verbo Nocten Cayet, es. Hay una gran variedad de estos verbos que significan algo parecido a nuestro verbo sustantivo: su base ó raíces 
parece que son pronombres de la :3" persona. Ver Vocabulirrio.

- Cireo errada mi copial en esta tengo Euetagui. Ver verbo Estar.

- Mas bien despues de hechas. Ver Vocabulario.

OTRAS PREGUNTAS DIC'TA DAS POR MARIANO ORELLANA, CAUTIVO CORDOBES YA DIFUNTO

Mique negué ', Con qué (ú sea cúmo)

Grageuete, se pagan (nuestra paga)

Nanat (damos)

Groalougete? pecados?

Erá, Con la

Lelougâ, muerte de

Jesu Christo, Jesu Cristo

Dios Laetat, Hijo de Dios.

Ejá, El cuando

Laoaod́, murió (con

Canigra,

Loquec, se fué

Quera, al

Ypiam, Cielo

Euetaatam, para estar con

Yĩi, el

Leta, Padre

Namachit ${ }^{2}$, para (nunca)

Cataicañam ², siempre (acabara)

Aoam ${ }^{3}$, andará.

Nauiriñam ${ }^{4}$, Ha de volver

Quena, al

Alóa? mundo, tierra?
Ee nauiriñam, Si ha de rolver.

Egmalquiam? ¿ 'iucundo?

Amblajanámañi, Cuando muramos

Naniriñam ${ }^{4}$, vendrá

Najatañam, á preguntar

Queno, á los

Eleiera, vivos

Cach, $y$

Queno, á los

Eguergueica, muertos.

Migué, 6 Cuáles

Enougue, estos

Namque, son (esos)

Eleiera? viros?

Eno, Estos

Nam, son (esos los?)

Nacarilá $\ddot{~}$ ) cristianos (bauti-

Lemachi, $\left\{\begin{array}{c}z a d o s \\ \text { (las cabezas) }\end{array}\right.$

Nam, esos

Teequetapilite, que cumplen (creen)

Lelatancate, los mandamientos Yñi nam, de (del mismo)

Dios, Dios 
Cach, $y$

Queno, los

A oammotque, guardan.

Migue, ¿ Cuáles

Enougué, estos

Namque, son

Equergueica? muertos?

Eno nam, Estos son

Nachiga, $\int$ los Infieles

Nacarila Lemachi (los queno)

Nacarila, (los que han lavado)

Lemachi, (las cabezas)

Cachqueno, y á los

(Namla, (mismos)

Nacarila (que los han la-l

( vado)

(Lemacachi, (las cabezas)

Nachigue (los) que no

Eueleté, creen

Lelatancate, los mandamientos

Yñi nam, de(l mismo)

Dios, Dios

Cachqueno, y á los que

Nachiga, no

Aoammótque, guardan.

Eno nam, (de) Estos que son

Nacarila, , Cristianos

Lemacachi (cabezas lavadas)

Lemachachi

Eguemeem. 6Qué se ha de hacer (Cómo será)

Amlaigate? cuando mueran?

Nometilitam, Taparán

Quena, con la

Alóa, tierra.

Auagam, pero

Laajoura, ) han

Guimam de ir
Eco (de ellos)

Loacalí, las almas

Cach, $y$

Queco (de ellos)

Noeyagá, los cuerpos

Enetraatám, á estar

Yñi, con el

Nancaori, Dios (mismo)

Quera, en el

Ypiam, Cielo

Namachit, para siempre

Cataicañam, sin fin

Loamága, con gusto

Latenc, grande

Namachitca, que no ha de

Najalatañi, acabarse.

Quichguecó ó

Quichgue ecó, ¡ ¿Qué de los

Eguergueicá, muertos

Equemenam? se ha de hacer?

Clachque, Tambien

Enam (á ellos) los

Nemetilitam, taparán

Quena, con la

Alóa, tierra

Oaagam, pero

Ambla, luego, cuando

Gratatapiugué, resucitan ellos

Lagourañam ${ }^{6}$, (han de ir)

Loacali, almas

Cachqueno, y los

Noeyagá, cuerpos

Queca, á la

Alóa, (de la) tierra

Laoachiñi, centro

Loetagrigoam, bajarán

Hec nam (estos mismos)

Naagueut, á habitar 


\begin{tabular}{|c|c|}
\hline $\begin{array}{l}\text { jahaichi (con Loeta enell oc.), } \\
\text { inficrno. }\end{array}$ & $\begin{array}{l}\text { Igná, No. } \\
\text { Iligue negue, \& Por qué }\end{array}$ \\
\hline Mauitapilite, \& Creis & Ilaoé, causas \\
\hline Eno, estos & Manitapilité? crecis? \\
\hline $\begin{array}{l}\text { Lapaganatancate, mandamien- } \\
\text { los }\end{array}$ & $\begin{array}{l}\text { Tam, Porque } \\
\text { Laaccacca, son palabras }\end{array}$ \\
\hline Hec, de el & Yini, de \\
\hline Nancaoli? Dios? & Nancaori, Dios (mismo) \\
\hline Eé, Si & Namachichi, no, nunca \\
\hline Ijoucapilite, creemos. & Yojorigam, mentira \\
\hline I sifuc & Cachichi, ni \\
\hline ami & Groncachi, nos engait \\
\hline
\end{tabular}

laccacca, palabras mías

Manitapilité? acaso las creerillis?

Notas. - ${ }^{1}$ Se pagan, dice es romance por pagamos.

? Otro ejemplo de romances por versión literai.

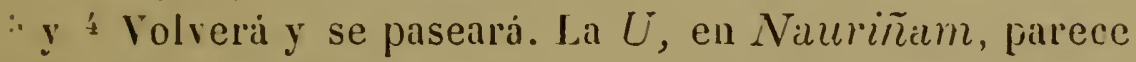
que es error por $N$.

jOtro romance. Literalmente: que los han lavado las cabezas.

${ }^{6}$ Ver Laajoura. Se sugiere esta interpretacion.

\section{LOS MANDAMIEXTOS DE LA LEY DE DIOS}

Era namachit, El primero

Ero naim 2o, etc., El segundo, tercero, etc.

Ercapitam, Querer

Hec, $a$

Vallcarri, Dios

Lamerpeéi, sobre

logué, todas
Quenó, las

Jogué, cosas.

Chit iiguiam, No nombrar

Dios, de Dios

Laclaoé, el nombre

Am, si (cuando)

Nojarigañi, mientes

Oammachitecam. Guardar 
Neotá, los dias

Latencŕ, grandes.

Aaguilam, Respetar

Gretalí, á los padres

Cach, $y$

Grachii, madres.

Chit, No

Cajammatañam, matar.

Chit, No

Grajapchaccam, querer

Eno, á las

Nachiga, que no son

Graoené, tu mujer (esposa).

Chit, No

Etpañam, robar.

Chit, No

Píiriñam, levantar falso testimonio

Cachit, ni

Nojarigañam, mentir.

Chit grigiam, No querer

Añi, á la

Oanerma, mujer

Nachiga, que no es

Graoené, tu mujer (esposa).

Chit, No
Arcapichilam, desear

Enó enoá, los bienes

Nachiga, que no

Catoi, son tuyos.

Enoujá, Estos

Dios, de Dios

Lelatancaté, mandamientos

Enoaogué, todos

Eneteleté, están

Quirió, en estos

Yrioacá, dos

Ercapilam, en querer

Hec, $a$

Nancaorí, Dios

Lamerpeéi, sobre

Aogué, todas

Quenó, las

Aogué, cosas

Cachque, $y$

Có, esos

Lajóa, los mas

Arcaoique, tener lástima

Meerá, como nos tenemos

Arcaocaltá, lástima de nosolros

mismos. Amen.

\section{SALVE REGINA}

Ñiquiñioagoa, Salúdote

Maria Santísima, Maria Santi$\operatorname{sim} a$

Nelaícate Reina

Cach, $y$

Grate, nuestra madre

Ychigrenatanaye, de piedad

Acami, tí eres
Nam (eres ó misma)

Greleigá, nuestra rida

Cach, $y$

Groanga nuestro provecho

Cach, $y$

Guerpeé, nuestra esperanza

Niquiñioagoa, salúdote

Acami, á tí 
Ipiamquetagri ', llamanos

Icam, nosotros

Ichigriaca, los poltres

Eva, de Era

Laitcate, hijos

ditatacapec, afligidos

Cach, y

Cieoaicatapee, llorando

Ena, en este

Naŕ, malo

.lóa, mundo

Arirec(quetagrí ', queremos

Icami, tue liu

Noacarí, Nuestra Señora

Cach, y

Ancaocarí, que nos tengas lás-

lima
Quegeigotaoatam, nos mires ()ueno, con esos

lehigrenatanaye ", de piedad

Gratoichi, tus ojos

Cach, y

Cambla, despues

Uaoucí, que muramos

Quená, en este

Aloa, mundo

Griachiñi, muéstranos

Taoctám ${ }^{3}$, que está contigo

Ená, ese

Graitachi, tu hijo

Jesus, Jesus

Santa, Santa

Maria, etc., Maria, etc., como en el Are Maria.

Notas. - ${ }^{1}$ Compárese ese Apiampetagri, llamamos, con Grirecquetagri, queremos. Llama la atencion la falta de prefijo en el primer caso, y la identidad de terminación en los dos términos.

? Forma femenina: piadosa.

3 Voz de que sólo se sabe que Dobrizhoffer la traduce asi. Vease: P.idre nuestro; Quiñitaoat, están contigo.

nodo de persignarse, Segun dobrizhoffer (t. it, p. 204)

Kaána ${ }^{1}$, Por

Vachahét, la señal

Santa, de la Sunta

Likinr'ánala, Cruz

Oahayegralgé ${ }^{2}$, líbranos
Gnaagr'oá ${ }^{3}$, de nuestros enemigos

Dios, Dios

(jnoakàra, nuestro Señor. 
Men ${ }^{4}$, En el

Lakalatoét " nombre

Netá, del Padre

Kat, $y$

Naitar'at ${ }^{6}$, del hijo
Kachka, $y$

Espílitu Santo, del Espiritu Santo.

Amen, Amen.

Notas. - ${ }^{1}$ Uso del demostrativo con prefijo para hacer nuestra preposicion.

2 Oaha es raíz verbal, avanzar, y yegalgé puede ser variante del subfijo de caso régimen; yegarik, nos.

${ }^{3}$ Casos en Dobrizhofier del prefijo Gn. Gnaagr'oa es voz. que no se halla en Brigniel; este autor da Ampaagnogou, uuestros enemigos.

4 Men, otro caso de prefijis $M$ con demostrativo para hacer preposicion.

5 En Brigniel, Laclataoé.

${ }^{6}$ Nailat en Bárcena.

Adelung, en su "Mithridates", reprodujo de Hervas (Saggio Pratico) un Paternoster Abipon, pero sin traduccion, lo que importa decir que ninguno de los dos autores se creyó capaz de dar salida ni á este texto, ni á otro igual en Mocoví. Con la ayuda de Brigniel, etc., hoy se hizo posible la interpretacion, que en forma de Apéndice se agregó á mi "Mocoví ". No está de más reproducir aquí los dos ejemplos del Pater Noster para que el estudiante pueda hacer el cotejo de las variantes.

Herras

Gretaa

Encaaniaegmeeque

Keera

Hipiguem

Chigrieecat

Raaguiat

Gracalatahuichit
Romance Brigniel

$\begin{array}{cl}\text { Padre nuestro } & \text { Gretá } \\ \text { que estás } & \text { Cañime } \\ \text { en los } & \text { Quir } \\ \text { Cielos. } & \text { Ypiam } \\ \text { iOjalá! } & \text { Chiqgrica } \\ \text { respeteı } & \text { Traaquiam era } \\ \text { tu nombre. } & \text { Graclatauichi }\end{array}$


Il.rva-

rit lat

Anaguagacam

(increapichhegoa

Arimi.

Chigrrie (Ojalii)

La greeketegue ( $\mathbf{Y}_{\text {il }}$ )

Ken

Aaloba

Grichin

Men meram

leekntegué.

Ecó

Ycaa initagoat

lier

Hipiguem

Eco

Gnacanaagüenga

Kienoré

Neogata

Calat

Nañiegarenran

Ke neoga (cn este dii)

Cillichca

Eenam

Güercabokegoá

Kenó

Taaye

Graegieca

Meraa
Romatmec

(?) Yil

quićrenos á

tí.

Ojalii

cumplamos

ell liı

tierra

nosolios

Grig̨itam(()ueremos)

Greequetequé

Quema

Alóa

Querá (como)

nosotros haciendo Marigich (tú quicres)

así como Meem querí

cumplen Yeequetegué

los que Quécó

están contigro Quiñitaoat

en el Quir

Cielo. $\quad$ Ipiam

Esos Queco

nuestros alimentos Nacaquena

(del cuerpo Noeyagá

y Cachigue

alma) Ylquigi

de cada Quenore

día Neotá

tambien Tat

danos Nanañiermam

hoy. Eneogá

También Clach

esto más Enam

perdonanos Ercaoquela

por esa Queno

malas Naaye

musstras c ostumbres Gragir rica

así como Quera 
Hervas

Guercabogala

Keco

Nacayeteragoa

Chitquita

Oagayitaalam

Am layam

Graañiñi

Eno

Loencatagüe gueca

Eca

Nam naá

Keeguet

Ychgroangachitapcam

Keno

Naaye
Romance

perdonamos

de esos

nuestros enemigos. Naquiatragoa

Tampoco

escuchemos

cuando

caigamos

en los

engaños

del

mas malo

Biujo.

Nos guardarás

de los

males.
Brigniel

Arcaoque

Quecó

Chit

Oaltalam

Amblayam

Grajañiñi

Queiso

Niloencatannaca

Hec

Namnaa

Quent.

Ychigroammachitapcam

Queno

Naaye.

Notas. - Casi no son necesarias. Con el cotejo de las dos oraciones y la consulta del Vocabulario basta para explicarlo todo.

Puede observarse :

$1^{\circ}$ Que el indio dice : tener lástima; vice, perdonar.

$2^{\circ}$ Que el posesivo por construccion puede ocupar el segundo lugar, es decir, que no está obligado á preceder.

$3^{\circ}$ Que la construccion sintáctica es de lo más sencillo y sigue lo que para nosotros es la consecuencia lógica del pensamiento; á saber : sujeto, verbo, caso régimen y complementos. 
$2=-2$ 



SMITHSONIAN INSTITUTION LIBRARIES

39088005783592 